\title{
The rise of Ramularia from the Mycosphaerella labyrinth
}

Sandra Isabel Rodrigues Videira ${ }^{\mathrm{a}, \mathrm{c}}$, Johannes Zacharias Groenewald ${ }^{\mathrm{a}}$, Gerard J.M. Verkley ${ }^{\mathrm{a}}$, Uwe Braun ${ }^{\mathrm{d}}$, Pedro Willem Crous ${ }^{\mathrm{a}, \mathrm{b}, \mathrm{c}, \text { * }}$

${ }^{a}$ CBS-KNAW Fungal Biodiversity Centre, Uppsalalaan 8, 3584 CT, Utrecht, The Netherlands

${ }^{b}$ Department of Microbiology and Plant Pathology, Forestry and Agricultural Biotechnology Institute (FABI), University of Pretoria, Pretoria, 0002, South Africa

${ }^{c}$ Wageningen University and Research Centre (WUR), Laboratory of Phytopathology, Droevendaalsesteeg 1, 6708 PB, Wageningen, The Netherlands

${ }^{\mathrm{d}}$ Martin-Luther-Universität at Halle-Wittenberg, Institut für Biologie, Geobotanik, Herbarium, Neuwerk 21, 06099, Halle (Saale), Germany

*Corresponding author. Tel.: +31 (0) 30 2122600; fax: +31 (0) 302512097.

\section{Highlights}

- Ramulariais the correct name for species in Mycosphaerella s. str.

- Most species named in Mycosphaerella represent other genera.

- Very few Ramularia spp. have confirmed Mycosphaerella sexual morphs.

- Ramularia contains both host-specific, and wide host range species.

\begin{abstract}
In this study we aimed to resolve the Ramularia endophylla species-complex by applying a polyphasic approach involving morphology and multi-gene phylogeny. Eleven partial genes were targeted for amplification and sequencing for a total of 81 isolates representing $R$. endophylla s. lat. and 32 isolates representing 11 Ramularia species that were previously linked to a Mycosphaerella sexual morph in literature. A Bayesian phylogenetic analysis, as well as a parsimony analysis, was performed on a combined five-locus dataset and the resulting trees showed significant support for three species within the complex, including the previously described $R$. endophylla and $R$. vizellae, and one novel species, Ramularia unterseheri. A parsimony analysis was also separately performed with mating-type gene sequences (MAT1-1-1 and MAT1-2-1) and the resulting tree topologies were in accordance with that of the multigene analysis. A bibliographic review of the proposed links between Ramularia spp. and their purported Mycosphaerella sexual morphs is also presented, confirming six connections in Ramularia. In spite of more than 10000 species having been described in Mycosphaerella, the majority is shown to belong to other genera, suggesting that the taxa identified as Mycosphaerella in much of the plant pathology literature needs to be revisited.
\end{abstract}

Keywords : Cercosporoid; Cryptic species; Multigene; Nomenclature; Phylogeny 


\section{Introduction}

Mycosphaerella s. lat. ( Johanson 1884) is one of the largest genera of Ascomycetes and comprises numerous economically important crop pathogens. Over the years more than 10000 species were described in this genus mainly based on host association or simply because their fruiting bodies were spherical ( Aptroot, 2006 and Crous et al., 2009a; Koike et al. 2011). Although the morphology of the sexual morph is relatively uniform, the genus has been associated with more than 40 asexual genera (Crous et al. 2009a) including both coelomycetes and hyphomycetes. Early molecular work based on ITS DNA sequencing indicated that Mycosphaerella was monophyletic, although the subsequent introduction of additional loci and more taxa showed it was polyphyletic ( Crous et al., 2009a and Crous et al., 2009c). As a consequence, members of this genus were allocated to different families such as Schizothyriaceae ( Batzer et al. 2008), Cladosporiaceae ( Schubert et al., 2007, Dugan et al., 2008, Bensch et al., 2010 and Bensch et al., 2012), Dissoconiaceae, Mycosphaerellaceae and Teratosphaeriaceae (Crous et al., 2009b and Li et al., 2012). From these results it became evident that the mycosphaerella-like morphology had evolved multiple times and a new circumscription of Mycosphaerella was urgently required.

The type species Mycosphaerella punctiformis was epitypified from freshly collected material and its asexual morph described as Ramularia endophylla (Verkley et al. 2004). Phylogenetic analyses based on DNA sequence data of the SSU and ITS regions grouped Mycosphaerella species with Ramularia asexual morphs in a monophyletic group with high bootstrap support ( Verkley et al., 2004 and Crous et al., 2007). This partly led to the proposal by Crous et al. (2009a) that Mycosphaerella s. str. should be limited to species with Ramularia asexual morphs, and that the remaining mycosphaerella-like species should be allocated to other genera. In order to halt the unnecessary proliferation of generic names, it was proposed at the time that it would be preferable to not continue using the traditional dual nomenclature system, and that a single generic name should be attributed to each unambiguous phylogenetic lineage such as in the case of the Botriosphaeriaceae ( Crous et al. 2006).

The widespread use of phylogenetic analyses, based on DNA sequence comparisons, has fuelled the idea that dual nomenclature in fungi is superfluous (Taylor 2012). A number of far reaching proposals were accepted at the eighteenth International Botanical Congress in Melbourne, which led to a revised and renamed International Code of Nomenclature for Algae, Fungi, and Plants (ICN), signalling the end of dual nomenclature (Hawksworth et al., 2011 and Wingfield et al., 2012). In pleomorphic fungi priority should be given to the oldest name, regardless of its sexuality. However, for widely used names, particularly where the asexual morph names replace sexual morph names, additional considerations are needed as specified in ICN Art. 57.2. The name Ramularia ( Unger 1833) is older than Mycosphaerella ( Johanson 1884) and, while Mycosphaerella sensu lato represents numerous genera distributed over different families, Mycosphaerella sensu strictu has Ramularia asexual morphs. Choosing Ramularia over Mycosphaerella requires less name changes since most established connections already have species names in Ramularia. Therefore, the name Ramularia has been selected for this genus and included in a list of protected names ( Wijayawardene et al. 2014).

Ramularia includes species that are usually defined as hyphomycetes with hyaline conidiophores and conidia with thickened, darkened, and refractive conidial hila and conidiogenous loci (scars on conidiogenous cells). The structure and colour of conidiogenous 
loci were considered important characters to define the genus and distinguish it from closely allied genera ( Braun, 1995 and Braun, 1998). Recent molecular studies indicate that these characters were not always phylogenetically informative, and that the generic concept of some asexual genera warranted revision ( Verkley et al., 2004 and Kirschner, 2009). For example, Cercosporella is usually distinguished from Ramularia by bulging, hyaline conidiogenous loci. These characters are variable and difficult to distinguish with light microscopy ( Kirshner 2009). A DNA phylogeny based on sequences obtained from the large nuclear ribosomal subunit (LSU) places the type species of Cercosporella (Cercosporella virgaureae) in a sister clade to Ramularia, but Cercosporella centaureicola, for example, clustered within Ramularia sensu stricto. The ultrastructure of conidiogenous loci differed between these genera, with Ramularia having a raised rim with a central dome that is cladosporium-like, while Cercosporella has flat scars in the shape of a truncated cone ( Kirschner 2009).

The genus Ramularia includes around 1000 species that vary in lifestyle from phytopathogenic to saprobic, endophytic and even hyperparasitic. Phytopathogenic species cause leaf spots, necrosis or chlorosis that lead to early defoliation and disease symptoms that usually develop under conditions of high air humidity and low temperatures. Endophytic species usually grow symptomless within the leaves and mature in overwintering leaves on the soil, releasing ascospores in spring that can re-infect young leaves in spring. $R$. endophylla (syn. M. punctiformis) is an endophyte often associated with broad-leaved trees, and has a worldwide distribution (Verkley et al. 2004). Recent DNA sequence comparisons based on sequence obtained from the intergenic nuclear ribosomal spacer region (ITS) has shown that a number of $R$. endophylla strains collected from several hosts appear to be heterogeneous, indicating the presence of cryptic species ( Verkley et al., 2004 and Minnis et al., 2011). This applies to Ramularia nyssicola, which is morphologically indistinguishable from $R$. endophylla, but based on DNA sequence comparisons and host specificity represents a distinct species on Nyssa ( Minnis et al., 2011 and Videira et al., 2015).

Identification of closely related species based on morphology is often difficult and the ITS barcode of fungi alone (Schoch et al. 2012) is unreliable for species identification among several cercosporoid genera (e.g. Groenewald et al., 2013, Crous et al., 2013 and Bakhshi et al., 2015). Several studies in recent years have highlighted the need to use additional phylogenetic markers to achieve accurate species identification (e.g. Bensch et al., 2012, Damm et al., 2012a, Damm et al., 2012b, Quaedvlieg et al., 2012, Phillips et al., 2013 and Wikee et al., 2013). In general, protein-coding genes have higher species resolution power due to their variable intron sequences. In addition, partial sequences from the matingtype ideomorphs (MAT1-1 and MAT1-2), specifically the alpha box (MAT1-1-1) and the high mobility group (MAT1-2-1), have also been found valuable due to their high interspecific variability and low intraspecific variability (Du et al., 2005 and Paoletti et al., 2005). Species delimitation is challenging and guided by several concepts but no strict rule applies. The use of concordance of multiple gene genealogies has been frequently used in mycology to determine species boundaries. This is known as the Genealogical Concordance Phylogenetic Species Recognition (GCPSR) principle and is an adaptation of the Phylogenetic Species Concept (PSC) (Taylor et al. 2000). With the addition of ecological and morphological data to support the multiple gene phylogenies in a polyphasic approach, mycologists have been increasingly relying on the Consolidated Species Concept (CSC) for fungal species delimitation (Quaedvlieg et al. 2014). 
The aims of this study were to: (i) resolve the variation in the $R$. endophylla species complex by applying morphology, ecology and multi-gene phylogeny based on five partial genes and partial mating-type locus DNA sequences; (ii) to investigate all purported links between Ramularia and Mycosphaerella in literature, and (iii) provide a platform that will enable a revision of this generic complex.

\section{Materials and methods}

\section{Isolates}

The isolates included in this study were obtained from the culture collection of the CBSKNAW Fungal Biodiversity Centre (CBS), Utrecht, the Netherlands, from the working collection of Pedro Crous (CPC), housed at CBS-KNAW, or were freshly isolated from a range of different plant hosts (Table 1). Single-conidia and single-ascospore cultures were obtained using the techniques described for species of Mycosphaerella and its asexual morphs ( Crous et al., 1991 and Crous, 1998). Representative cultures of the new species delineated in this study were deposited in the CBS culture collection.

Table 1. Collection details and GenBank accession numbers of strains included in this study.

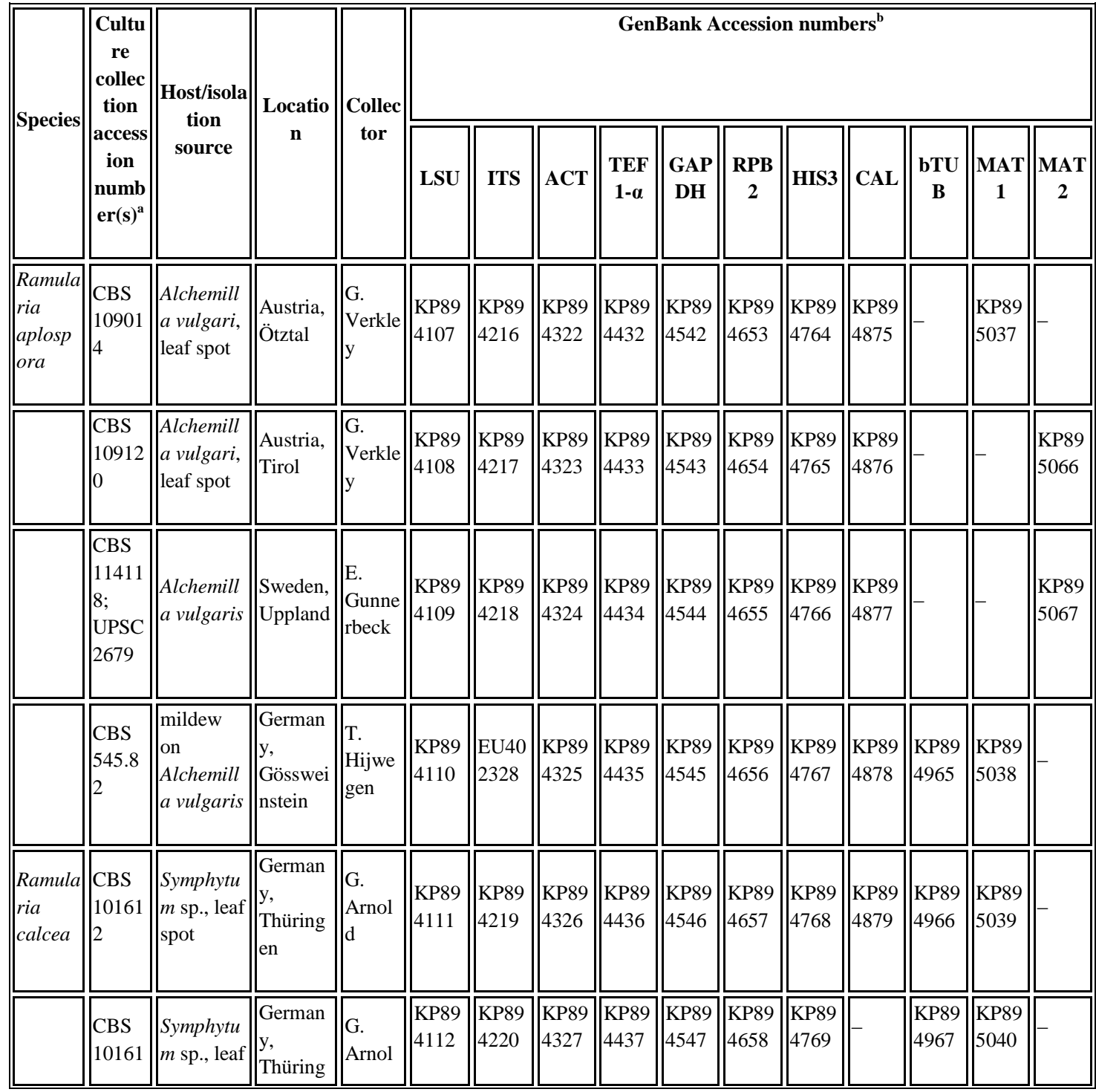




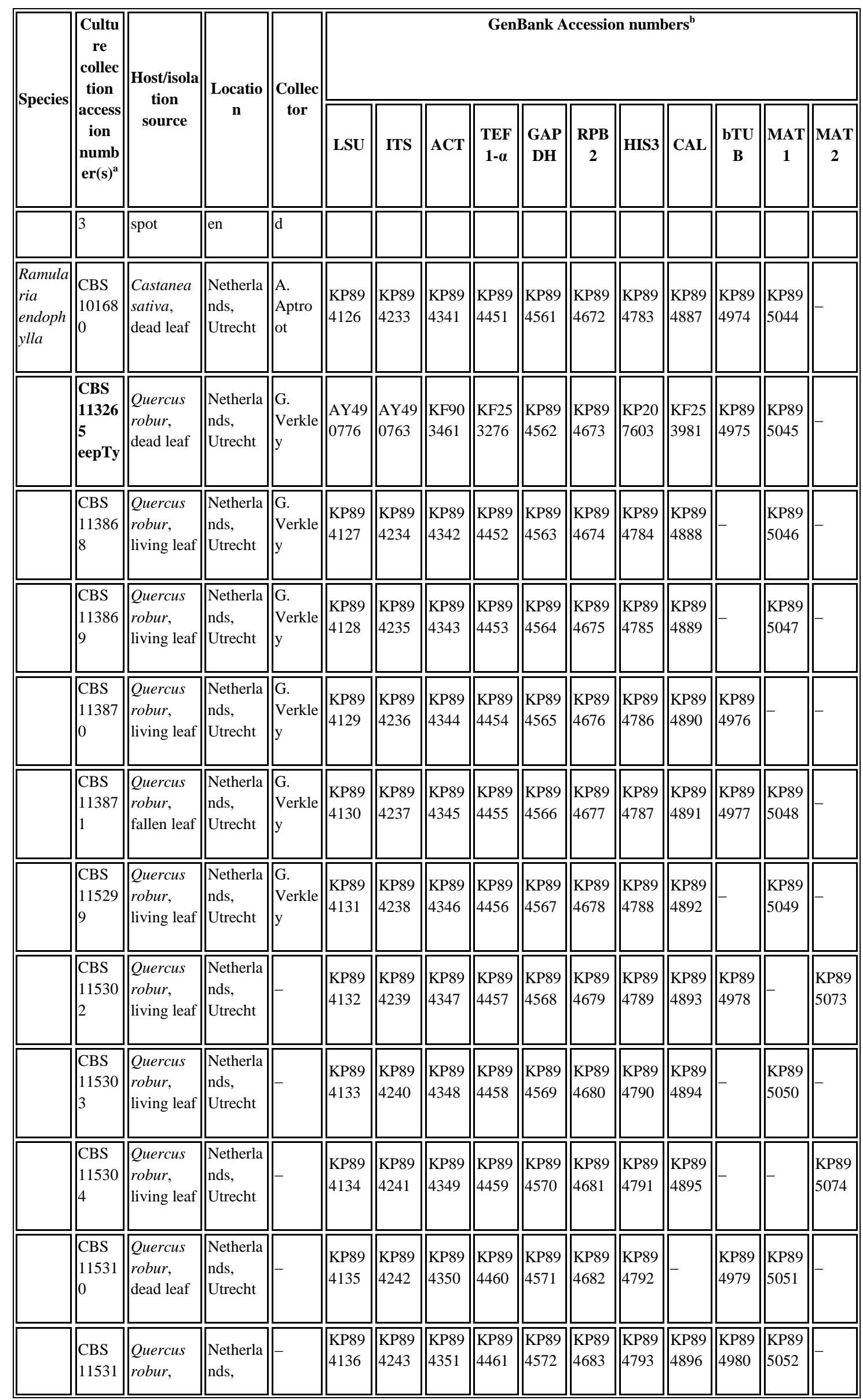




\begin{tabular}{|c|c|c|c|c|c|c|c|c|c|c|c|c|c|c|c|}
\hline \multirow{3}{*}{ Species } & \multirow{2}{*}{$\begin{array}{c}\text { Cultu } \\
\text { re } \\
\text { collec } \\
\text { tion } \\
\text { access } \\
\text { ion } \\
\text { numb } \\
\text { er }(s)^{\mathrm{a}}\end{array}$} & \multirow{2}{*}{$\mid \begin{array}{c}\text { Host/isola } \\
\text { tion } \\
\text { source }\end{array}$} & \multirow{2}{*}{$\begin{array}{c}\text { Locatio } \\
n\end{array}$} & \multirow{2}{*}{$\begin{array}{c}\text { Collec } \\
\text { tor }\end{array}$} & \multicolumn{11}{|c|}{ GenBank Accession numbers $^{b}$} \\
\hline & & & & & LSU & ITS & ACT & $\begin{array}{r}\text { TEF } \\
1-\alpha\end{array}$ & $\begin{array}{c}\text { GAP } \\
\text { DH }\end{array}$ & $\begin{array}{c}\text { RPB } \\
2\end{array}$ & HIS3 & CAL & $\begin{array}{c}\text { bTU } \\
\text { B }\end{array}$ & $\begin{array}{c}\text { MAT } \\
1\end{array}$ & $\begin{array}{c}\text { MAT } \\
2\end{array}$ \\
\hline & 1 & dead leaf & Utrecht & & & & & & & & & & & & \\
\hline & \begin{tabular}{|l} 
CBS \\
11787 \\
$6 ;$ \\
CPC \\
11203
\end{tabular} & $\begin{array}{l}\text { Quercus } \\
\text { robur }\end{array}$ & $\begin{array}{l}\text { Netherla } \\
\text { nds, } \\
\text { Utrecht }\end{array}$ & $\begin{array}{l}\text { G. } \\
\text { Verkle } \\
\text { y }\end{array}$ & $\begin{array}{l}\text { KP89 } \\
4137\end{array}$ & $\begin{array}{l}\text { KP89 } \\
4244\end{array}$ & $\begin{array}{l}\text { KP89 } \\
4352\end{array}$ & $\begin{array}{l}\text { KP89 } \\
4462\end{array}$ & $\begin{array}{l}\text { KP89 } \\
4573\end{array}$ & $\begin{array}{l}\text { KP89 } \\
4684\end{array}$ & $\begin{array}{l}\text { KP89 } \\
4794\end{array}$ & $\begin{array}{l}\text { KP89 } \\
4897\end{array}$ & $\begin{array}{l}\text { KP89 } \\
4981\end{array}$ & $\begin{array}{l}\text { KP89 } \\
5053\end{array}$ & - \\
\hline & \begin{tabular}{|l} 
CBS \\
11787 \\
$7 ;$ \\
CPC \\
11204
\end{tabular} & $\begin{array}{l}\text { Quercus } \\
\text { robur }\end{array}$ & $\begin{array}{l}\text { Netherla } \\
\text { nds, } \\
\text { Utrecht }\end{array}$ & $\begin{array}{l}\text { G. } \\
\text { Verkle } \\
\text { y }\end{array}$ & $\begin{array}{l}\text { KP89 } \\
4138\end{array}$ & $\begin{array}{l}\text { KP89 } \\
4245\end{array}$ & $\begin{array}{l}\text { KP89 } \\
4353\end{array}$ & $\begin{array}{l}\text { KP89 } \\
4463\end{array}$ & $\begin{array}{l}\text { KP89 } \\
4574\end{array}$ & $\begin{array}{l}\text { KP89 } \\
4685\end{array}$ & $\begin{array}{l}\text { KP89 } \\
4795\end{array}$ & $\begin{array}{l}\text { KP89 } \\
4898\end{array}$ & $\begin{array}{l}\text { KP89 } \\
4982\end{array}$ & & $\begin{array}{l}\text { KP89 } \\
5075\end{array}$ \\
\hline & $\begin{array}{l}\text { CBS } \\
942.9 \\
7\end{array}$ & $\begin{array}{l}\text { Quercus } \\
\text { sp., leaves }\end{array}$ & $\begin{array}{l}\text { Belgium } \\
\text {, Namur }\end{array}$ & $\begin{array}{l}\text { A. } \\
\text { Aptro } \\
\text { ot }\end{array}$ & $\begin{array}{l}\text { KP89 } \\
4139\end{array}$ & $\begin{array}{l}\text { KP89 } \\
4246\end{array}$ & $\begin{array}{l}\text { KP89 } \\
4354\end{array}$ & $\begin{array}{l}\text { KP89 } \\
4464\end{array}$ & $\begin{array}{l}\text { KP89 } \\
4575\end{array}$ & $\mid \begin{array}{l}\text { EU87 } \\
4860\end{array}$ & $\mid \begin{array}{l}\text { KP89 } \\
4796\end{array}$ & $\begin{array}{l}\text { KP89 } \\
4899\end{array}$ & $\begin{array}{l}\text { KP89 } \\
4983\end{array}$ & - & - \\
\hline & $\begin{array}{l}\mathrm{CPC} \\
11503\end{array}$ & - & $\begin{array}{l}\text { South } \\
\text { Korea }\end{array}$ & $\begin{array}{l}\text { H.D. } \\
\text { Shin }\end{array}$ & $\begin{array}{l}\text { KP89 } \\
4140\end{array}$ & $\begin{array}{l}\text { KP89 } \\
4247\end{array}$ & $\begin{array}{l}\text { KP89 } \\
4355\end{array}$ & $\begin{array}{l}\text { KP89 } \\
4465\end{array}$ & $\begin{array}{l}\text { KP89 } \\
4576\end{array}$ & $\begin{array}{l}\text { KP89 } \\
4686\end{array}$ & $\begin{array}{l}\text { KP89 } \\
4797\end{array}$ & $\begin{array}{l}\text { KP89 } \\
4900\end{array}$ & $\begin{array}{l}\text { KP89 } \\
4984\end{array}$ & $\begin{array}{l}\text { KP89 } \\
5054\end{array}$ & - \\
\hline \multirow[t]{4}{*}{$\begin{array}{l}\text { Ramula } \\
\text { ria } \\
\text { greville } \\
\text { ana }\end{array}$} & \begin{tabular}{|l} 
CBS \\
11473 \\
$2 ;$ \\
UPSC \\
3244
\end{tabular} & $\begin{array}{l}\text { Fragaria } \\
\text { ananassa }\end{array}$ & $\begin{array}{l}\text { Sweden, } \\
\text { Uppland }\end{array}$ & $\begin{array}{l}\text { E. } \\
\text { Gunne } \\
\text { rbeck }\end{array}$ & $\begin{array}{l}\text { KP89 } \\
4113\end{array}$ & $\begin{array}{l}\text { KP89 } \\
4221\end{array}$ & $\begin{array}{l}\text { KP89 } \\
4328\end{array}$ & $\begin{array}{l}\text { KP89 } \\
4438\end{array}$ & $\begin{array}{l}\text { KP89 } \\
4548\end{array}$ & $\begin{array}{l}\text { KP89 } \\
4659\end{array}$ & $\begin{array}{l}\text { KP89 } \\
4770\end{array}$ & & $\begin{array}{l}\text { KP89 } \\
4968\end{array}$ & - & - \\
\hline & $\begin{array}{l}\text { CBS } \\
259.3 \\
6\end{array}$ & - & $\begin{array}{l}\text { Netherla } \\
\text { nds }\end{array}$ & - & $\begin{array}{l}\text { KP89 } \\
4114\end{array}$ & $\begin{array}{l}\text { KP89 } \\
4222\end{array}$ & $\begin{array}{l}\text { KP89 } \\
4329\end{array}$ & $\begin{array}{l}\text { KP89 } \\
4439\end{array}$ & $\begin{array}{l}\text { KP89 } \\
4549\end{array}$ & $\begin{array}{l}\text { KP89 } \\
4660\end{array}$ & $\begin{array}{l}\text { KP89 } \\
4771\end{array}$ & & & - & $\begin{array}{l}\text { KP89 } \\
5068\end{array}$ \\
\hline & $\begin{array}{l}\text { CBS } \\
298.3 \\
4\end{array}$ & - & $\begin{array}{l}\text { Netherla } \\
\text { nds }\end{array}$ & - & $\begin{array}{l}\text { KP89 } \\
4115\end{array}$ & $\begin{array}{l}\text { KP89 } \\
4223\end{array}$ & $\begin{array}{l}\text { KP89 } \\
4330\end{array}$ & $\begin{array}{l}\text { KP89 } \\
4440\end{array}$ & $\begin{array}{l}\text { KP89 } \\
4550\end{array}$ & $\begin{array}{l}\text { KP89 } \\
4661\end{array}$ & $\begin{array}{l}\text { KP89 } \\
4772\end{array}$ & $\begin{array}{l}\text { KP89 } \\
4880\end{array}$ & $\begin{array}{l}\text { KP89 } \\
4969\end{array}$ & - & - \\
\hline & $\begin{array}{l}\text { CBS } \\
719.8 \\
4\end{array}$ & $\begin{array}{l}\text { Fragariax } \\
\text { ananassa } \\
\text { 'Tioga' }\end{array}$ & $\begin{array}{l}\text { New } \\
\text { Zealand, } \\
\text { Aucklan } \\
\text { d }\end{array}$ & - & $\begin{array}{l}\text { KP89 } \\
4116\end{array}$ & $\begin{array}{l}\text { EU16 } \\
7605\end{array}$ & $\begin{array}{l}\text { KP89 } \\
4331\end{array}$ & $\begin{array}{l}\text { KP89 } \\
4441\end{array}$ & $\begin{array}{l}\text { KP89 } \\
4551\end{array}$ & $\begin{array}{l}\text { KP89 } \\
4662\end{array}$ & $\begin{array}{l}\text { KP89 } \\
4773\end{array}$ & $\begin{array}{l}\text { KP89 } \\
4881\end{array}$ & & - & - \\
\hline \multirow[t]{2}{*}{$\begin{array}{l}\text { Ramula } \\
\text { ria } \\
\text { inaequ } \\
\text { alis }\end{array}$} & $\begin{array}{l}\text { CBS } \\
250.9 \\
6\end{array}$ & $\begin{array}{l}\text { Taraxacu } \\
m \\
\text { officinale }\end{array}$ & $\begin{array}{l}\text { Canada, } \\
\text { Nova } \\
\text { Scotia }\end{array}$ & $\begin{array}{l}\text { S. } \\
\text { Green }\end{array}$ & $\begin{array}{l}\text { KP89 } \\
4117\end{array}$ & $\begin{array}{l}\text { KP89 } \\
4224\end{array}$ & $\begin{array}{l}\text { KP89 } \\
4332\end{array}$ & $\begin{array}{l}\text { KP89 } \\
4442\end{array}$ & $\begin{array}{l}\text { KP89 } \\
4552\end{array}$ & $\begin{array}{l}\text { KP89 } \\
4663\end{array}$ & $\begin{array}{l}\text { KP89 } \\
4774\end{array}$ & $\begin{array}{l}\text { KP89 } \\
4882\end{array}$ & $\begin{array}{l}\text { KP89 } \\
4970\end{array}$ & - & $\begin{array}{l}\text { KP89 } \\
5069\end{array}$ \\
\hline & $\begin{array}{l}\text { CPC } \\
15752\end{array}$ & $\begin{array}{l}\text { Taraxacu } \\
m \text { sp. }\end{array}$ & $\begin{array}{l}\text { Mexico, } \\
\text { Monteci } \\
\text { llo }\end{array}$ & \begin{tabular}{|l} 
M. de \\
J. \\
Yanez \\
- \\
Moral \\
es
\end{tabular} & $\begin{array}{l}\text { KP89 } \\
4118\end{array}$ & $\begin{array}{l}\text { KP89 } \\
4225\end{array}$ & $\begin{array}{l}\text { KP89 } \\
4333\end{array}$ & $\begin{array}{l}\text { KP89 } \\
4443\end{array}$ & $\begin{array}{l}\text { KP89 } \\
4553\end{array}$ & $\begin{array}{l}\text { KP89 } \\
4664\end{array}$ & $\begin{array}{l}\text { KP89 } \\
4775\end{array}$ & & & $\begin{array}{l}\text { KP89 } \\
5041\end{array}$ & - \\
\hline
\end{tabular}




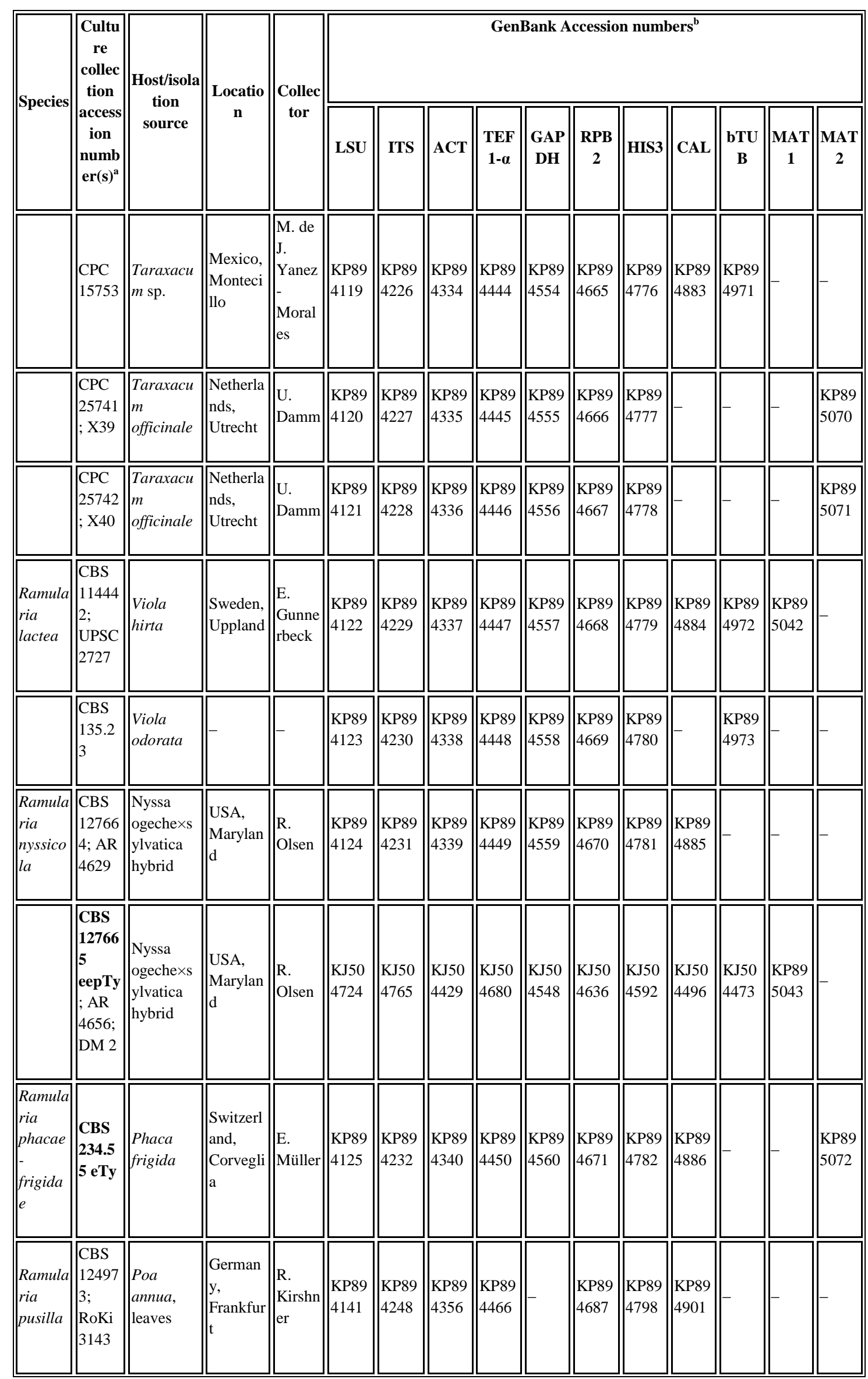




\begin{tabular}{|c|c|c|c|c|c|c|c|c|c|c|c|c|c|c|c|}
\hline \multirow{2}{*}{ Species } & \multirow{2}{*}{\begin{tabular}{|c} 
Cultu \\
re \\
collec \\
tion \\
access \\
ion \\
numb \\
er(s)
\end{tabular}} & \multirow{2}{*}{$\begin{array}{c}\text { Host/isola } \\
\text { tion } \\
\text { source }\end{array}$} & \multirow{2}{*}{$\begin{array}{c}\text { Locatio } \\
\mathbf{n}\end{array}$} & \multirow{2}{*}{$\begin{array}{c}\text { Collec } \\
\text { tor }\end{array}$} & \multicolumn{11}{|c|}{ GenBank Accession numbers $^{b}$} \\
\hline & & & & & LSU & ITS & ACT & $\begin{array}{r}\text { TEF } \\
1-\alpha\end{array}$ & $\begin{array}{c}\text { GAP } \\
\text { DH }\end{array}$ & $\begin{array}{c}\text { RPB } \\
2\end{array}$ & HIS3 & CAL & $\begin{array}{c}\text { bTU } \\
\text { B }\end{array}$ & $\begin{array}{c}\text { MAT } \\
1\end{array}$ & $\begin{array}{c}\text { MAT T } \\
2\end{array}$ \\
\hline \multirow[t]{5}{*}{$\begin{array}{l}\text { Ramula } \\
\text { ria } \\
\text { tricher } \\
\text { ae }\end{array}$} & $\begin{array}{l}\text { CBS } \\
10897 \\
3\end{array}$ & $\begin{array}{l}\text { Knautia } \\
\text { arvensis, } \\
\text { leaf spot }\end{array}$ & $\begin{array}{l}\text { Netherla } \\
\text { nds, } \\
\text { Limburg }\end{array}$ & $\begin{array}{l}\text { G. } \\
\text { Verkle } \\
\text { y }\end{array}$ & $\begin{array}{l}\text { KP89 } \\
4142\end{array}$ & $\begin{array}{l}\text { KP89 } \\
4249\end{array}$ & $\begin{array}{l}\text { KP89 } \\
4357\end{array}$ & $\begin{array}{l}\text { KP89 } \\
4467\end{array}$ & $\begin{array}{l}\text { KP89 } \\
4577\end{array}$ & $\begin{array}{l}\text { KP89 } \\
4688\end{array}$ & $\mid \begin{array}{l}\text { KP89 } \\
4799\end{array}$ & $\begin{array}{l}\text { KP89 } \\
4902\end{array}$ & $\begin{array}{l}\text { KP89 } \\
4985\end{array}$ & $\begin{array}{l}\text { KP89 } \\
5055\end{array}$ & - \\
\hline & $\begin{array}{l}\text { CBS } \\
10898 \\
9\end{array}$ & \begin{tabular}{|l|} 
Knautia \\
dipsacifoli \\
$a$, leaf \\
spot
\end{tabular} & $\begin{array}{l}\text { Austria, } \\
\text { Ötztal }\end{array}$ & $\begin{array}{l}\text { G. } \\
\text { Verkle } \\
y\end{array}$ & $\begin{array}{l}\text { KP89 } \\
4143\end{array}$ & $\begin{array}{l}\text { KP89 } \\
4250\end{array}$ & $\begin{array}{l}\text { KP89 } \\
4358\end{array}$ & $\begin{array}{l}\text { KP89 } \\
4468\end{array}$ & $\begin{array}{l}\text { KP89 } \\
4578\end{array}$ & $\begin{array}{l}\text { KP89 } \\
4689\end{array}$ & $\begin{array}{l}\text { KP89 } \\
4800\end{array}$ & $\begin{array}{l}\text { KP89 } \\
4903\end{array}$ & $\begin{array}{l}\text { KP89 } \\
4986\end{array}$ & - & $\begin{array}{l}\text { KP89 } \\
5076\end{array}$ \\
\hline & $\begin{array}{l}\text { CBS } \\
10899 \\
0\end{array}$ & \begin{tabular}{|l|} 
Knautia \\
dipsacifoli \\
$a$, leaf \\
spot
\end{tabular} & $\begin{array}{l}\text { Austria, } \\
\text { Ötztal }\end{array}$ & $\begin{array}{l}\text { G. } \\
\text { Verkle } \\
y\end{array}$ & $\begin{array}{l}\text { KP89 } \\
4144\end{array}$ & $\begin{array}{l}\text { KP89 } \\
4251\end{array}$ & $\begin{array}{l}\text { KP89 } \\
4359\end{array}$ & $\begin{array}{l}\text { KP89 } \\
4469\end{array}$ & $\begin{array}{l}\text { KP89 } \\
4579\end{array}$ & $\begin{array}{l}\text { KP89 } \\
4690\end{array}$ & $\begin{array}{l}\text { KP89 } \\
4801\end{array}$ & $\begin{array}{l}\text { KP89 } \\
4904\end{array}$ & - & - & - \\
\hline & $\begin{array}{l}\text { CBS } \\
10899 \\
4\end{array}$ & $\begin{array}{l}\text { Knautia } \\
\text { arvensis, } \\
\text { leaf spot }\end{array}$ & $\begin{array}{l}\text { Netherla } \\
\text { nds, } \\
\text { Limburg }\end{array}$ & \begin{tabular}{|l} 
G. \\
Verkle \\
y
\end{tabular} & $\begin{array}{l}\text { KP89 } \\
4145\end{array}$ & $\begin{array}{l}\text { KP89 } \\
4252\end{array}$ & $\begin{array}{l}\text { KP89 } \\
4360\end{array}$ & $\begin{array}{l}\text { KP89 } \\
4470\end{array}$ & $\begin{array}{l}\text { KP89 } \\
4580\end{array}$ & $\begin{array}{l}\text { KP89 } \\
4691\end{array}$ & $\begin{array}{l}\text { KP89 } \\
4802\end{array}$ & $\begin{array}{l}\text { KP89 } \\
4905\end{array}$ & $\begin{array}{l}\text { KP89 } \\
4987\end{array}$ & $\begin{array}{l}\text { KP89 } \\
5056\end{array}$ & - \\
\hline & \begin{tabular}{|l} 
CBS \\
236.7 \\
$3 ;$ \\
CCM \\
F-369
\end{tabular} & $\begin{array}{l}\text { Knautia } \\
\text { drymeia }\end{array}$ & $\begin{array}{l}\text { Czechos } \\
\text { lovakia }\end{array}$ & - & $\begin{array}{l}\text { KP89 } \\
4146\end{array}$ & $\begin{array}{l}\text { KP89 } \\
4253\end{array}$ & $\begin{array}{l}\text { KP89 } \\
4361\end{array}$ & $\begin{array}{l}\text { KP89 } \\
4471\end{array}$ & $\begin{array}{l}\text { KP89 } \\
4581\end{array}$ & $\begin{array}{l}\text { KP89 } \\
4692\end{array}$ & $\begin{array}{l}\text { KP89 } \\
4803\end{array}$ & $\begin{array}{l}\text { KP89 } \\
4906\end{array}$ & & $\begin{array}{l}\text { KP89 } \\
5057\end{array}$ & - \\
\hline $\begin{array}{l}\text { Ramula } \\
\text { ria } \\
\text { unterse } \\
\text { heri }\end{array}$ & \begin{tabular}{|l} 
CBS \\
11780 \\
$1 ;$ \\
CPC \\
12091
\end{tabular} & $\begin{array}{l}\text { Fagus } \\
\text { sylvatica, } \\
\text { dead } \\
\text { leaves }\end{array}$ & $\begin{array}{l}\text { Netherla } \\
\text { nds, } \\
\text { Utrecht }\end{array}$ & $\begin{array}{l}\text { G. } \\
\text { Verkle } \\
\text { y }\end{array}$ & $\begin{array}{l}\text { KP89 } \\
4147\end{array}$ & $\begin{array}{l}\text { KP89 } \\
4254\end{array}$ & $\begin{array}{l}\text { KP89 } \\
4362\end{array}$ & $\begin{array}{l}\text { KP89 } \\
4472\end{array}$ & $\begin{array}{l}\text { KP89 } \\
4582\end{array}$ & $\begin{array}{l}\text { KP89 } \\
4693\end{array}$ & $\begin{array}{l}\text { KP89 } \\
4804\end{array}$ & $\begin{array}{l}\text { KP89 } \\
4907\end{array}$ & $\begin{array}{l}\text { KP89 } \\
4988\end{array}$ & & - \\
\hline & \begin{tabular}{|l} 
CBS \\
11780 \\
$7 ;$ \\
CPC \\
12095
\end{tabular} & $\begin{array}{l}\text { Fagus } \\
\text { sylvatica, } \\
\text { dead } \\
\text { leaves }\end{array}$ & $\begin{array}{l}\text { Netherla } \\
\text { nds, } \\
\text { Utrecht }\end{array}$ & $\begin{array}{l}\text { G. } \\
\text { Verkle } \\
\text { y }\end{array}$ & $\begin{array}{l}\text { KP89 } \\
4148\end{array}$ & $\begin{array}{l}\text { KP89 } \\
4255\end{array}$ & $\begin{array}{l}\text { KP89 } \\
4363\end{array}$ & $\begin{array}{l}\text { KP89 } \\
4473\end{array}$ & $\begin{array}{l}\text { KP89 } \\
4583\end{array}$ & $\begin{array}{l}\text { KP89 } \\
4694\end{array}$ & $\begin{array}{l}\text { KP89 } \\
4805\end{array}$ & $\begin{array}{l}\text { KP89 } \\
4908\end{array}$ & $\begin{array}{l}\text { KP89 } \\
4989\end{array}$ & - & $\begin{array}{l}\text { KP89 } \\
5077\end{array}$ \\
\hline & $\begin{array}{l}\text { CBS } \\
11787 \\
8 ; \\
\text { CPC } \\
11206\end{array}$ & \begin{tabular}{|l|} 
Acer \\
pseudopla \\
tanus, \\
decaying \\
leaves
\end{tabular} & $\begin{array}{l}\text { Netherla } \\
\text { nds, } \\
\text { Utrecht }\end{array}$ & $\begin{array}{l}\text { G. } \\
\text { Verkle } \\
y\end{array}$ & $\begin{array}{l}\text { KP89 } \\
4149\end{array}$ & $\begin{array}{l}\text { KP89 } \\
4256\end{array}$ & $\begin{array}{l}\text { KP89 } \\
4364\end{array}$ & $\begin{array}{l}\text { KP89 } \\
4474\end{array}$ & $\begin{array}{l}\text { KP89 } \\
4584\end{array}$ & $\begin{array}{l}\text { KP89 } \\
4695\end{array}$ & $\begin{array}{l}\text { KP89 } \\
4806\end{array}$ & $\begin{array}{l}\text { KP89 } \\
4909\end{array}$ & $\begin{array}{l}\text { KP89 } \\
4990\end{array}$ & & - \\
\hline & \begin{tabular}{|l} 
CBS \\
11787 \\
$9 ;$ \\
CPC \\
11207
\end{tabular} & \begin{tabular}{|l|} 
Acer \\
pseudopla \\
tanus, \\
decaying \\
leaves
\end{tabular} & $\begin{array}{l}\text { Netherla } \\
\text { nds, } \\
\text { Utrecht }\end{array}$ & $\begin{array}{l}\text { G. } \\
\text { Verkle } \\
y\end{array}$ & $\begin{array}{l}\text { KP89 } \\
4150\end{array}$ & $\begin{array}{l}\text { KP89 } \\
4257\end{array}$ & $\begin{array}{l}\text { KP89 } \\
4365\end{array}$ & $\begin{array}{l}\text { KP89 } \\
4475\end{array}$ & $\begin{array}{l}\text { KP89 } \\
4585\end{array}$ & $\begin{array}{l}\text { KP89 } \\
4696\end{array}$ & $\begin{array}{l}\text { KP89 } \\
4807\end{array}$ & $\begin{array}{l}\text { KP89 } \\
4910\end{array}$ & & - & - \\
\hline & $\begin{array}{l}\text { CBS } \\
11788 \\
0 ;\end{array}$ & Tilia sp. & $\begin{array}{l}\text { Netherla } \\
\text { nds, }\end{array}$ & $\begin{array}{l}\text { G. } \\
\text { Verkle }\end{array}$ & $\begin{array}{l}\text { KP89 } \\
4151\end{array}$ & $\begin{array}{l}\text { KP89 } \\
4258\end{array}$ & $\begin{array}{l}\text { KP89 } \\
4366\end{array}$ & $\begin{array}{l}\text { KP89 } \\
4476\end{array}$ & $\begin{array}{l}\text { KP89 } \\
4586\end{array}$ & $\begin{array}{l}\text { KP89 } \\
4697\end{array}$ & $\begin{array}{l}\text { KP89 } \\
4808\end{array}$ & $\begin{array}{l}\text { KP89 } \\
4911\end{array}$ & \begin{tabular}{|l|} 
KP89 \\
4991
\end{tabular} & - & - \\
\hline
\end{tabular}




\begin{tabular}{|c|c|c|c|c|c|c|c|c|c|c|c|c|c|c|c|}
\hline \multirow{3}{*}{ Species } & \multirow{2}{*}{$\begin{array}{c}\text { Cultu } \\
\text { re } \\
\text { collec } \\
\text { tion } \\
\text { access } \\
\text { ion } \\
\text { numb } \\
\text { er(s) }\end{array}$} & \multirow{2}{*}{$\begin{array}{c}\text { Host/isola } \\
\text { tion } \\
\text { source }\end{array}$} & \multirow{2}{*}{$\begin{array}{c}\text { Locatio } \\
n\end{array}$} & \multirow{2}{*}{$\begin{array}{c}\text { Collec } \\
\text { tor }\end{array}$} & \multicolumn{11}{|c|}{ GenBank Accession numbers $^{b}$} \\
\hline & & & & & LSU & ITS & ACT & $\begin{array}{r}\text { TEF } \\
1-\alpha\end{array}$ & $\begin{array}{c}\text { GAP } \\
\text { DH }\end{array}$ & $\begin{array}{c}\text { RPB } \\
2\end{array}$ & HIS3 & CAL & $\begin{array}{c}\text { bTU } \\
\text { B }\end{array}$ & $\begin{array}{c}\text { MAT } \\
\mathbf{1}\end{array}$ & $\begin{array}{c}\text { MAT } \\
2\end{array}$ \\
\hline & $\begin{array}{l}\mathrm{CPC} \\
11209\end{array}$ & & Utrecht & $\mathrm{y}$ & & & & & & & & & & & \\
\hline & $\begin{array}{l}\text { CBS } \\
11788 \\
1 ; \\
\text { CPC } \\
11211\end{array}$ & Tilia sp. & $\begin{array}{l}\text { Netherla } \\
\text { nds, } \\
\text { Utrecht }\end{array}$ & $\begin{array}{l}\text { G. } \\
\text { Verkle } \\
y\end{array}$ & $\begin{array}{l}\text { KP89 } \\
4152\end{array}$ & $\begin{array}{l}\text { KP89 } \\
4259\end{array}$ & $\begin{array}{l}\text { KP89 } \\
4367\end{array}$ & $\begin{array}{l}\text { KP89 } \\
4477\end{array}$ & $\begin{array}{l}\text { KP89 } \\
4587\end{array}$ & $\begin{array}{l}\text { KP89 } \\
4698\end{array}$ & $\begin{array}{l}\text { KP89 } \\
4809\end{array}$ & $\begin{array}{l}\text { KP89 } \\
4912\end{array}$ & $\begin{array}{l}\text { KP89 } \\
4992\end{array}$ & & $\begin{array}{l}\text { KP89 } \\
5078\end{array}$ \\
\hline & $\begin{array}{l}\text { CBS } \\
12482 \\
7\end{array}$ & $\begin{array}{l}\text { Fagus } \\
\text { sylvatica, } \\
\text { living } \\
\text { leaves }\end{array}$ & $\begin{array}{l}\text { German } \\
y, \\
\text { Greifsw } \\
\text { ald }\end{array}$ & $\begin{array}{l}\text { M. } \\
\text { Unters } \\
\text { eher }\end{array}$ & $\begin{array}{l}\text { KP89 } \\
4153\end{array}$ & $\begin{array}{l}\text { KP89 } \\
4260\end{array}$ & $\begin{array}{l}\text { KP89 } \\
4368\end{array}$ & $\begin{array}{l}\text { KP89 } \\
4478\end{array}$ & $\begin{array}{l}\text { KP89 } \\
4588\end{array}$ & $\begin{array}{l}\text { KP89 } \\
4699\end{array}$ & $\begin{array}{l}\text { KP89 } \\
4810\end{array}$ & $\begin{array}{l}\text { KP89 } \\
4913\end{array}$ & $\begin{array}{l}\text { KP89 } \\
4993\end{array}$ & & - \\
\hline & $\begin{array}{l}\text { CBS } \\
12483 \\
0\end{array}$ & $\begin{array}{l}\text { Fagus } \\
\text { sylvatica, } \\
\text { living } \\
\text { leaves }\end{array}$ & $\begin{array}{l}\text { German } \\
y, \\
\text { Greifsw } \\
\text { ald }\end{array}$ & $\begin{array}{l}\text { M. } \\
\text { Unters } \\
\text { eher }\end{array}$ & $\begin{array}{l}\text { KP89 } \\
4154\end{array}$ & $\begin{array}{l}\text { KP89 } \\
4261\end{array}$ & $\begin{array}{l}\text { KP89 } \\
4369\end{array}$ & $\begin{array}{l}\text { KP89 } \\
4479\end{array}$ & $\begin{array}{l}\text { KP89 } \\
4589\end{array}$ & $\begin{array}{l}\text { KP89 } \\
4700\end{array}$ & $\begin{array}{l}\text { KP89 } \\
4811\end{array}$ & $\begin{array}{l}\text { KP89 } \\
4914\end{array}$ & $\begin{array}{l}\text { KP89 } \\
4994\end{array}$ & & - \\
\hline & $\begin{array}{l}\text { CBS } \\
12483 \\
1\end{array}$ & $\begin{array}{l}\text { Fagus } \\
\text { sylvatica, } \\
\text { living } \\
\text { leaves }\end{array}$ & $\begin{array}{l}\text { German } \\
\text { y, } \\
\text { Greifsw } \\
\text { ald }\end{array}$ & $\begin{array}{l}\text { M. } \\
\text { Unters } \\
\text { eher }\end{array}$ & $\begin{array}{l}\text { KP89 } \\
4155\end{array}$ & $\begin{array}{l}\text { KP89 } \\
4262\end{array}$ & $\begin{array}{l}\text { KP89 } \\
4370\end{array}$ & $\begin{array}{l}\text { KP89 } \\
4480\end{array}$ & $\begin{array}{l}\text { KP89 } \\
4590\end{array}$ & $\begin{array}{l}\text { KP89 } \\
4701\end{array}$ & $\begin{array}{l}\text { KP89 } \\
4812\end{array}$ & $\begin{array}{l}\text { KP89 } \\
4915\end{array}$ & $\begin{array}{l}\text { KP89 } \\
4995\end{array}$ & & - \\
\hline & $\begin{array}{l}\text { CBS } \\
12483 \\
4\end{array}$ & $\begin{array}{l}\text { Fagus } \\
\text { sylvatica, } \\
\text { living } \\
\text { leaves }\end{array}$ & $\begin{array}{l}\text { German } \\
y, \\
\text { Greifsw } \\
\text { ald }\end{array}$ & $\begin{array}{l}\text { M. } \\
\text { Unters } \\
\text { eher }\end{array}$ & $\begin{array}{l}\text { KP89 } \\
4156\end{array}$ & $\begin{array}{l}\text { KP89 } \\
4263\end{array}$ & $\begin{array}{l}\text { KP89 } \\
4371\end{array}$ & $\begin{array}{l}\text { KP89 } \\
4481\end{array}$ & $\begin{array}{l}\text { KP89 } \\
4591\end{array}$ & $\begin{array}{l}\text { KP89 } \\
4702\end{array}$ & $\begin{array}{l}\text { KP89 } \\
4813\end{array}$ & $\begin{array}{l}\text { KP89 } \\
4916\end{array}$ & $\begin{array}{l}\text { KP89 } \\
4996\end{array}$ & & $\begin{array}{l}\text { KP89 } \\
5079\end{array}$ \\
\hline & $\begin{array}{l}\text { CBS } \\
12483 \\
6\end{array}$ & $\begin{array}{l}\text { Fagus } \\
\text { sylvatica, } \\
\text { living } \\
\text { leaves }\end{array}$ & $\begin{array}{l}\text { German } \\
\text { y, } \\
\text { Greifsw } \\
\text { ald }\end{array}$ & $\begin{array}{l}\text { M. } \\
\text { Unters } \\
\text { eher }\end{array}$ & $\begin{array}{l}\text { KP89 } \\
4157\end{array}$ & $\begin{array}{l}\text { KP89 } \\
4264\end{array}$ & $\begin{array}{l}\text { KP89 } \\
4372\end{array}$ & $\begin{array}{l}\text { KP89 } \\
4482\end{array}$ & $\begin{array}{l}\text { KP89 } \\
4592\end{array}$ & $\begin{array}{l}\text { KP89 } \\
4703\end{array}$ & $\begin{array}{l}\text { KP89 } \\
4814\end{array}$ & $\begin{array}{l}\text { KP89 } \\
4917\end{array}$ & $\begin{array}{l}\text { KP89 } \\
4997\end{array}$ & & - \\
\hline & $\begin{array}{l}\text { CBS } \\
12483 \\
8\end{array}$ & $\begin{array}{l}\text { Fagus } \\
\text { sylvatica, } \\
\text { living } \\
\text { leaves }\end{array}$ & $\begin{array}{l}\text { German } \\
y, \\
\text { Greifsw } \\
\text { ald }\end{array}$ & $\begin{array}{l}\text { M. } \\
\text { Unters } \\
\text { eher }\end{array}$ & $\begin{array}{l}\text { KP89 } \\
4158\end{array}$ & $\begin{array}{l}\text { KP89 } \\
4265\end{array}$ & $\begin{array}{l}\text { KP89 } \\
4373\end{array}$ & $\begin{array}{l}\text { KP89 } \\
4483\end{array}$ & $\begin{array}{l}\text { KP89 } \\
4593\end{array}$ & $\begin{array}{l}\text { KP89 } \\
4704\end{array}$ & $\begin{array}{l}\text { KP89 } \\
4815\end{array}$ & $\begin{array}{l}\text { KP89 } \\
4918\end{array}$ & & - & - \\
\hline & $\begin{array}{l}\text { CBS } \\
12484 \\
4\end{array}$ & $\begin{array}{l}\text { Fagus } \\
\text { sylvatica, } \\
\text { leaf litter }\end{array}$ & $\begin{array}{l}\text { German } \\
y, \\
\text { Greifsw } \\
\text { ald }\end{array}$ & $\begin{array}{l}\text { M. } \\
\text { Unters } \\
\text { eher }\end{array}$ & $\begin{array}{l}\text { KP89 } \\
4159\end{array}$ & $\begin{array}{l}\text { KP89 } \\
4266\end{array}$ & $\begin{array}{l}\text { KP89 } \\
4374\end{array}$ & $\begin{array}{l}\text { KP89 } \\
4484\end{array}$ & $\begin{array}{l}\text { KP89 } \\
4594\end{array}$ & $\begin{array}{l}\text { KP89 } \\
4705\end{array}$ & $\begin{array}{l}\text { KP89 } \\
4816\end{array}$ & $\begin{array}{l}\text { KP89 } \\
4919\end{array}$ & $\begin{array}{l}\text { KP89 } \\
4998\end{array}$ & & - \\
\hline & $\begin{array}{l}\text { CBS } \\
12484 \\
6\end{array}$ & $\begin{array}{l}\text { Fagus } \\
\text { sylvatica, } \\
\text { leaf litter }\end{array}$ & $\begin{array}{l}\text { German } \\
\mathrm{y}, \\
\text { Greifsw } \\
\text { ald }\end{array}$ & $\begin{array}{l}\text { M. } \\
\text { Unters } \\
\text { eher }\end{array}$ & $\begin{array}{l}\text { KP89 } \\
4160\end{array}$ & $\begin{array}{l}\text { KP89 } \\
4267\end{array}$ & $\begin{array}{l}\text { KP89 } \\
4375\end{array}$ & $\begin{array}{l}\text { KP89 } \\
4485\end{array}$ & $\begin{array}{l}\text { KP89 } \\
4595\end{array}$ & $\begin{array}{l}\text { KP89 } \\
4706\end{array}$ & $\begin{array}{l}\text { KP89 } \\
4817\end{array}$ & $\begin{array}{l}\text { KP89 } \\
4920\end{array}$ & $\begin{array}{l}\text { KP89 } \\
4999\end{array}$ & & - \\
\hline & $\begin{array}{l}\text { CBS } \\
12485\end{array}$ & $\begin{array}{l}\text { Fagus } \\
\text { sylvatica, }\end{array}$ & $\begin{array}{l}\text { German } \\
y, \\
\text { Greifsw }\end{array}$ & $\begin{array}{l}\text { M. } \\
\text { Unters }\end{array}$ & $\begin{array}{l}\text { KP89 } \\
4161\end{array}$ & $\begin{array}{l}\text { KP89 } \\
4268\end{array}$ & $\begin{array}{l}\text { KP89 } \\
4376\end{array}$ & $\begin{array}{l}\text { KP89 } \\
4486\end{array}$ & $\begin{array}{l}\text { KP89 } \\
4596\end{array}$ & $\begin{array}{l}\text { KP89 } \\
4707\end{array}$ & $\begin{array}{l}\text { KP89 } \\
4818\end{array}$ & $\begin{array}{l}\text { KP89 } \\
4921\end{array}$ & $\begin{array}{l}\text { KP89 } \\
5000\end{array}$ & - & - \\
\hline
\end{tabular}




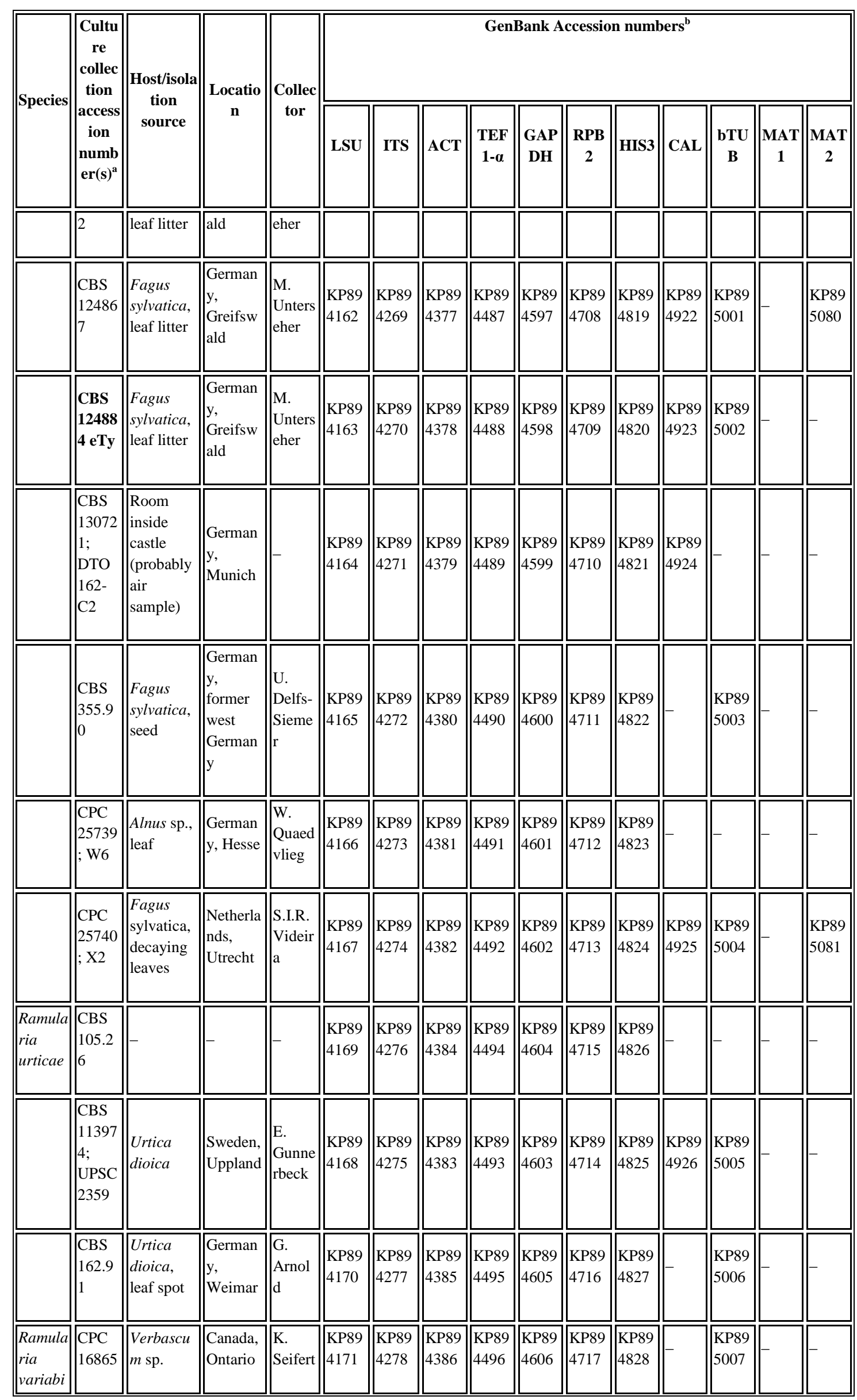




\begin{tabular}{|c|c|c|c|c|c|c|c|c|c|c|c|c|c|c|c|}
\hline \multirow{2}{*}{ Species } & \multirow{2}{*}{$\begin{array}{c}\text { Cultu } \\
\text { re } \\
\text { collec } \\
\text { tion } \\
\text { access } \\
\text { ion } \\
\text { numb } \\
\text { er(s) }\end{array}$} & \multirow{2}{*}{$\begin{array}{c}\text { Host/isola } \\
\text { tion } \\
\text { source }\end{array}$} & \multirow{2}{*}{$\begin{array}{c}\text { Locatio } \\
\mathbf{n}\end{array}$} & \multirow{2}{*}{$\begin{array}{c}\text { Collec } \\
\text { tor }\end{array}$} & \multicolumn{11}{|c|}{ GenBank Accession numbers $^{b}$} \\
\hline & & & & & LSU & ITS & ACT & $\begin{array}{c}\text { TEF } \\
1-\alpha\end{array}$ & $\begin{array}{c}\text { GAP } \\
\text { DH }\end{array}$ & $\begin{array}{c}\text { RPB } \\
2\end{array}$ & HIS3 & CAL & $\begin{array}{c}\text { bTU } \\
\text { B }\end{array}$ & $\begin{array}{c}\text { MAT } \\
\mathbf{1}\end{array}$ & $\begin{array}{c}\text { MAT } \\
2\end{array}$ \\
\hline \multicolumn{16}{|l|}{ lis } \\
\hline & $\begin{array}{l}\text { CPC } \\
16866\end{array}$ & $\begin{array}{l}\text { Verbascu } \\
m \text { sp. }\end{array}$ & $\begin{array}{l}\text { Canada, } \\
\text { Ontario }\end{array}$ & $\begin{array}{l}\mathrm{K} . \\
\text { Seifert }\end{array}$ & $\begin{array}{l}\text { KP89 } \\
4172\end{array}$ & $\begin{array}{l}\text { KP89 } \\
4279\end{array}$ & $\begin{array}{l}\text { KP89 } \\
4387\end{array}$ & $\begin{array}{l}\text { KP89 } \\
4497\end{array}$ & $\begin{array}{l}\text { KP89 } \\
4607\end{array}$ & $\begin{array}{l}\text { KP89 } \\
4718\end{array}$ & \begin{tabular}{|l} 
KP89 \\
4829
\end{tabular} & & $\begin{array}{l}\text { KP89 } \\
5008\end{array}$ & & - \\
\hline & $\begin{array}{l}\text { CPC } \\
25967\end{array}$ & $\begin{array}{l}\text { Verbascu } \\
m \mathrm{sp} .\end{array}$ & $\begin{array}{l}\text { Austria, } \\
\text { Graz }\end{array}$ & $\begin{array}{l}\text { C. } \\
\text { Scheu } \\
\text { er }\end{array}$ & $\begin{array}{l}\text { KP89 } \\
4173\end{array}$ & $\mid \begin{array}{l}\text { KP89 } \\
4280\end{array}$ & $\begin{array}{l}\text { KP89 } \\
4388\end{array}$ & $\mid \begin{array}{l}\text { KP89 } \\
4498\end{array}$ & $\begin{array}{l}\text { KP89 } \\
4608\end{array}$ & $\begin{array}{l}\text { KP89 } \\
4719\end{array}$ & $\mid \begin{array}{l}\text { KP89 } \\
4830\end{array}$ & - & - & - & - \\
\hline \multirow[t]{2}{*}{$\left|\begin{array}{l}\text { Ramula } \\
\text { ria } \\
\text { vizellae }\end{array}\right|$} & $\begin{array}{l}\text { CBS } \\
11326 \\
7\end{array}$ & $\begin{array}{l}\text { Quercus } \\
\text { robur, } \\
\text { dead } \\
\text { fallen } \\
\text { leaves }\end{array}$ & $\begin{array}{l}\text { Netherla } \\
\text { nds, } \\
\text { Utrecht }\end{array}$ & $\begin{array}{l}\text { G. } \\
\text { Verkle } \\
y\end{array}$ & $\begin{array}{l}\text { KP89 } \\
4174\end{array}$ & $\mid \begin{array}{l}\text { KP89 } \\
4281\end{array}$ & $\begin{array}{l}\text { KP89 } \\
4389\end{array}$ & $\begin{array}{l}\text { KP89 } \\
4499\end{array}$ & $\begin{array}{l}\text { KP89 } \\
4609\end{array}$ & $\begin{array}{l}\text { KP89 } \\
4720\end{array}$ & \begin{tabular}{|l} 
KP89 \\
4831
\end{tabular} & $\mid \begin{array}{l}\text { KP89 } \\
4927\end{array}$ & $\begin{array}{l}\text { KP89 } \\
5009\end{array}$ & & - \\
\hline & $\begin{array}{l}\text { CBS } \\
11598 \\
0\end{array}$ & $\begin{array}{l}\text { Malus sp., } \\
\text { dead leaf } \\
\text { litter }\end{array}$ & $\begin{array}{l}\text { Netherla } \\
\text { nds, } \\
\text { Gelderla } \\
\text { nd }\end{array}$ & - & $\begin{array}{l}\text { KP89 } \\
4175\end{array}$ & $\mid \begin{array}{l}\text { KP89 } \\
4282\end{array}$ & $\begin{array}{l}\text { KP89 } \\
4390\end{array}$ & $\mid \begin{array}{l}\text { KP89 } \\
4500\end{array}$ & $\begin{array}{l}\text { KP89 } \\
4610\end{array}$ & $\mid \begin{array}{l}\text { KP89 } \\
4721\end{array}$ & $\mid \begin{array}{l}\text { KP89 } \\
4832\end{array}$ & - & - & $\begin{array}{l}\text { KP89 } \\
5058\end{array}$ & - \\
\hline & $\begin{array}{l}\text { CBS } \\
11598 \\
1\end{array}$ & $\begin{array}{l}\text { Malus sp., } \\
\text { dead leaf } \\
\text { litter }\end{array}$ & $\begin{array}{l}\text { Netherla } \\
\text { nds, } \\
\text { Gelderla } \\
\text { nd }\end{array}$ & - & $\begin{array}{l}\text { KP89 } \\
4176\end{array}$ & $\begin{array}{l}\text { KP89 } \\
4283\end{array}$ & $\begin{array}{l}\text { KP89 } \\
4391\end{array}$ & $\begin{array}{l}\text { KP89 } \\
4501\end{array}$ & $\begin{array}{l}\text { KP89 } \\
4611\end{array}$ & $\begin{array}{l}\text { KP89 } \\
4722\end{array}$ & $\begin{array}{l}\text { KP89 } \\
4833\end{array}$ & $\begin{array}{l}\text { KP89 } \\
4928\end{array}$ & $\begin{array}{l}\text { KP89 } \\
5010\end{array}$ & & - \\
\hline & $\begin{array}{l}\text { CBS } \\
11598 \\
2\end{array}$ & $\begin{array}{l}\text { Malus sp., } \\
\text { dead leaf } \\
\text { litter }\end{array}$ & $\begin{array}{l}\text { Netherla } \\
\text { nds, } \\
\text { Gelderla } \\
\text { nd }\end{array}$ & - & $\begin{array}{l}\text { KP89 } \\
4177\end{array}$ & \begin{tabular}{|l} 
KP89 \\
4284
\end{tabular} & $\begin{array}{l}\text { KP89 } \\
4392\end{array}$ & $\begin{array}{l}\text { KP89 } \\
4502\end{array}$ & $\begin{array}{l}\text { KP89 } \\
4612\end{array}$ & $\begin{array}{l}\text { KP89 } \\
4723\end{array}$ & $\mid \begin{array}{l}\text { KP89 } \\
4834\end{array}$ & $\mid \begin{array}{l}\text { KP89 } \\
4929\end{array}$ & $\begin{array}{l}\text { KP89 } \\
5011\end{array}$ & & - \\
\hline & $\begin{array}{l}\text { CBS } \\
11598 \\
3\end{array}$ & $\begin{array}{l}\text { Malus sp., } \\
\text { dead leaf } \\
\text { litter }\end{array}$ & $\begin{array}{l}\text { Netherla } \\
\text { nds, } \\
\text { Gelderla } \\
\text { nd }\end{array}$ & - & $\begin{array}{l}\text { KP89 } \\
4178\end{array}$ & $\mid \begin{array}{l}\text { KP89 } \\
4285\end{array}$ & $\begin{array}{l}\text { KP89 } \\
4393\end{array}$ & $\begin{array}{l}\text { KP89 } \\
4503\end{array}$ & $\begin{array}{l}\text { KP89 } \\
4613\end{array}$ & $\begin{array}{l}\text { KP89 } \\
4724\end{array}$ & $\begin{array}{l}\text { KP89 } \\
4835\end{array}$ & $\mid \begin{array}{l}\text { KP89 } \\
4930\end{array}$ & $\begin{array}{l}\text { KP89 } \\
5012\end{array}$ & & $\begin{array}{l}\text { KP89 } \\
5082\end{array}$ \\
\hline & $\begin{array}{l}\text { CBS } \\
11598 \\
4\end{array}$ & $\begin{array}{l}\text { Malus sp., } \\
\text { dead leaf } \\
\text { litter }\end{array}$ & $\begin{array}{l}\text { Netherla } \\
\text { nds, } \\
\text { Gelderla } \\
\text { nd }\end{array}$ & - & $\begin{array}{l}\text { KP89 } \\
4179\end{array}$ & $\mid \begin{array}{l}\text { KP89 } \\
4286\end{array}$ & $\begin{array}{l}\text { KP89 } \\
4394\end{array}$ & $\begin{array}{l}\text { KP89 } \\
4504\end{array}$ & $\begin{array}{l}\text { KP89 } \\
4614\end{array}$ & $\begin{array}{l}\text { KP89 } \\
4725\end{array}$ & $\mid \begin{array}{l}\text { KP89 } \\
4836\end{array}$ & $\mid \begin{array}{l}\text { KP89 } \\
4931\end{array}$ & $\begin{array}{l}\text { KP89 } \\
5013\end{array}$ & & $\begin{array}{l}\text { KP89 } \\
5083\end{array}$ \\
\hline & $\begin{array}{l}\text { CBS } \\
11601 \\
5\end{array}$ & $\begin{array}{l}\text { Malus sp., } \\
\text { dead leaf } \\
\text { litter }\end{array}$ & $\begin{array}{l}\text { Netherla } \\
\text { nds, } \\
\text { Gelderla } \\
\text { nd }\end{array}$ & - & $\begin{array}{l}\text { KP89 } \\
4180\end{array}$ & $\mid \begin{array}{l}\text { KP89 } \\
4287\end{array}$ & $\begin{array}{l}\text { KP89 } \\
4395\end{array}$ & $\begin{array}{l}\text { KP89 } \\
4505\end{array}$ & $\begin{array}{l}\text { KP89 } \\
4615\end{array}$ & $\begin{array}{l}\text { KP89 } \\
4726\end{array}$ & $\mid \begin{array}{l}\text { KP89 } \\
4837\end{array}$ & $\mid \begin{array}{l}\text { KP89 } \\
4932\end{array}$ & $\begin{array}{l}\text { KP89 } \\
5014\end{array}$ & & $\begin{array}{l}\text { KP89 } \\
5084\end{array}$ \\
\hline & $\begin{array}{l}\text { CBS } \\
11606 \\
9\end{array}$ & $\begin{array}{l}\text { Malus sp., } \\
\text { dead leaf } \\
\text { litter }\end{array}$ & $\begin{array}{l}\text { Netherla } \\
\text { nds, } \\
\text { Gelderla } \\
\text { nd }\end{array}$ & - & $\begin{array}{l}\text { KP89 } \\
4181\end{array}$ & $\mid \begin{array}{l}\text { KP89 } \\
4288\end{array}$ & $\begin{array}{l}\text { KP89 } \\
4396\end{array}$ & $\begin{array}{l}\text { KP89 } \\
4506\end{array}$ & $\begin{array}{l}\text { KP89 } \\
4616\end{array}$ & $\begin{array}{l}\text { KP89 } \\
4727\end{array}$ & $\begin{array}{l}\text { KP89 } \\
4838\end{array}$ & $\mid \begin{array}{l}\text { KP89 } \\
4933\end{array}$ & $\begin{array}{l}\text { KP89 } \\
5015\end{array}$ & & $\begin{array}{l}\text { KP89 } \\
5085\end{array}$ \\
\hline & CBS & Carpinus & Netherla & G. & KP89 & KP89 & KP89 & KP89 & KP89 & KP89 & KP89 & - & - & & KP89 \\
\hline
\end{tabular}




\begin{tabular}{|c|c|c|c|c|c|c|c|c|c|c|c|c|c|c|c|}
\hline \multirow{2}{*}{ Species } & \multirow{2}{*}{$\begin{array}{c}\text { Cultu } \\
\text { re } \\
\text { collec } \\
\text { tion } \\
\text { access } \\
\text { ion } \\
\text { numb } \\
\text { er(s) }\end{array}$} & \multirow{2}{*}{$\begin{array}{c}\text { Host/isola } \\
\text { tion } \\
\text { source }\end{array}$} & \multirow{2}{*}{$\begin{array}{c}\text { Locatio } \\
n\end{array}$} & \multirow{2}{*}{$\begin{array}{c}\text { Collec } \\
\text { tor }\end{array}$} & \multicolumn{11}{|c|}{ GenBank Accession numbers $^{\mathrm{b}}$} \\
\hline & & & & & LSU & ITS & ACT & $\begin{array}{r}\text { TEF } \\
1-\alpha\end{array}$ & $\begin{array}{c}\text { GAP } \\
\text { DH }\end{array}$ & $\begin{array}{c}\text { RPB } \\
2\end{array}$ & HIS3 & CAL & $\begin{array}{c}\text { bTU } \\
\text { B }\end{array}$ & $\begin{array}{c}\text { MAT } \\
1\end{array}$ & $\begin{array}{c}\text { MAT } \\
2\end{array}$ \\
\hline & \begin{tabular}{|l}
11779 \\
$8 ;$ \\
CPC \\
12088
\end{tabular} & $\begin{array}{l}\text { betulus, } \\
\text { fruit } \\
\text { scales }\end{array}$ & $\begin{array}{l}\text { nds, } \\
\text { Utrecht }\end{array}$ & $\begin{array}{l}\text { Verkle } \\
\text { y }\end{array}$ & 4182 & 4289 & 4397 & 4507 & 4617 & 4728 & 4839 & & & & 5086 \\
\hline & \begin{tabular}{|l} 
CBS \\
11779 \\
$9 ;$ \\
CPC \\
12089
\end{tabular} & $\mid \begin{array}{l}\text { Acer } \\
\text { pseudopla } \\
\text { tanus, } \\
\text { dead } \\
\text { leaves }\end{array}$ & $\begin{array}{l}\text { Netherla } \\
\text { nds, } \\
\text { Utrecht }\end{array}$ & $\begin{array}{l}\text { G. } \\
\text { Verkle } \\
\text { y }\end{array}$ & $\mid \begin{array}{l}\text { KP89 } \\
4183\end{array}$ & $\begin{array}{l}\text { KP89 } \\
4290\end{array}$ & $\begin{array}{l}\text { KP89 } \\
4398\end{array}$ & $\begin{array}{l}\text { KP89 } \\
4508\end{array}$ & $\begin{array}{l}\text { KP89 } \\
4618\end{array}$ & $\begin{array}{l}\text { KP89 } \\
4729\end{array}$ & $\begin{array}{l}\text { KP89 } \\
4840\end{array}$ & $\begin{array}{l}\text { KP89 } \\
4934\end{array}$ & $\begin{array}{l}\text { KP89 } \\
5016\end{array}$ & & - \\
\hline & $\begin{array}{l}\text { CBS } \\
11780 \\
2 ; \\
\text { CPC } \\
12092\end{array}$ & $\begin{array}{l}\text { Carpinus } \\
\text { betulus, } \\
\text { dead } \\
\text { leaves }\end{array}$ & $\begin{array}{l}\text { Netherla } \\
\text { nds, } \\
\text { Utrecht }\end{array}$ & $\begin{array}{l}\text { G. } \\
\text { Verkle } \\
\text { y }\end{array}$ & $\mid \begin{array}{l}\text { KP89 } \\
4184\end{array}$ & $\begin{array}{l}\text { KP89 } \\
4291\end{array}$ & $\begin{array}{l}\text { KP89 } \\
4399\end{array}$ & $\begin{array}{l}\text { KP89 } \\
4509\end{array}$ & $\begin{array}{l}\text { KP89 } \\
4619\end{array}$ & $\begin{array}{l}\text { KP89 } \\
4730\end{array}$ & $\begin{array}{l}\text { KP89 } \\
4841\end{array}$ & $\begin{array}{l}\text { KP89 } \\
4935\end{array}$ & $\begin{array}{l}\text { KP89 } \\
5017\end{array}$ & & - \\
\hline & \begin{tabular}{|l} 
CBS \\
11780 \\
$5 ;$ \\
CPC \\
12094
\end{tabular} & \begin{tabular}{|l} 
Aesculus \\
hippocast \\
anum, \\
dead \\
leaves
\end{tabular} & $\begin{array}{l}\text { Netherla } \\
\text { nds, } \\
\text { Utrecht }\end{array}$ & $\begin{array}{l}\text { G. } \\
\text { Verkle } \\
\text { y }\end{array}$ & $\begin{array}{l}\text { KP89 } \\
4185\end{array}$ & $\begin{array}{l}\text { KP89 } \\
4292\end{array}$ & $\begin{array}{l}\text { KP89 } \\
4400\end{array}$ & $\begin{array}{l}\text { KP89 } \\
4510\end{array}$ & $\begin{array}{l}\text { KP89 } \\
4620\end{array}$ & $\begin{array}{l}\text { KP89 } \\
4731\end{array}$ & $\begin{array}{l}\text { KP89 } \\
4842\end{array}$ & $\begin{array}{l}\text { KP89 } \\
4936\end{array}$ & $\begin{array}{l}\text { KP89 } \\
5018\end{array}$ & & $\begin{array}{l}\text { KP89 } \\
5087\end{array}$ \\
\hline & \begin{tabular}{|l} 
CBS \\
11780 \\
$6 ;$ \\
CPC \\
12096
\end{tabular} & $\begin{array}{l}\text { Tilia sp., } \\
\text { dead } \\
\text { leaves }\end{array}$ & $\begin{array}{l}\text { Netherla } \\
\text { nds, } \\
\text { Utrecht }\end{array}$ & $\begin{array}{l}\text { G. } \\
\text { Verkle } \\
\text { y }\end{array}$ & $\mid \begin{array}{l}\text { KP89 } \\
4186\end{array}$ & $\begin{array}{l}\text { KP89 } \\
4293\end{array}$ & $\begin{array}{l}\text { KP89 } \\
4401\end{array}$ & $\begin{array}{l}\text { KP89 } \\
4511\end{array}$ & $\begin{array}{l}\text { KP89 } \\
4621\end{array}$ & $\begin{array}{l}\text { KP89 } \\
4732\end{array}$ & $\begin{array}{l}\text { KP89 } \\
4843\end{array}$ & $\begin{array}{l}\text { KP89 } \\
4937\end{array}$ & $\begin{array}{l}\text { KP89 } \\
5019\end{array}$ & & $\begin{array}{l}\text { KP89 } \\
5088\end{array}$ \\
\hline & $\begin{array}{l}\text { CBS } \\
11787 \\
0 ; \\
\text { CPC } \\
11193\end{array}$ & $\begin{array}{l}\text { Quercus } \\
\text { rubra, } \\
\text { deacaying } \\
\text { leaves }\end{array}$ & $\begin{array}{l}\text { Netherla } \\
\text { nds, } \\
\text { Utrecht }\end{array}$ & $\begin{array}{l}\text { G. } \\
\text { Verkle } \\
\text { y }\end{array}$ & $\begin{array}{l}\text { KP89 } \\
4187\end{array}$ & $\begin{array}{l}\text { KP89 } \\
4294\end{array}$ & $\begin{array}{l}\text { KP89 } \\
4402\end{array}$ & $\begin{array}{l}\text { KP89 } \\
4512\end{array}$ & $\begin{array}{l}\text { KP89 } \\
4622\end{array}$ & $\begin{array}{l}\text { KP89 } \\
4733\end{array}$ & $\begin{array}{l}\text { KP89 } \\
4844\end{array}$ & $\begin{array}{l}\text { KP89 } \\
4938\end{array}$ & $\begin{array}{l}\text { KP89 } \\
5020\end{array}$ & & $\begin{array}{l}\text { KP89 } \\
5089\end{array}$ \\
\hline & \begin{tabular}{|l} 
CBS \\
11787 \\
$1 ;$ \\
CPC \\
11194
\end{tabular} & $\begin{array}{l}\text { Quercus } \\
\text { rubra, } \\
\text { deacaying } \\
\text { leaves }\end{array}$ & $\begin{array}{l}\text { Netherla } \\
\text { nds, } \\
\text { Utrecht }\end{array}$ & $\begin{array}{l}\text { G. } \\
\text { Verkle } \\
\text { y }\end{array}$ & $\begin{array}{l}\text { KP89 } \\
4188\end{array}$ & $\begin{array}{l}\text { KP89 } \\
4295\end{array}$ & $\begin{array}{l}\text { KP89 } \\
4403\end{array}$ & $\begin{array}{l}\text { KP89 } \\
4513\end{array}$ & $\begin{array}{l}\text { KP89 } \\
4623\end{array}$ & $\begin{array}{l}\text { KP89 } \\
4734\end{array}$ & $\begin{array}{l}\text { KP89 } \\
4845\end{array}$ & $\begin{array}{l}\text { KP89 } \\
4939\end{array}$ & $\begin{array}{l}\text { KP89 } \\
5021\end{array}$ & - & - \\
\hline & $\begin{array}{l}\text { CBS } \\
11787 \\
2 ; \\
\text { CPC } \\
11197\end{array}$ & $\begin{array}{l}\text { Amelanch } \\
\text { ier } \\
\text { lamarckii }\end{array}$ & $\begin{array}{l}\text { Netherla } \\
\text { nds, } \\
\text { Utrecht }\end{array}$ & $\begin{array}{l}\text { G. } \\
\text { Verkle } \\
\text { y }\end{array}$ & $\mid \begin{array}{l}\text { KP89 } \\
4189\end{array}$ & $\begin{array}{l}\text { KP89 } \\
4296\end{array}$ & $\begin{array}{l}\text { KP89 } \\
4404\end{array}$ & $\begin{array}{l}\text { KP89 } \\
4514\end{array}$ & $\begin{array}{l}\text { KP89 } \\
4624\end{array}$ & $\begin{array}{l}\text { KP89 } \\
4735\end{array}$ & $\begin{array}{l}\text { KP89 } \\
4846\end{array}$ & $\begin{array}{l}\text { KP89 } \\
4940\end{array}$ & $\begin{array}{l}\text { KP89 } \\
5022\end{array}$ & - & $\begin{array}{l}\text { KP89 } \\
5090\end{array}$ \\
\hline & \begin{tabular}{|l} 
CBS \\
11787 \\
$3 ;$ \\
CPC \\
11198
\end{tabular} & $\begin{array}{l}\text { Amelanch } \\
\text { ier } \\
\text { lamarckii }\end{array}$ & $\begin{array}{l}\text { Netherla } \\
\text { nds, } \\
\text { Utrecht }\end{array}$ & $\begin{array}{l}\text { G. } \\
\text { Verkle } \\
\text { y }\end{array}$ & $\mid \begin{array}{l}\text { KP89 } \\
4190\end{array}$ & $\begin{array}{l}\text { KP89 } \\
4297\end{array}$ & $\begin{array}{l}\text { KP89 } \\
4405\end{array}$ & $\begin{array}{l}\text { KP89 } \\
4515\end{array}$ & $\begin{array}{l}\text { KP89 } \\
4625\end{array}$ & $\begin{array}{l}\text { KP89 } \\
4736\end{array}$ & $\begin{array}{l}\text { KP89 } \\
4847\end{array}$ & $\begin{array}{l}\text { KP89 } \\
4941\end{array}$ & $\begin{array}{l}\text { KP89 } \\
5023\end{array}$ & - & - \\
\hline
\end{tabular}




\begin{tabular}{|c|c|c|c|c|c|c|c|c|c|c|c|c|c|c|c|}
\hline \multirow{2}{*}{ Species } & \multirow{2}{*}{$\begin{array}{c}\text { Cultu } \\
\text { re } \\
\text { collec } \\
\text { tion } \\
\text { access } \\
\text { ion } \\
\text { numb } \\
\text { er }(s)^{a}\end{array}$} & \multirow{2}{*}{$\begin{array}{c}\text { Host/isola } \\
\text { tion } \\
\text { source }\end{array}$} & \multirow{2}{*}{$\begin{array}{c}\text { Locatio } \\
n\end{array}$} & \multirow{2}{*}{$\begin{array}{c}\text { Collec } \\
\text { tor }\end{array}$} & \multicolumn{11}{|c|}{ GenBank Accession numbers $^{b}$} \\
\hline & & & & & LSU & ITS & ACT & $\begin{array}{r}\text { TEF } \\
1-\alpha\end{array}$ & $\begin{array}{c}\text { GAP } \\
\text { DH }\end{array}$ & $\begin{array}{c}\text { RPB } \\
2\end{array}$ & HIS3 & CAL & $\begin{array}{c}\text { bTU } \\
\text { B }\end{array}$ & $\begin{array}{c}\text { MAT } \\
\mathbf{1}\end{array}$ & $\begin{array}{c}\text { MAT } \\
2\end{array}$ \\
\hline & \begin{tabular}{|l|} 
CBS \\
11787 \\
$4 ;$ \\
CPC \\
11200
\end{tabular} & $\begin{array}{l}\text { Aesculus } \\
\text { hippocast } \\
\text { anum }\end{array}$ & $\begin{array}{l}\text { Netherla } \\
\text { nds, } \\
\text { Utrecht }\end{array}$ & $\begin{array}{l}\text { G. } \\
\text { Verkle } \\
y\end{array}$ & $\begin{array}{l}\text { KP89 } \\
4191\end{array}$ & $\begin{array}{l}\text { KP89 } \\
4298\end{array}$ & $\begin{array}{l}\text { KP89 } \\
4406\end{array}$ & $\begin{array}{l}\text { KP89 } \\
4516\end{array}$ & $\begin{array}{l}\text { KP89 } \\
4626\end{array}$ & $\begin{array}{l}\text { KP89 } \\
4737\end{array}$ & $\begin{array}{l}\text { KP89 } \\
4848\end{array}$ & $\begin{array}{l}\text { KP89 } \\
4942\end{array}$ & $\begin{array}{l}\text { KP89 } \\
5024\end{array}$ & & $\begin{array}{l}\text { KP89 } \\
5091\end{array}$ \\
\hline & \begin{tabular}{|l|} 
CBS \\
11787 \\
$5 ;$ \\
CPC \\
11201
\end{tabular} & $\begin{array}{l}\text { Aesculus } \\
\text { hippocast } \\
\text { anum }\end{array}$ & $\begin{array}{l}\text { Netherla } \\
\text { nds, } \\
\text { Utrecht }\end{array}$ & $\begin{array}{l}\text { G. } \\
\text { Verkle } \\
y\end{array}$ & $\begin{array}{l}\text { KP89 } \\
4192\end{array}$ & $\begin{array}{l}\text { KP89 } \\
4299\end{array}$ & $\begin{array}{l}\text { KP89 } \\
4407\end{array}$ & $\begin{array}{l}\text { KP89 } \\
4517\end{array}$ & $\begin{array}{l}\text { KP89 } \\
4627\end{array}$ & $\begin{array}{l}\text { KP89 } \\
4738\end{array}$ & $\begin{array}{l}\text { KP89 } \\
4849\end{array}$ & $\begin{array}{l}\text { KP89 } \\
4943\end{array}$ & $\begin{array}{l}\text { KP89 } \\
5025\end{array}$ & & - \\
\hline & \begin{tabular}{|l|} 
CBS \\
11788 \\
$2 ;$ \\
CPC \\
11212
\end{tabular} & $\begin{array}{l}\text { Sorbus } \\
\text { aucuparia } \\
\text {, decaying } \\
\text { leaves }\end{array}$ & $\begin{array}{l}\text { Netherla } \\
\text { nds, } \\
\text { Utrecht }\end{array}$ & $\begin{array}{l}\text { G. } \\
\text { Verkle } \\
\text { y }\end{array}$ & $\begin{array}{l}\text { KP89 } \\
4193\end{array}$ & $\begin{array}{l}\text { KP89 } \\
4300\end{array}$ & $\begin{array}{l}\text { KP89 } \\
4408\end{array}$ & $\begin{array}{l}\text { KP89 } \\
4518\end{array}$ & $\begin{array}{l}\text { KP89 } \\
4628\end{array}$ & $\begin{array}{l}\text { KP89 } \\
4739\end{array}$ & $\begin{array}{l}\text { KP89 } \\
4850\end{array}$ & $\begin{array}{l}\text { KP89 } \\
4944\end{array}$ & $\begin{array}{l}\text { KP89 } \\
5026\end{array}$ & $\begin{array}{l}\text { KP89 } \\
5059\end{array}$ & - \\
\hline & \begin{tabular}{|l|} 
CBS \\
11788 \\
$3 ;$ \\
CPC \\
11213
\end{tabular} & $\begin{array}{l}\text { Sorbus } \\
\text { aucuparia } \\
\text {, decaying } \\
\text { leaves }\end{array}$ & $\begin{array}{l}\text { Netherla } \\
\text { nds, } \\
\text { Utrecht }\end{array}$ & $\begin{array}{l}\text { G. } \\
\text { Verkle } \\
\text { y }\end{array}$ & $\begin{array}{l}\text { KP89 } \\
4194\end{array}$ & $\begin{array}{l}\text { KP89 } \\
4301\end{array}$ & $\begin{array}{l}\text { KP89 } \\
4409\end{array}$ & $\begin{array}{l}\text { KP89 } \\
4519\end{array}$ & $\begin{array}{l}\text { KP89 } \\
4629\end{array}$ & $\begin{array}{l}\text { KP89 } \\
4740\end{array}$ & $\begin{array}{l}\text { KP89 } \\
4851\end{array}$ & $\begin{array}{l}\text { KP89 } \\
4945\end{array}$ & $\begin{array}{l}\text { KP89 } \\
5027\end{array}$ & $\begin{array}{l}\text { KP89 } \\
5060\end{array}$ & - \\
\hline & $\begin{array}{l}\text { CBS } \\
12486 \\
1\end{array}$ & $\begin{array}{l}\text { Fagus } \\
\text { sylvatica, } \\
\text { leaf litter } \\
\text { from } 2007\end{array}$ & $\begin{array}{l}\text { German } \\
y, \\
\text { Greifsw } \\
\text { ald }\end{array}$ & $\begin{array}{l}\text { M. } \\
\text { Unters } \\
\text { eher }\end{array}$ & $\begin{array}{l}\text { KP89 } \\
4195\end{array}$ & $\begin{array}{l}\text { KP89 } \\
4302\end{array}$ & $\begin{array}{l}\text { KP89 } \\
4410\end{array}$ & $\begin{array}{l}\text { KP89 } \\
4520\end{array}$ & $\begin{array}{l}\text { KP89 } \\
4630\end{array}$ & $\begin{array}{l}\text { KP89 } \\
4741\end{array}$ & $\begin{array}{l}\text { KP89 } \\
4852\end{array}$ & $\begin{array}{l}\text { KP89 } \\
4946\end{array}$ & & & $\begin{array}{l}\text { KP89 } \\
5092\end{array}$ \\
\hline & \begin{tabular}{|l|} 
CBS \\
$\mathbf{1 3 0 6 0}$ \\
$\mathbf{1}$ eTy; \\
CPC \\
18283
\end{tabular} & $\begin{array}{l}\text { Protea } \\
\text { sp., leaves }\end{array}$ & $\begin{array}{l}\text { South } \\
\text { Africa }\end{array}$ & $\begin{array}{l}\text { P.W. } \\
\text { Crous }\end{array}$ & $\begin{array}{l}\text { JN71 } \\
2567\end{array}$ & $\begin{array}{l}\text { KJ50 } \\
4808\end{array}$ & $\begin{array}{l}\text { KJ50 } \\
4472\end{array}$ & $\begin{array}{l}\text { KJ50 } \\
4723\end{array}$ & $\begin{array}{l}\text { KJ50 } \\
4591\end{array}$ & $\begin{array}{l}\text { KJ50 } \\
4679\end{array}$ & $\begin{array}{l}\text { KJ50 } \\
4635\end{array}$ & & $\begin{array}{l}\text { KJ50 } \\
4495\end{array}$ & $\begin{array}{l}\text { KP89 } \\
5061\end{array}$ & - \\
\hline & $\begin{array}{l}\text { CBS } \\
184.9 \\
7\end{array}$ & \begin{tabular}{|l} 
Acer \\
pseudopla \\
tanus, \\
dead \\
leaves
\end{tabular} & $\begin{array}{l}\text { Netherla } \\
\text { nds, } \\
\text { Utrecht }\end{array}$ & $\begin{array}{l}\text { H.A. } \\
\text { van } \\
\text { der Aa }\end{array}$ & $\begin{array}{l}\text { KP89 } \\
4196\end{array}$ & $\begin{array}{l}\text { KP89 } \\
4303\end{array}$ & $\begin{array}{l}\text { KP89 } \\
4411\end{array}$ & $\begin{array}{l}\text { KP89 } \\
4521\end{array}$ & $\begin{array}{l}\text { KP89 } \\
4631\end{array}$ & $\begin{array}{l}\text { KP89 } \\
4742\end{array}$ & $\begin{array}{l}\text { KP89 } \\
4853\end{array}$ & $\begin{array}{l}\text { KP89 } \\
4947\end{array}$ & $\begin{array}{l}\text { KP89 } \\
5028\end{array}$ & $\begin{array}{l}\text { KP89 } \\
5062\end{array}$ & \\
\hline & $\begin{array}{l}\text { CBS } \\
185.9 \\
7\end{array}$ & $\begin{array}{l}\text { Acer } \\
\text { pseudopla } \\
\text { tanus, } \\
\text { dead } \\
\text { leaves }\end{array}$ & $\begin{array}{l}\text { Netherla } \\
\text { nds, } \\
\text { Utrecht }\end{array}$ & $\begin{array}{l}\text { H.A. } \\
\text { van } \\
\text { der Aa }\end{array}$ & $\begin{array}{l}\text { KP89 } \\
4197\end{array}$ & $\begin{array}{l}\text { KP89 } \\
4304\end{array}$ & $\begin{array}{l}\text { KP89 } \\
4412\end{array}$ & $\begin{array}{l}\text { KP89 } \\
4522\end{array}$ & $\begin{array}{l}\text { KP89 } \\
4632\end{array}$ & $\begin{array}{l}\text { KP89 } \\
4743\end{array}$ & $\begin{array}{l}\text { KP89 } \\
4854\end{array}$ & $\begin{array}{l}\text { KP89 } \\
4948\end{array}$ & $\begin{array}{l}\text { KP89 } \\
5029\end{array}$ & $\begin{array}{l}\text { KP89 } \\
5063\end{array}$ & - \\
\hline & $\begin{array}{l}\text { CBS } \\
324.8 \\
7\end{array}$ & $\begin{array}{l}\text { Brassica } \\
\text { sp., in leaf } \\
\text { spot }\end{array}$ & $\begin{array}{l}\text { Netherla } \\
\text { nds }\end{array}$ & - & $\begin{array}{l}\text { GU21 } \\
4581\end{array}$ & $\begin{array}{l}\text { GU21 } \\
4581\end{array}$ & $\begin{array}{l}\text { KP89 } \\
4413\end{array}$ & $\begin{array}{l}\text { KP89 } \\
4523\end{array}$ & $\begin{array}{l}\text { KP89 } \\
4633\end{array}$ & $\begin{array}{l}\text { KP89 } \\
4744\end{array}$ & $\begin{array}{l}\text { KP89 } \\
4855\end{array}$ & $\begin{array}{l}\text { KP89 } \\
4949\end{array}$ & $\begin{array}{l}\text { KP89 } \\
5030\end{array}$ & - & $\begin{array}{l}\text { KP89 } \\
5093\end{array}$ \\
\hline
\end{tabular}




\begin{tabular}{|c|c|c|c|c|c|c|c|c|c|c|c|c|c|c|c|}
\hline \multirow{2}{*}{ Species } & \multirow{2}{*}{$\begin{array}{c}\text { Cultu } \\
\text { re } \\
\text { collec } \\
\text { tion } \\
\text { access } \\
\text { ion } \\
\text { numb } \\
\text { er(s) }\end{array}$} & \multirow{2}{*}{$\begin{array}{c}\text { Host/isola } \\
\text { tion } \\
\text { source }\end{array}$} & \multirow{2}{*}{$\begin{array}{c}\text { Locatio } \\
\mathbf{n}\end{array}$} & \multirow{2}{*}{$\begin{array}{c}\text { Collec } \\
\text { tor }\end{array}$} & \multicolumn{11}{|c|}{ GenBank Accession numbers $^{\text {b }}$} \\
\hline & & & & & LSU & ITS & ACT & $\begin{array}{r}\text { TEF } \\
1-\alpha\end{array}$ & $\begin{array}{l}\text { GAP } \\
\text { DH }\end{array}$ & $\begin{array}{c}\text { RPB } \\
2\end{array}$ & HIS3 & CAL & $\begin{array}{c}\text { bTU } \\
\text { B }\end{array}$ & $\begin{array}{c}\text { MAT } \\
1\end{array}$ & $\begin{array}{c}\text { MAT } \\
2\end{array}$ \\
\hline & $\begin{array}{l}\text { CBS } \\
367.6 \\
4\end{array}$ & $\begin{array}{l}\text { Malus } \\
\text { sylvestris, } \\
\text { fruit }\end{array}$ & France & \begin{tabular}{|l} 
C. \\
Morea \\
$\mathrm{u}$
\end{tabular} & $\begin{array}{l}\text { KP89 } \\
4198\end{array}$ & $\begin{array}{l}\text { KP89 } \\
4305\end{array}$ & $\begin{array}{l}\text { KP89 } \\
4414\end{array}$ & $\begin{array}{l}\text { KP89 } \\
4524\end{array}$ & $\begin{array}{l}\text { KP89 } \\
4634\end{array}$ & $\mid \begin{array}{l}\text { KP89 } \\
4745\end{array}$ & $\begin{array}{l}\text { KP89 } \\
4856\end{array}$ & $\begin{array}{l}\text { KP89 } \\
4950\end{array}$ & $\begin{array}{l}\text { KP89 } \\
5031\end{array}$ & & $\begin{array}{l}\text { KP89 } \\
5094\end{array}$ \\
\hline & $\begin{array}{l}\text { CBS } \\
369.6 \\
7\end{array}$ & $\mid \begin{array}{l}\text { Lotus } \\
\text { uliginosus } \\
\text {, young } \\
\text { leaves }\end{array}$ & $\begin{array}{l}\text { Netherla } \\
\text { nds, } \\
\text { Utrecht }\end{array}$ & $\begin{array}{l}\text { H.A. } \\
\text { van } \\
\text { der Aa }\end{array}$ & $\begin{array}{l}\text { KP89 } \\
4199\end{array}$ & $\begin{array}{l}\text { KP89 } \\
4306\end{array}$ & $\begin{array}{l}\text { KP89 } \\
4415\end{array}$ & $\begin{array}{l}\text { KP89 } \\
4525\end{array}$ & $\begin{array}{l}\text { KP89 } \\
4635\end{array}$ & $\mid \begin{array}{l}\text { KP89 } \\
4746\end{array}$ & $\begin{array}{l}\text { KP89 } \\
4857\end{array}$ & $\begin{array}{l}\text { KP89 } \\
4951\end{array}$ & - & & $\begin{array}{l}\text { KP89 } \\
5095\end{array}$ \\
\hline & \begin{tabular}{|l|} 
CBS \\
428.7 \\
$4 ;$ \\
IHEM \\
3995
\end{tabular} & $\begin{array}{l}\text { Phaseolus } \\
\text { sp. }\end{array}$ & $\begin{array}{l}\text { Switzerl } \\
\text { and }\end{array}$ & - & $\begin{array}{l}\text { KP89 } \\
4200\end{array}$ & $\begin{array}{l}\text { KP89 } \\
4307\end{array}$ & $\begin{array}{l}\text { KP89 } \\
4416\end{array}$ & $\begin{array}{l}\text { KP89 } \\
4526\end{array}$ & $\begin{array}{l}\text { KP89 } \\
4636\end{array}$ & $\begin{array}{l}\text { KP89 } \\
4747\end{array}$ & $\begin{array}{l}\text { KP89 } \\
4858\end{array}$ & $\begin{array}{l}\text { KP89 } \\
4952\end{array}$ & $\begin{array}{l}\text { KP89 } \\
5032\end{array}$ & & - \\
\hline & $\begin{array}{l}\text { CBS } \\
515.6 \\
9\end{array}$ & $\begin{array}{l}\text { Acer } \\
\text { pseudopla } \\
\text { tanus }\end{array}$ & $\begin{array}{l}\text { Netherla } \\
\text { nds, } \\
\text { Utrecht }\end{array}$ & $\begin{array}{l}\text { H.A. } \\
\text { van } \\
\text { der Aa }\end{array}$ & $\begin{array}{l}\text { KP89 } \\
4201\end{array}$ & $\begin{array}{l}\text { AY49 } \\
0759\end{array}$ & $\begin{array}{l}\text { KP89 } \\
4417\end{array}$ & $\begin{array}{l}\text { KP89 } \\
4527\end{array}$ & $\begin{array}{l}\text { KP89 } \\
4637\end{array}$ & $\begin{array}{l}\text { KP89 } \\
4748\end{array}$ & $\begin{array}{l}\text { KP89 } \\
4859\end{array}$ & $\begin{array}{l}\text { KP89 } \\
4953\end{array}$ & $\begin{array}{l}\text { KP89 } \\
5033\end{array}$ & & $\begin{array}{l}\text { KP89 } \\
5096\end{array}$ \\
\hline & $\begin{array}{l}\text { CBS } \\
724.7 \\
9\end{array}$ & $\begin{array}{l}\text { Tilia sp., } \\
\text { overwinte } \\
\text { ring leaf } \\
\text { on the } \\
\text { ground }\end{array}$ & $\begin{array}{l}\text { German } \\
\text { y, } \\
\text { Munche } \\
\text { n }\end{array}$ & $\begin{array}{l}\text { A. } \\
\text { John }\end{array}$ & $\begin{array}{l}\text { KP89 } \\
4202\end{array}$ & $\begin{array}{l}\text { KP89 } \\
4308\end{array}$ & $\begin{array}{l}\text { KP89 } \\
4418\end{array}$ & $\begin{array}{l}\text { KP89 } \\
4528\end{array}$ & $\begin{array}{l}\text { KP89 } \\
4638\end{array}$ & $\begin{array}{l}\text { KP89 } \\
4749\end{array}$ & $\begin{array}{l}\text { KP89 } \\
4860\end{array}$ & $\begin{array}{l}\text { KP89 } \\
4954\end{array}$ & $\begin{array}{l}\text { KP89 } \\
5034\end{array}$ & & $\begin{array}{l}\text { KP89 } \\
5097\end{array}$ \\
\hline & $\begin{array}{l}\text { CBS } \\
943.9 \\
7\end{array}$ & $\begin{array}{l}\text { Quercus } \\
\text { sp., leaves }\end{array}$ & $\begin{array}{l}\text { Netherla } \\
\text { nds }\end{array}$ & $\begin{array}{l}\text { A. } \\
\text { Aptro } \\
\text { ot }\end{array}$ & $\begin{array}{l}\text { KP89 } \\
4203\end{array}$ & $\begin{array}{l}\text { KP89 } \\
4309\end{array}$ & $\begin{array}{l}\text { KP89 } \\
4419\end{array}$ & $\begin{array}{l}\text { KP89 } \\
4529\end{array}$ & $\begin{array}{l}\text { KP89 } \\
4639\end{array}$ & $\mid \begin{array}{l}\text { KP89 } \\
4750\end{array}$ & $\mid \begin{array}{l}\text { KP89 } \\
4861\end{array}$ & $\begin{array}{l}\text { KP89 } \\
4955\end{array}$ & $\begin{array}{l}\text { KP89 } \\
5035\end{array}$ & - & - \\
\hline & $\begin{array}{l}\text { CPC } \\
15541\end{array}$ & $\begin{array}{l}\text { Acer } \\
\text { campestre }\end{array}$ & $\begin{array}{l}\text { Ukraine, } \\
\text { Seversk } \\
\text { y Donets } \\
\text { river }\end{array}$ & $\begin{array}{l}\text { A. } \\
\text { Akulo } \\
\text { v }\end{array}$ & $\begin{array}{l}\text { KP89 } \\
4204\end{array}$ & $\begin{array}{l}\text { KP89 } \\
4310\end{array}$ & $\begin{array}{l}\text { KP89 } \\
4420\end{array}$ & $\begin{array}{l}\text { KP89 } \\
4530\end{array}$ & $\begin{array}{l}\text { KP89 } \\
4640\end{array}$ & $\begin{array}{l}\text { KP89 } \\
4751\end{array}$ & $\mid \begin{array}{l}\text { KP89 } \\
4862\end{array}$ & & - & - & - \\
\hline & \begin{tabular}{|l} 
CPC \\
25728 \\
MP19
\end{tabular} & $\begin{array}{l}\text { Corylus } \\
\text { sp. }\end{array}$ & $\begin{array}{l}\text { Netherla } \\
\text { nds, } \\
\text { Utrecht }\end{array}$ & $\begin{array}{l}\text { S.I.R. } \\
\text { Videir } \\
\text { a }\end{array}$ & $\begin{array}{l}\text { KP89 } \\
4205\end{array}$ & $\begin{array}{l}\text { KP89 } \\
4311\end{array}$ & $\begin{array}{l}\text { KP89 } \\
4421\end{array}$ & $\begin{array}{l}\text { KP89 } \\
4531\end{array}$ & $\begin{array}{l}\text { KP89 } \\
4641\end{array}$ & $\begin{array}{l}\text { KP89 } \\
4752\end{array}$ & $\begin{array}{l}\text { KP89 } \\
4863\end{array}$ & $\begin{array}{l}\text { KP89 } \\
4956\end{array}$ & - & & - \\
\hline & \begin{tabular}{|l} 
CPC \\
25729 \\
$;$ \\
MP20
\end{tabular} & $\begin{array}{l}\text { Quercus } \\
\text { sp. }\end{array}$ & $\begin{array}{l}\text { Netherla } \\
\text { nds, } \\
\text { Utrecht }\end{array}$ & $\begin{array}{l}\text { S.I.R. } \\
\text { Videir } \\
\text { a }\end{array}$ & $\begin{array}{l}\text { KP89 } \\
4206\end{array}$ & $\begin{array}{l}\text { KP89 } \\
4312\end{array}$ & $\begin{array}{l}\text { KP89 } \\
4422\end{array}$ & $\begin{array}{l}\text { KP89 } \\
4532\end{array}$ & $\begin{array}{l}\text { KP89 } \\
4642\end{array}$ & $\begin{array}{l}\text { KP89 } \\
4753\end{array}$ & $\begin{array}{l}\text { KP89 } \\
4864\end{array}$ & $\begin{array}{l}\text { KP89 } \\
4957\end{array}$ & - & $\begin{array}{l}\text { KP89 } \\
5064\end{array}$ & - \\
\hline & \begin{tabular}{|l}
$\mathrm{CPC}$ \\
25730 \\
MP21
\end{tabular} & $\begin{array}{l}\text { Carpinus } \\
\text { sp. }\end{array}$ & $\begin{array}{l}\text { Netherla } \\
\text { nds, } \\
\text { Utrecht }\end{array}$ & $\begin{array}{l}\text { S.I.R. } \\
\text { Videir } \\
\mathrm{a}\end{array}$ & $\begin{array}{l}\text { KP89 } \\
4207\end{array}$ & $\begin{array}{l}\text { KP89 } \\
4313\end{array}$ & $\begin{array}{l}\text { KP89 } \\
4423\end{array}$ & $\begin{array}{l}\text { KP89 } \\
4533\end{array}$ & $\begin{array}{l}\text { KP89 } \\
4643\end{array}$ & $\begin{array}{l}\text { KP89 } \\
4754\end{array}$ & $\begin{array}{l}\text { KP89 } \\
4865\end{array}$ & $\begin{array}{l}\text { KP89 } \\
4958\end{array}$ & - & & $\begin{array}{l}\text { KP89 } \\
5098\end{array}$ \\
\hline & $\begin{array}{l}\text { CPC } \\
25731\end{array}$ & $\begin{array}{l}\text { Quercus } \\
\text { sp. }\end{array}$ & $\begin{array}{l}\text { Netherla } \\
\text { nds, }\end{array}$ & $\begin{array}{l}\text { S.I.R. } \\
\text { Videir }\end{array}$ & $\begin{array}{l}\text { KP89 } \\
4208\end{array}$ & $\begin{array}{l}\text { KP89 } \\
4314\end{array}$ & $\begin{array}{l}\text { KP89 } \\
4424\end{array}$ & $\begin{array}{l}\text { KP89 } \\
4534\end{array}$ & $\begin{array}{l}\text { KP89 } \\
4644\end{array}$ & $\begin{array}{l}\text { KP89 } \\
4755\end{array}$ & $\begin{array}{l}\text { KP89 } \\
4866\end{array}$ & $\begin{array}{l}\text { KP89 } \\
4959\end{array}$ & - & & $\begin{array}{l}\text { KP89 } \\
5099\end{array}$ \\
\hline
\end{tabular}




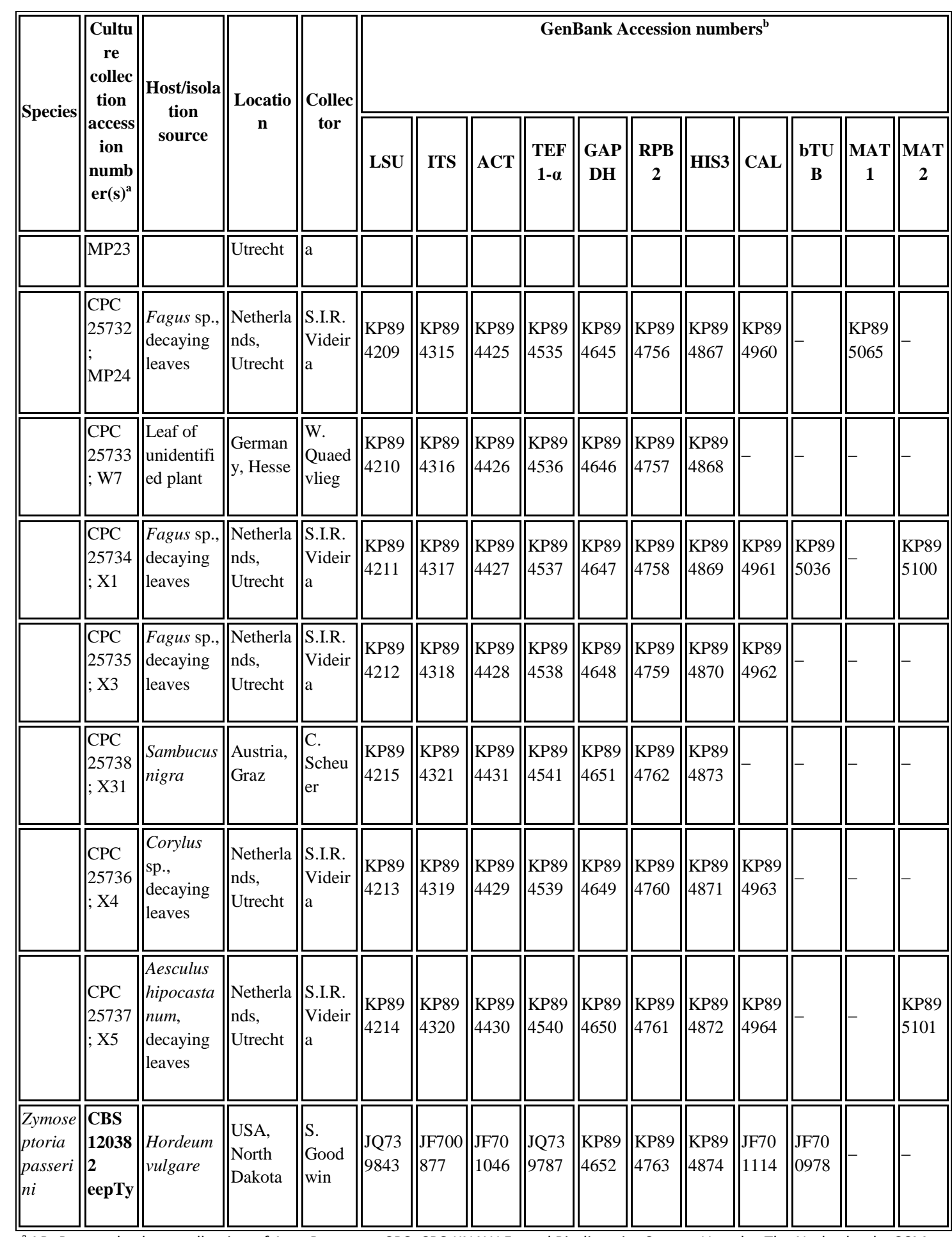

${ }^{a}$ AR: Personal culture collection of Amy Rossman; CBS: CBS-KNAW Fungal Biodiversity Centre, Utrecht, The Netherlands; CCM: Czech Collection of Microorganisms, Masaryk University, Brno, Czech Republic; CPC: Personal culture collection of Pedro Crous, housed at CBS; DTO: Personal culture collection of the Applied and Industrial Mycology, housed at CBS; IHEM: Collection of the Laboratorium voor Microbiologie en Microbiele Genetica, Gent, Belgium; IPO: Research Institute for Plant Protection, Wageningen; RoKI: Personal culture collection of Roland Kirschner; UPSC: Uppsala University Culture Collection of Fungi, Botanical Museum University of Uppsala, Uppsala, Sweden.

${ }^{b}$ LSU: large subunit (28S) of the nrRNA gene operon; ITS: internal transcribed spacers and intervening 5.8S nrDNA; ACT: partial actin gene; TEF1- $\alpha$ : partial translation elongation factor 1-alpha gene; GAPDH: partial glyceraldehyde-3-phosphate dehydrogenase (GAPDH) gene; RPB2: partial RNA polymerase II second largest subunit gene; HIS3: partial histone H3 gene; CAL: partial calmodulin gene; bTUB: partial beta-tubulin gene; MAT1: partial MAT1-1-1 mating type gene; MAT2: partial MAT1-2 mating type gene. eTy: ex-type; eepTy: ex-epitype; ' $X$ ' represents a DNA sequence that will be submitted to Genbank and '-' a DNA sequence that was not generated. 


\section{DNA extraction, amplification and sequencing}

Fungal mycelium of strains (Table 1) was harvested with a sterile scalpel and the genomic DNA was isolated using the UltraClean ${ }^{\mathrm{TM}}$ Microbial DNA Isolation Kit (MoBio

Laboratories, Solana Beach, CA, USA) following the manufacturers' protocols. Eleven partial nuclear genes were initially targeted for PCR amplification and sequencing: 28S nrRNA gene (LSU), internal transcribed spacer regions and intervening 5.8S nrRNA gene (ITS) of the nrDNA operon, actin (ACT), translation elongation factor 1- $\alpha$ (TEF1- $\alpha$ ), histone H3 (HIS3), glyceraldehyde-3-phosphate dehydrogenase (GAPDH), RNA polymerase II second largest subunit (RPB2), calmodulin (CAL), $\beta$-tubulin (bTUB), mating-type gene 1 (MAT1-1-1) and mating-type gene 2 (MAT1-2-1). The primers employed are listed in Table 2. The PCR amplifications were performed on a GeneAmp PCR System 9700 (Applied Biosystems, Foster City, CA, USA). The PCR mixtures consisted of $1 \mu \mathrm{L}$ genomic DNA, $1 \times$ GoTaq $^{\circledR}$ Flexi buffer (Promega, Madison, WI, USA), $2 \mu \mathrm{M} \mathrm{MgCl}_{2}, 40 \mu \mathrm{M}$ of each dNTP, $0.2 \mu \mathrm{M}$ of each primer and 0.5 Unit GoTaq ${ }^{\circledR}$ Flexi DNA polymerase (Promega) in a total volume of $12.5 \mu \mathrm{L}$. The PCR mixtures for HIS3, GAPDH, RPB2, CAL and bTUB contained $2 \mu \mathrm{L}$ genomic DNA. The PCR conditions were: initial denaturation $\left(94{ }^{\circ} \mathrm{C}, 3 \mathrm{~min}\right) ; 35$ cycles amplification $\left(94{ }^{\circ} \mathrm{C}, 30 \mathrm{~s}\right.$; annealing temperature listed in Table $\left.2,30 \mathrm{~s} ; 72{ }^{\circ} \mathrm{C}, 45 \mathrm{~s}\right)$, and final extension $\left(72{ }^{\circ} \mathrm{C}, 5 \mathrm{~min}\right)$. For GAPDH and HIS3, 40 amplification cycles were used. To obtain the partial RPB2, a touchdown PCR protocol was used: initial denaturation $\left(94{ }^{\circ} \mathrm{C}\right.$, $3 \mathrm{~min}), 5$ amplification cycles $\left(94^{\circ} \mathrm{C}, 45 \mathrm{~s} ; 60^{\circ} \mathrm{C}, 45 \mathrm{~s} ; 72^{\circ} \mathrm{C}, 2 \mathrm{~min}\right), 5$ amplification cycles $\left(94{ }^{\circ} \mathrm{C}, 45 \mathrm{~s} ; 58{ }^{\circ} \mathrm{C}, 45 \mathrm{~s} ; 72{ }^{\circ} \mathrm{C}, 2 \mathrm{~min}\right), 30$ amplification cycles $\left(94{ }^{\circ} \mathrm{C}, 45 \mathrm{~s} ; 54{ }^{\circ} \mathrm{C}, 45 \mathrm{~s}\right.$; $\left.72{ }^{\circ} \mathrm{C}, 2 \mathrm{~min}\right)$ and a final extension $\left(72{ }^{\circ} \mathrm{C}, 8 \mathrm{~min}\right)$. The resulting fragments were sequenced in both directions using the PCR primers and the BigDye Terminator Cycle Sequencing Kit v. 3.1 (Applied Biosystems Life Technologies, Carlsbad, CA, USA). DNA sequencing amplicons were purified through Sephadex G-50 Superfine columns (Sigma-Aldrich, St. Louis, MO) in MultiScreen HV plates (Millipore, Billerica, MA). Purified sequence reactions were analysed on an Applied Biosystems 3730xl DNA Analyzer (Life Technologies, Carlsbad, CA, USA). The DNA sequences generated were analysed and consensus sequences were computed using the BioNumerics v. 4.61 software package (Applied Maths, StMartens-Latem, Belgium).

Table 2. Details of primers used for amplification and sequencing in this study.

\begin{tabular}{|c|c|c|c|c|c|}
\hline Locus $^{\mathrm{a}}$ & Primer name & Primer sequence $\left(5^{\prime} \rightarrow 3^{\prime}\right)$ & $\begin{array}{c}\text { Annealing } \\
\text { temperature }\left({ }^{\circ} \mathbf{C}\right)\end{array}$ & Orientation & Reference \\
\hline \multirow[t]{3}{*}{ ACT } & ACT-512F & ATG TGC AAG GCC GGT TTC GC & 55 & Forward & $\begin{array}{l}\text { Carbone \& Kohn } \\
(1999)\end{array}$ \\
\hline & ACT-783 R & TAC GAG TCC TTC TGG CCC AT & 55 & Reverse & $\begin{array}{l}\text { Carbone \& Kohn } \\
(1999)\end{array}$ \\
\hline & ACT-2Rd & ARR TCR CGD CCR GCC ATG TC & 55 & Reverse & $\begin{array}{l}\text { Groenewald } \text { et al. } \\
\text { (2013) }\end{array}$ \\
\hline \multirow[t]{2}{*}{ bTUB } & $\mathrm{T} 1$ & $\begin{array}{l}\text { AAC ATG CGT GAG ATT GTA } \\
\text { AGT }\end{array}$ & 52 & Forward & $\begin{array}{l}\text { O'Donnell \& Cigelnik, } \\
1997\end{array}$ \\
\hline & $\beta$-Sandy-R & GCR CGN GGV ACR TAC TTG TT & 52 & Reverse & $\begin{array}{l}\text { Stukenbrock } \text { et al. } \\
(2012)\end{array}$ \\
\hline
\end{tabular}




\begin{tabular}{|c|c|c|c|c|c|}
\hline Locus $^{\mathrm{a}}$ & Primer name & Primer sequence $\left(5^{\prime} \rightarrow 3^{\prime}\right)$ & $\begin{array}{c}\text { Annealing } \\
\text { temperature }\left({ }^{\circ} \mathbf{C}\right)\end{array}$ & Orientation & Reference \\
\hline & $\mathrm{Bt} 2 \mathrm{a}$ & $\begin{array}{l}\text { GGT AAC CAA ATC GGT GCT } \\
\text { GCT TTC }\end{array}$ & 52 & Forward & $\begin{array}{l}\text { Glass \& Donaldson } \\
\text { (1995) }\end{array}$ \\
\hline & $\mathrm{Bt} 2 \mathrm{~b}$ & $\begin{array}{l}\text { ACC CTC AGT GTA GTG ACC CTT } \\
\text { GGC }\end{array}$ & 52 & Reverse & $\begin{array}{l}\text { Glass \& Donaldson } \\
(1995)\end{array}$ \\
\hline \multirow[t]{3}{*}{ CAL } & CAL-228F & $\begin{array}{l}\text { GAG TTC AAG GAG GCC TTC TCC } \\
\text { C }\end{array}$ & 58 & Forward & $\begin{array}{l}\text { Carbone \& Kohn } \\
(1999)\end{array}$ \\
\hline & CAL-737R & CAT CTT TCT GGC CAT CAT GG & 58 & Reverse & $\begin{array}{l}\text { Carbone \& Kohn } \\
\text { (1999) }\end{array}$ \\
\hline & CAL2Rd & $\begin{array}{l}\text { TGR TCN GCC TCD CGG ATC ATC } \\
\text { TC }\end{array}$ & 58 & Reverse & $\begin{array}{l}\text { Groenewald et al. } \\
\text { (2013) }\end{array}$ \\
\hline \multirow[t]{2}{*}{ GAPDH } & gpd1 & CAA CGG CTT CGG TCG CAT TG & 55 & Forward & Berbee et al. (1999) \\
\hline & gpd2 & GCC AAG CAG TTG GTT GTG C & 55 & Reverse & Berbee et al. (1999) \\
\hline \multirow[t]{2}{*}{ HIS3 } & CylH3F & AGG TCC ACT GGT GGC AAG & 52 & Forward & Crous et al. (2004b) \\
\hline & CylH3R & AGC TGG ATG TCC TTG GAC TG & 52 & Reverse & Crous et al. (2004b) \\
\hline \multirow[t]{2}{*}{ ITS } & V9G & TTA CGT CCC TGC CCT TTG TA & 52 & Forward & $\begin{array}{l}\text { de Hoog \& Gerrits van } \\
\text { den Ende (1998) }\end{array}$ \\
\hline & ITS4 & TCC TCC GCT TAT TGA TAT GC & 52 & Reverse & White et al. (1990) \\
\hline \multirow[t]{2}{*}{ LSU } & LSU1Fd & GRA TCA GGT AGG RAT ACC CG & 52 & Forward & Crous et al. (2009a) \\
\hline & LR5 & TCC TGA GGG AAA CTT CG & 52 & Reverse & $\begin{array}{l}\text { Vilgalys \& Hester } \\
\text { (1990) }\end{array}$ \\
\hline \multirow[t]{2}{*}{$\begin{array}{l}\text { MAT1- } \\
1-1\end{array}$} & $\begin{array}{l}\text { MgMfSpMat1- } \\
\text { 1f1 }\end{array}$ & CATTNGCNCATCCCTTTG & 54 & Forward & $\begin{array}{l}\text { Groenewald } \text { et al. } \\
\text { (2006) }\end{array}$ \\
\hline & $\begin{array}{l}\text { MgMfSpMat1- } \\
1 \mathrm{r} 2\end{array}$ & GGCTTNGANACCATGGTGAG & 54 & Reverse & $\begin{array}{l}\text { Groenewald } \text { et al. } \\
(2006)\end{array}$ \\
\hline \multirow[t]{2}{*}{$\begin{array}{l}\text { MAT1- } \\
2-1\end{array}$} & $\begin{array}{l}\text { MgMfSpMat1- } \\
2 \mathrm{f} 2\end{array}$ & CAAAGAANGCNTTCNTGATCT & 54 & Forward & $\begin{array}{l}\text { Groenewald } \text { et al. } \\
\text { (2006) }\end{array}$ \\
\hline & $\begin{array}{l}\text { MgMfSpMat1- } \\
\text { 2r1 }\end{array}$ & TTCTTCTCNGATGGCTTGC & 54 & Reverse & $\begin{array}{l}\text { Groenewald } \text { et al. } \\
(2006)\end{array}$ \\
\hline \multirow[t]{4}{*}{ RPB2 } & RPB2-5F & $\begin{array}{l}\text { GAY GAY MGW GAT CAY TTY } \\
\text { GG }\end{array}$ & $60 \rightarrow 58 \rightarrow 54$ & Forward & Liu et al. (1999) \\
\hline & RPB2-7cR & CCC ATR GCT TGY TTR CCC AT & $60 \rightarrow 58 \rightarrow 54$ & Reverse & Liu et al. (1999) \\
\hline & Rpb2-F1 & GGTGTCAGTCARGTGYTGAA & $60 \rightarrow 58 \rightarrow 54$ & Forward & Videira et al. (2015) \\
\hline & Rpb2-R1 & TCC TCN GGV GTC ATG ATR ATC & $60 \rightarrow 58 \rightarrow 54$ & Reverse & Videira et al. (2015) \\
\hline
\end{tabular}




\begin{tabular}{|l|l|l|l|l|l||}
\hline Locus $^{\mathbf{a}}$ & Primer name & \multicolumn{1}{|c|}{ Primer sequence $\left(\mathbf{5}^{\prime} \rightarrow \mathbf{3}^{\prime}\right)$} & $\begin{array}{c}\text { Annealing } \\
\text { temperature }\left({ }^{\circ} \mathbf{C}\right)\end{array}$ & Orientation & Reference \\
\hline \hline TEF1- & EF1-728F & CAT CGA GAA GTT CGA GAA GG & 54 & Forward & $\begin{array}{l}\text { Carbone \& Kohn } \\
(1999)\end{array}$ \\
\hline \hline & EF-2 & GGA RGT ACC AGT SAT CAT GTT & 54 & Reverse & O'Donnell et al. (1998) \\
\hline \hline
\end{tabular}

${ }^{a}$ ACT: partial actin gene; bTUB: partial beta-tubulin gene; CAL: partial calmodulin gene; GAPDH: partial glyceraldehyde-3phosphate dehydrogenase (GAPDH) gene; HIS3: partial histone H3 gene; ITS: internal transcribed spacers and intervening $5.8 \mathrm{~S}$ nrDNA; LSU: large subunit (28S) of the nrRNA gene operon; MAT1: partial MAT1-1-1 mating type gene; MAT2: partial MAT1-2 mating type gene; RPB2: partial RNA polymerase II second largest subunit gene; TEF1- $\alpha$ : partial translation elongation factor 1alpha gene.

\section{Phylogenetic analysis}

The generated sequences for each gene were aligned with MAFFT v. 7 (Katoh \& Standley 2013) and the alignments were manually checked and improved where necessary using MEGA v. 5 (Tamura et al. 2011). From the strains listed in Table 1, only those with the complete dataset of genes were used in the phylogenetic analyses, with the exception of Ramularia pusilla, which was missing the sequence of GAPDH and was considered as missing data in the alignment. Phylogenetic analyses of sequence data consisted of both Neighbour-Joining analysis and parsimony analysis performed with PAUP v. 4.0b10 ( Swofford 2003) and also a Bayesian analysis performed with MrBayes v. 3.2.1 (Ronquist et al. 2011).

The Neighbour-Joining analysis using the HKY85 substitution model was applied to each gene partition individually. The single gene trees were manually compared in order to check the stability of each species clade and exclude incongruent genes from the multigene analysis (data not shown, individual gene trees deposited on TreeBASE). Alignment gaps were treated as missing data and all characters were unordered and of equal weight. Any ties were broken randomly when encountered. The selected genes for the multigene parsimony and Bayesian analysis were concatenated with Mesquite v. 2.75 (Maddison \& Maddison 2011).

The parsimony analysis was performed on three datasets, namely the concatenated alignment of five genes and the individual alignments of the mating-type sequences (MAT1-1-1 and MAT1-2-1). The analysis used a heuristic search with 100 random taxa additions and the branch-swapping algorithm for tree bisection and reconstruction. Alignment gaps were treated as fifth base and all characters were unordered and of equal weight. Branches of zero length were collapsed and all multiple, equally parsimonious trees were saved. The robustness of the trees obtained was evaluated by 1000 bootstrap replications (Hillis \& Bull 1993). Other measures calculated included tree length (TL), consistency index (CI), retention index (RI) and rescaled consistency index (RC). The resulting trees were printed with Geneious v. 7.0.6 (Kearse et al. 2012).

The Bayesian analysis was performed on the combined multigene alignment only. MrModeltest v. 2.2 (Nylander 2004) was used to determine the best nucleotide substitution model settings for each data partition in order to perform a model-optimized Bayesian 
phylogenetic reconstruction using MrBayes v. 3.2.1 (Ronquist et al. 2011). The heating chain was set to 0.15 and the Markov Chain Monte Carlo (MCMC) analysis of four chains was started in parallel from a random tree topology and lasted until the average standard deviation of split frequencies reached 0.01 . Burn-in was set to $25 \%$ after which the likelihood values were stationary. Trees were saved each 250 generations and the resulting phylogenetic tree was printed with Geneious v. 7.0.6 (Kearse et al. 2012). All new sequences generated in this study were deposited in NCBI's GenBank nucleotide database (www.ncbi.nlm.nih.gov) and the accession numbers of the sequences used for the phylogenetic analyses are listed in Table 1. The alignments and respective phylogenetic trees were deposited in TreeBASE (www.treeBASE.org).

\section{Taxonomy}

Isolates were cultivated for $7 \mathrm{~d}$ at $21^{\circ} \mathrm{C}$. Microscopic observations of the conidiogenous structures were performed using a Nikon Eclipse 80i light microscope with differential interference contrast (DIC) illumination. Slides were prepared using the inclined coverslip method (Kawato \& Shinobu 1959, revised in Nugent et al. 2006) and also transparent adhesive tape (Titan Ultra Clear Tape, Conglom Inc., Toronto, Canada) (Bensch et al. 2012). Clear lactic acid was used as mounting medium for the measurements. The morphological structure terminology followed those used for Ramularia species by Crous et al. (2011). The recorded measurements represent the minimum value followed by the $95 \%$ confidence interval of 30 individual measurements and the maximum value, for both length and width. For culture characterization the isolates were inoculated on $2 \%$ potato dextrose agar (PDA), oatmeal agar (OA) and $2 \%$ malt extract agar (MEA) (recipes according to Crous et al. $2009 \mathrm{~d}$ ), and incubated in the dark at $25^{\circ} \mathrm{C}$. After $14 \mathrm{~d}$, the colony diameter was measured and the colony colour described according to the mycological colour charts of Rayner (1970). Nomenclatural novelties and descriptions were deposited in MycoBank (Crous et al. 2004a).

\section{Results}

\section{DNA amplification and phylogenetic analysis}

Of the 11 loci tested in this study, seven were successfully amplified for most strains (LSU, ITS, ACT, TEF1- $\alpha$, HIS3, GAPDH, RPB2). The amplification of CAL and bTUB often resulted in multiple bands, despite the attempts of protocol optimization and were not used in the multigene analysis. The amplification of the mating-type loci was not successful for all the strains (Table 1) and was particularly challenging for the MAT1-2-1 with the use of the degenerate primers (Table 2) that were reported successful for other Mycosphaerellaceae ( Groenewald et al., 2006 and Groenewald et al., 2007). Due to the observed variation of the position of these loci in other species, an attempt was made to amplify the loci using the forward primer for MAT1-1-1 and the reverse primer of MAT1-2-1 and vice-versa. A sequence of approximately $670 \mathrm{bp}$ was obtained for several strains with the combination of the primers MgMfSpMat1-1f1 (MAT1-1-1 forward) and MgMfSpMat1-2r1 (MAT1-2-1 reverse) for which the last portion of approximately $200 \mathrm{bp}$ corresponded to the MAT1-2-1 conserved high mobility group. When sequences of the MAT1-2-1 obtained with the regular primer combination were compared with the ones obtained with the described uncommon combination, they matched exactly. The mating-type genes were not used in the combined analysis since all isolates with a successful sequence had either the MAT1-1-1 or MAT1-2-1 amplicon. In addition, no sequences of MAT1-1-1 were obtained for any of the Ramularia 
unterseheri strains available in this study. All the obtained sequences were deposited in GenBank ( Table 1).

The Neighbour-joining analysis using the HKY85 substitution model used to check the stability and robustness of clades for the individual loci (data not shown) revealed that the both the LSU and ITS locus separated Ramularia endophylla strains in a unique clade but were not able to separate Ramularia vizellae from $R$. unterseheri (newly described). The single gene trees for ACT, HIS3, RPB2 and GAPDH could separate three species within the complex, namely $R$. endophylla, $R$. vizellae, and $R$. unterseheri. The partial sequences of TEF1- $\alpha$ were very heterogeneous and the resulting phylogenetic tree was not congruent with the other genes. The TEF1- $\alpha$ sequences were, therefore, not used in the multigene analysis.

The multigene analysis was based on a concatenated alignment of five loci (ITS, ACT, RPB2, GAPDH and HIS3) and contained 114 taxa, of which 81 belonged to the $R$. endophylla species complex, 32 represented other Ramularia species and the outgroup sequence of Zymoseptoria passerini. The final alignment contained a total of 2618 characters divided in five partitions containing 515 (ITS), 236 (ACT), 897 (RPB2), 575 (GAPDH) and 375 (HIS3) characters respectively, including alignment gaps. From the total alignment, 81 characters were excluded from the phylogenetic analysis: 20 characters that were artificially introduced as spacers between the genes; 10 characters (ITS) and 17 characters (GAPDH) that represented a longer sequence in the outgroup compared to the ingroup sequences; 20 characters (GAPDH) representing a longer intron that only existed for Ramularia nyssicola; 14 characters (ACT) representing a repetition in an intron on the strains in Ramularia grevilleana (see alignment in TreeBASE).

The results of the MrModelTest analyses for the multigene dataset indicated that the ITS partition had fixed (equal) base frequencies, whereas all the other partitions had dirichlet base frequencies. The optimised models for this alignment were SYM + I + G for ITS and $\mathrm{GTR}+\mathrm{I}+\mathrm{G}$ for all the other data partitions. The Bayesian analysis of the concatenated fivelocus alignment generated 104082 trees from which 26020 trees were discarded $(25 \%$ burnin). The $50 \%$ majority rule consensus tree (Fig 1) and posterior probabilities (values $\leq 1$ ) were calculated from the remaining 78062 trees. The alignment contained a total of 959 unique site patterns: 100 (ITS), 123 (ACT), 413 (RPB2), 209 (GAPDH), 114 (HIS3). 


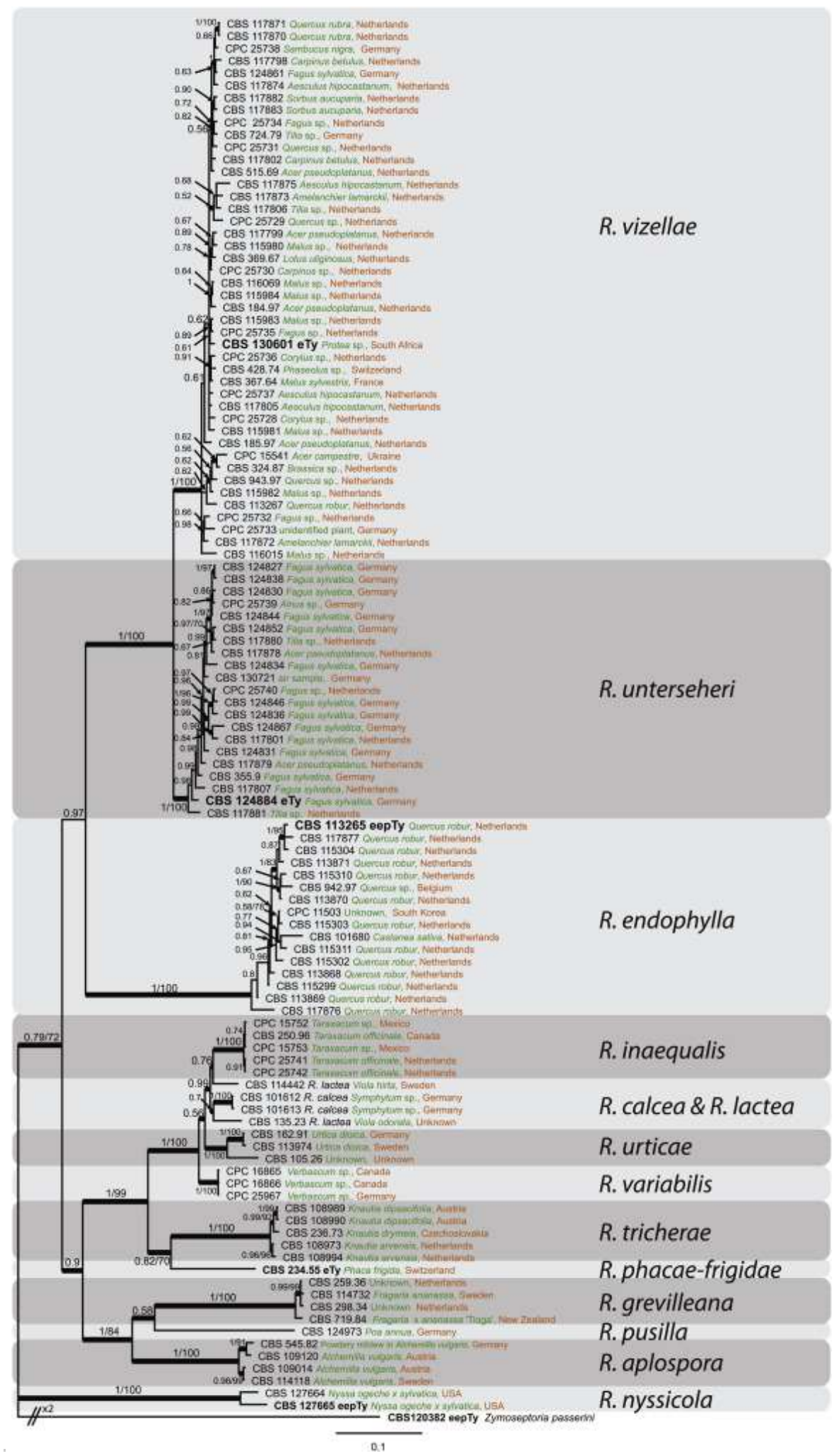

Fig 1. Phylogenetic tree resulting from a Bayesian analysis of the combined 5-gene sequence alignment. Both Bayesian posterior probabilities (left number) and parsimony bootstrap support values $>70 \%$ (right number) are indicated at the nodes; the scale bar represents the expected number of changes per site. Branches depicted in a thicker represent the branches present in the strict consensus parsimony tree. Strains in bold and marked as 'eTy' are ex-types and those marked as 'eepTy' are ex-epitypes. The tree was rooted to Zymoseptoria passerini (CBS 120382). 
The parsimony analysis on the multigene dataset generated 1000 equally most parsimonious trees. From the analysed characters, 1559 were constant, 205 were variable and parsimonyuninformative and 772 were parsimony-informative. A parsimony consensus tree was calculated from the equally most parsimonious trees and the branches were mapped with a thicker stroke on the Bayesian tree (Fig 1; bootstrap support values $>75$ ). The overall parsimony phylogeny supported the same species clades as those presented in the Bayesian phylogeny (Fig 1). Phylogenetic trees based on the combined dataset (Fig 1) and generated with both parsimony and Bayesian analyses, separated strains into three well supported species within the original complex: $R$. endophylla, $R$. vizellae, and $R$. unterseheri. The other Ramularia strains represent species that, in literature, have been associated with a Mycosphaerella sexual morph ( Table 3).

Table 3. Relations between Ramularia asexual morphs and their Mycosphaerella sexual morphs reported in literature. References in bold represent the reference where a link was experimentally proven.

\begin{tabular}{|c|c|c|c|c|c|c|}
\hline Asexual morph ${ }^{a}$ & Sexual morph ${ }^{a}$ & $\begin{array}{l}\text { Current } \\
\text { name }\end{array}$ & $\mathbf{C A}^{\mathrm{b}}$ & References & $\begin{array}{c}\text { Sexual } \\
\operatorname{link}^{c}\end{array}$ & Notes \\
\hline $\begin{array}{l}\text { R. endophylla } \\
\text { Verkley \& U. } \\
\text { Braun (2004) }\end{array}$ & \begin{tabular}{|l|} 
M. punctiformis \\
(Pers.) Starbäck \\
(1889) [bas. Sphaeria \\
punctiformis Pers. \\
$(1794)]$
\end{tabular} & \begin{tabular}{|l}
$\boldsymbol{R}$. \\
endophylla \\
Verkley \& \\
U. Braun \\
$(2004)$
\end{tabular} & $\mathrm{Y}$ & Verkley et al. (2004) & EP & $\begin{array}{l}\text { Verkley et al. (2004) } \\
\text { epitypified } M . \text { punctiformis } \\
\text { and linked it with } R \text {. } \\
\text { endophylla morphologically } \\
\text { and genetically. }\end{array}$ \\
\hline $\begin{array}{l}\text { R. grevilleana } \\
\text { (Oudem.) Jørst. } \\
\text { (1945) [bas. } \\
\text { Cylindrosporium } \\
\text { grevilleanum } \\
\text { Oudem. (1873)] }\end{array}$ & $\begin{array}{l}\text { M. fragariae (Tul.) } \\
\text { Lindau (1897) [bas. } \\
\text { Sphaeria fragariae } \\
\text { Tul. \& C. Tul. } \\
(1856)]\end{array}$ & $\begin{array}{l}\boldsymbol{R} . \\
\text { grevilleana } \\
\text { (Oudem.) } \\
\text { Jørst. (1945) }\end{array}$ & Y & $\begin{array}{l}\text { Dudley, 1889, Potebnja, } \\
\text { 1908, Schellenberger, } \\
\text { 1917, Plakidas, 1941, } \\
\text { Klebahn, 1918, Tomilin, } \\
\text { 1979, Sivanesan, 1984, } \\
\text { Braun, } 1998 \text { and Braun } \\
\text { and Pennycook, } 2003\end{array}$ & EP & $\begin{array}{l}\text { Dudley (1889) used conidia } \\
\text { from pure cultures to infect } \\
\text { strawberry leaves and } \\
\text { observed perithecia formed } \\
\text { in these lesions and that the } \\
\text { ascospores germinated } \\
\text { within the ascus, shot out } \\
\text { through the ostiole and gave } \\
\text { rise to conidia. }\end{array}$ \\
\hline $\begin{array}{l}\text { R. inaequalis } \\
\text { (Preuss) U. Braun } \\
\text { (1998) [bas. } \\
\text { Fusoma inaequale } \\
\text { Preuss (1855)] }\end{array}$ & $\begin{array}{l}\text { M. hieracii (Sacc. \& } \\
\text { Briard) Jaap (1908) } \\
\text { [bas. Sphaerella } \\
\text { nebulosa var. } \\
\text { hieracii } \\
\text { Sacc.\&Briard } \\
(1885) \text { ] }\end{array}$ & \begin{tabular}{|l|}
$\boldsymbol{R}$. \\
inaequalis \\
(Preuss) U. \\
Braun (1998)
\end{tabular} & $\mathrm{Y}$ & $\begin{array}{l}\text { Jaap, 1908, Klebahn, } \\
1918 \text { and Sivanesan, } \\
1984\end{array}$ & EP & $\begin{array}{l}\text { Klebahn (1918) isolated } \\
\text { ascospores and obtained a } \\
\text { culture in which the } \\
\text { conidiogenous stage was } \\
\text { observed. }\end{array}$ \\
\hline $\begin{array}{l}\text { R. variabilis Fuckel } \\
(1870)\end{array}$ & $\begin{array}{l}\text { M. mariae (Sacc. \& } \\
\text { E. Bommer) Lindau } \\
\text { (1903) [bas. } \\
\text { Sphaerella mariae } \\
\text { Sacc.\&E.Bommer } \\
(1886)]\end{array}$ & $\begin{array}{l}\text { R. variabilis } \\
\text { Fuckel } \\
(1870)\end{array}$ & $\mathrm{Y}$ & $\begin{array}{l}\text { Arx von, 1949, Tomilin, } \\
\text { 1979, Sivanesan, 1984, } \\
\text { Braun, } \\
1998 \text { and Aptroot, } 2006\end{array}$ & EP & $\begin{array}{l}\text { Ascospores were isolated } \\
\text { from perithecia in } \\
\text { overwintered leaves into } \\
\text { pure cultures from which the } \\
\text { conidial forms developed. }\end{array}$ \\
\hline $\begin{array}{l}\boldsymbol{R} . \\
\text { nyssicola }(\text { Cooke) } \\
\text { Videira \& Crous } \\
(2014)\end{array}$ & $\begin{array}{l}\text { M. nyssicola }(\text { Cooke }) \\
\text { F.A. Wolf }(1940)\end{array}$ & $\begin{array}{l}\text { R. nyssicola } \\
\text { (Cooke) } \\
\text { Videira \& } \\
\text { Crous (2014) }\end{array}$ & $\mathrm{Y}$ & $\begin{array}{l}\text { Minnis et al., } \\
2011 \text { and Videira et al., } \\
2015\end{array}$ & EP & $\begin{array}{l}\text { The asexual morph has not } \\
\text { observed but the available } \\
\text { strains obtained from the } \\
\text { sexual morph are genetically } \\
\text { placed within the Ramularia } \\
\text { clade. }\end{array}$ \\
\hline Ramularia & $\begin{array}{l}\text { M. phacae-frigidae } \\
\text { E. Müll. \& Wehm. }\end{array}$ & $\begin{array}{l}\text { R. phacae- } \\
\text { frigidae }(\mathrm{E} . \\
\text { Müll. \& }\end{array}$ & Y & $\begin{array}{l}\text { Müller \& Wehmeyer } \\
\text { (1954), Aptroot (2006); }\end{array}$ & EP & $\begin{array}{l}\text { Müller \& Wehmeyer (1954) } \\
\text { observed ramularia-like } \\
\text { spores when he described the }\end{array}$ \\
\hline
\end{tabular}




\begin{tabular}{|c|c|c|c|c|c|c|}
\hline Asexual morph ${ }^{a}$ & Sexual morph ${ }^{a}$ & $\begin{array}{c}\text { Current } \\
\text { name }\end{array}$ & $\mathrm{CA}^{\mathrm{b}}$ & References & $\left|\begin{array}{c}\text { Sexual } \\
\text { link }^{c}\end{array}\right|$ & Notes \\
\hline & (1954) & $\begin{array}{l}\text { Wehm.) } \\
\text { Videira \& } \\
\text { Crous } \\
(2015) \text {, this } \\
\text { study }\end{array}$ & & Present study & & $\begin{array}{l}\text { species, but did not name the } \\
\text { conidial form. }\end{array}$ \\
\hline $\begin{array}{l}\text { R. atropae Allesch. } \\
\text { (1892) }\end{array}$ & $\begin{array}{l}\text { ? M. montellica } \\
\text { (Sacc.) Guyot (1946) }\end{array}$ & - & $\mathrm{N}$ & $\begin{array}{l}\text { Tomilin, } \\
1979 \text { and Braun, } 1998\end{array}$ & DB & $\begin{array}{l}\text { Aptroot (2006) states the } \\
\text { type belongs to Davidiella. }\end{array}$ \\
\hline $\begin{array}{l}\text { R. chamerionis } \\
\text { Rostr. [as } \\
\text { 'chamaenerii'] } \\
(1885)\end{array}$ & $\begin{array}{l}\text { M. } \\
\text { chamaeneriiSavile } \\
(1962)\end{array}$ & - & $\mathrm{N}$ & $\begin{array}{l}\text { Savile, 1962, Sivanesan, } \\
1984 \text { and Aptroot, } 2006\end{array}$ & DB & $\begin{array}{l}\text { Aptroot (2006) stated this } \\
\text { belongs to Davidiella. }\end{array}$ \\
\hline $\begin{array}{l}\text { R. evanida (J. G. } \\
\text { Kühn) Sacc. (1886) }\end{array}$ & $\begin{array}{l}\text { M. gentianae } \\
\text { (Niessl) Lindau } \\
(1897) \text { [syn. M. } \\
\text { galatea (Sacc.) Jacz. } \\
(1917)]\end{array}$ & - & $\mathrm{N}$ & $\begin{array}{l}\text { Petrak, 1940a, Tomilin, } \\
1979 \text { and Braun, } 1998\end{array}$ & DB & $\begin{array}{l}\text { Aptroot (2006) states the } \\
\text { type and additional material } \\
\text { studied belong to Davidiella. }\end{array}$ \\
\hline $\begin{array}{l}\text { R. pteridiicola } \text { Petr. } \\
\text { (1927) }\end{array}$ & $\begin{array}{l}\text { ? M. aquilina (Fr.) J. } \\
\text { Schröt (1894) }\end{array}$ & - & $\mathrm{N}$ & $\begin{array}{l}\text { Petrak, 1927, Eriksson, } \\
\text { 1992, Braun, } \\
1998 \text { and Aptroot, } 2006\end{array}$ & DB & $\begin{array}{l}\text { Aptroot (2006) studied } \\
\text { material from India (IMI } \\
\text { 152515) and states it belongs } \\
\text { to } M \text {. punctiformis. }\end{array}$ \\
\hline $\begin{array}{l}\text { R. trifoliiJaap } \\
(1910)\end{array}$ & $\begin{array}{l}\text { M. carinthiacaJaap } \\
(1908)\end{array}$ & - & $\mathrm{N}$ & $\begin{array}{l}\text { Jaap, 1910, Tomilin, } \\
\text { 1979, Braun, } \\
1998 \text { and Aptroot, } 2006\end{array}$ & DB & $\begin{array}{l}\text { Aptroot (2006) studied } \\
\text { authentic material, states it is } \\
\text { a parasitic species of } \\
\text { Davidiella and proposed a } \\
\text { new combination Davidiella } \\
\text { carinthiaca (Jaap) Aptroot. }\end{array}$ \\
\hline Ramularia sp. & $\begin{array}{l}\text { M. nawae Hiura \& } \\
\text { Ikata (1929) }\end{array}$ & - & $\mathrm{N}$ & $\begin{array}{l}\text { Kwon and Park, } \\
2004 \text { and Berbegal et al., } \\
2013\end{array}$ & |DB & $\begin{array}{l}\text { Asexual ramularia-like } \\
\text { morph observed but ITS } \\
\text { closely related to } \\
\text { Phaeopleospora } \\
\text { (Mycosphaerellaceae). LSU } \\
\text { not available. }\end{array}$ \\
\hline $\begin{array}{l}\text { R. aplospora Speg. } \\
(1879)\end{array}$ & $\begin{array}{l}\text { M. alchemillicola } \\
\text { Vassiljevsky } 1925\end{array}$ & - & $\mathrm{Y}$ & $\begin{array}{l}\text { Vasil'evskij and } \\
\text { Karakulin, 1937, } \\
\text { Tomilin, } \\
1979 \text { and Braun, } 1998\end{array}$ & NEP & \\
\hline $\begin{array}{l}\text { R. brunnea Peck } \\
(1878)\end{array}$ & $\begin{array}{l}\text { M. tussilaginis } \\
\text { (Rehm) Lindau } \\
(1903)\end{array}$ & - & $\mathrm{N}$ & $\begin{array}{l}\text { Wolf, 1912, Vasil'evskij } \\
\text { and Karakulin, 1937, } \\
\text { Tomilin, 1979, Braun, } \\
1998 \text { and Aptroot, } 2006\end{array}$ & NEP & \\
\hline $\begin{array}{l}\text { R. lactea (Desm.) } \\
\text { Sacc. }(1882)\end{array}$ & $\begin{array}{l}\text { M. violae Potebnia } \\
1910\end{array}$ & - & $\mathrm{Y}$ & $\begin{array}{l}\text { Tomilin, } \\
1979 \text { and Braun, } 1998\end{array}$ & NEP & \\
\hline $\begin{array}{l}\text { R. obducens Thüm. } \\
(1881)\end{array}$ & $\begin{array}{l}\text { M. pedicularis (P. } \\
\text { Karst.) Lind (1913) }\end{array}$ & - & $\mathrm{N}$ & $\begin{array}{l}\text { Savile, } 1968 \text { and Braun, } \\
1998\end{array}$ & NEP & $\begin{array}{l}\text { Aptroot (2006) could not } \\
\text { locate the type but after } \\
\text { observing other } \\
\text { Scandinavian material states } \\
\text { that it belongs to section }\end{array}$ \\
\hline
\end{tabular}




\begin{tabular}{|c|c|c|c|c|c|c|}
\hline Asexual morph ${ }^{\mathrm{a}}$ & Sexual morph ${ }^{a}$ & $\begin{array}{c}\text { Current } \\
\text { name }\end{array}$ & $\mathrm{CA}^{\mathrm{b}}$ & References & $\begin{array}{c}\text { Sexual } \\
\text { link }^{\mathrm{c}}\end{array}$ & Notes \\
\hline & & & & & & Caterva. \\
\hline $\begin{array}{l}\text { R. onobrychidis } \\
\text { Allesch. (1892) }\end{array}$ & $\begin{array}{l}\text { ? M. onobrychidis } \\
\text { (Hollós) Tomilin } \\
\text { (1968) }\end{array}$ & - & $\mathrm{N}$ & $\begin{array}{l}\text { Švarcman et al., } \\
1973 \text { and Braun, } 1998\end{array}$ & NEP & $\begin{array}{l}\text { Aptroot (2006) states the } \\
\text { type may have been } \\
\text { destroyed during the war. }\end{array}$ \\
\hline $\begin{array}{l}\text { R. sambucina } \\
\text { Sacc. (1882) }\end{array}$ & $\begin{array}{l}\text { M. ebulina } \text { Petr. } \\
\text { (1915) }\end{array}$ & - & $\mathrm{N}$ & $\begin{array}{l}\text { Petrak, 1915, Tomilin, } \\
1979 \text { and Aptroot, } 2006\end{array}$ & NEP & $\begin{array}{l}\text { Aptroot (2006) states the } \\
\text { isotype in L belongs to } \\
\text { section Caterva. }\end{array}$ \\
\hline $\begin{array}{l}\text { R. tricherae Lindr. } \\
(1902)\end{array}$ & \begin{tabular}{|l} 
? Sphaerella \\
sylvatica Sacc. \& \\
Speg. (1878) [syn. \\
M. scabiosae \\
Tomilin (1971)]
\end{tabular} & - & $\mathrm{Y}$ & $\begin{array}{l}\text { Laibach, 1921, Braun, } \\
1998 \text { and Aptroot, } 2006\end{array}$ & NEP & $\begin{array}{l}\text { Aptroot (2006) states the } \\
\text { type belongs to section } \\
\text { Caterva. }\end{array}$ \\
\hline $\begin{array}{l}\text { R. ulmariae Cooke } \\
\text { (1876) }\end{array}$ & $\begin{array}{l}\text { M. filipendulae- } \\
\text { denudatae Kamilov } \\
(1973)\end{array}$ & - & $\mathrm{N}$ & $\begin{array}{l}\text { Tomilin, } \\
1979 \text { and Braun, } 1998\end{array}$ & NEP & \\
\hline $\begin{array}{l}\text { R. urticae Ces. } \\
(1863)\end{array}$ & $\begin{array}{l}\text { M. superflua } \\
\text { (Fuckel) Petr. (1940) }\end{array}$ & - & $\mathrm{Y}$ & \begin{tabular}{|l} 
Tomilin, 1979, \\
Sivanesan, \\
1984 and Petrak, 1940b
\end{tabular} & NEP & \\
\hline
\end{tabular}

a bas.: basionym; syn.: synonym.

${ }^{\mathrm{b}} \mathrm{CA}$ : Cultures of the Ramularia morph available; $\mathrm{Y}-\mathrm{Yes}, \mathrm{N}-\mathrm{No}$.

${ }^{\mathrm{c}}$ Sexual link; EP - Experimentally Proven; DB - Doubtfull; NEP - Not Experimentally Proven.

The MAT1-1-1 alignment contained 30 taxa, including the outgroup Cercospora beticola (GenBank DQ192581), and 570 characters, including alignment gaps, from which 175 were constant, 74 were variable and parsimony-uninformative, and 321 were parsimonyinformative. The MAT1-2-1 alignment contained 37 taxa, including the outgroup Cercospora beticola (GenBank DQ192582), and 233 characters, including alignment gaps. Of these characters, 67 were constant, 31 were variable and parsimony-uninformative, and 135 were parsimony-informative. Similar trees were obtained with both neighbour-joining and parsimony methods. Two most parsimonious trees were obtained from the MAT-1-1-1 sequence alignment and nine most parsimonious trees were obtained from the MAT1-2-1 sequence alignment. The most parsimonious trees differed slightly in the arrangement of the taxa within the clades of $R$. vizellae ( Fig 2 and Fig 3) and of $R$. unterseheri ( Fig 3) but the global tree topology was identical. The trees obtained for both MAT1-1-1 (Fig 2) and MAT12-1 (Fig 3) datasets showed that $R$. endophylla and $R$. vizellae cluster in separate clades with bootstrap support values of $100 \%$ (MAT1-1-1) and $100 \%$ and $97 \%$ (MAT1-2-1), respectively. In the tree obtained for MAT1-2-1 the clade of $R$. unterseheri is supported with $98 \%$ bootstrap. Strict consensus trees were calculated for each locus and the branches present were depicted in thicker lines ( Fig 2 and Fig 3). The phylogenetic trees obtained from the mating-type sequences are in agreement with the parsimony and Bayesian analyses of the multigene dataset. 


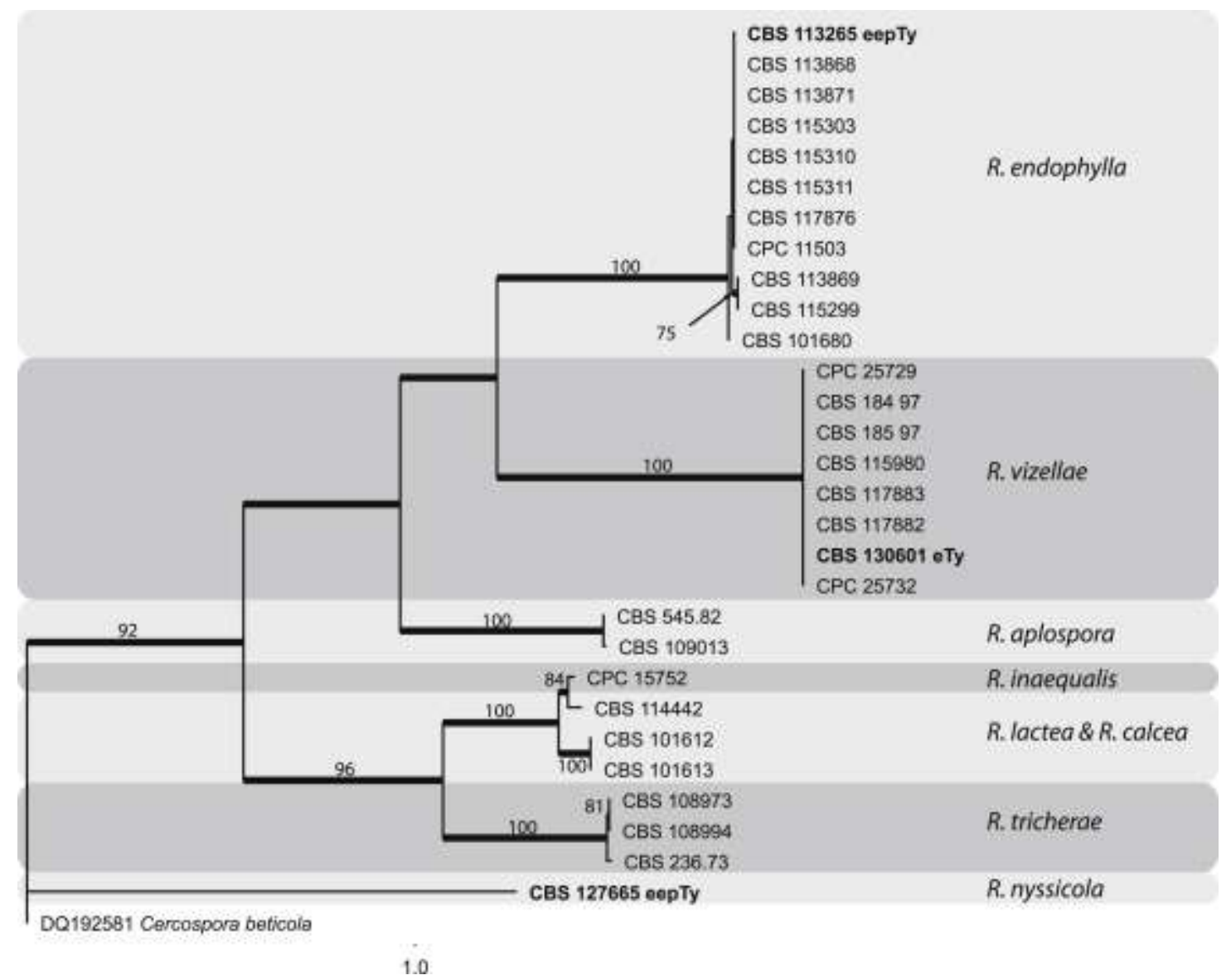

Fig 2. The first of two equally most parsimonious trees obtained from the MAT1-1-1 sequence alignment. Bootstrap support values from 1000 replicates are shown at the nodes. The tree was rooted to Cercospora beticola (GenBank DQ192581). TL $=912$ steps, $\mathrm{CI}=0.760, \mathrm{RI}=0.919, \mathrm{RC}=0.698, \mathrm{HI}=0.240$. Strains in bold and marked as 'eTy' are ex-types and those marked as 'eepTy' are ex-epitypes. 


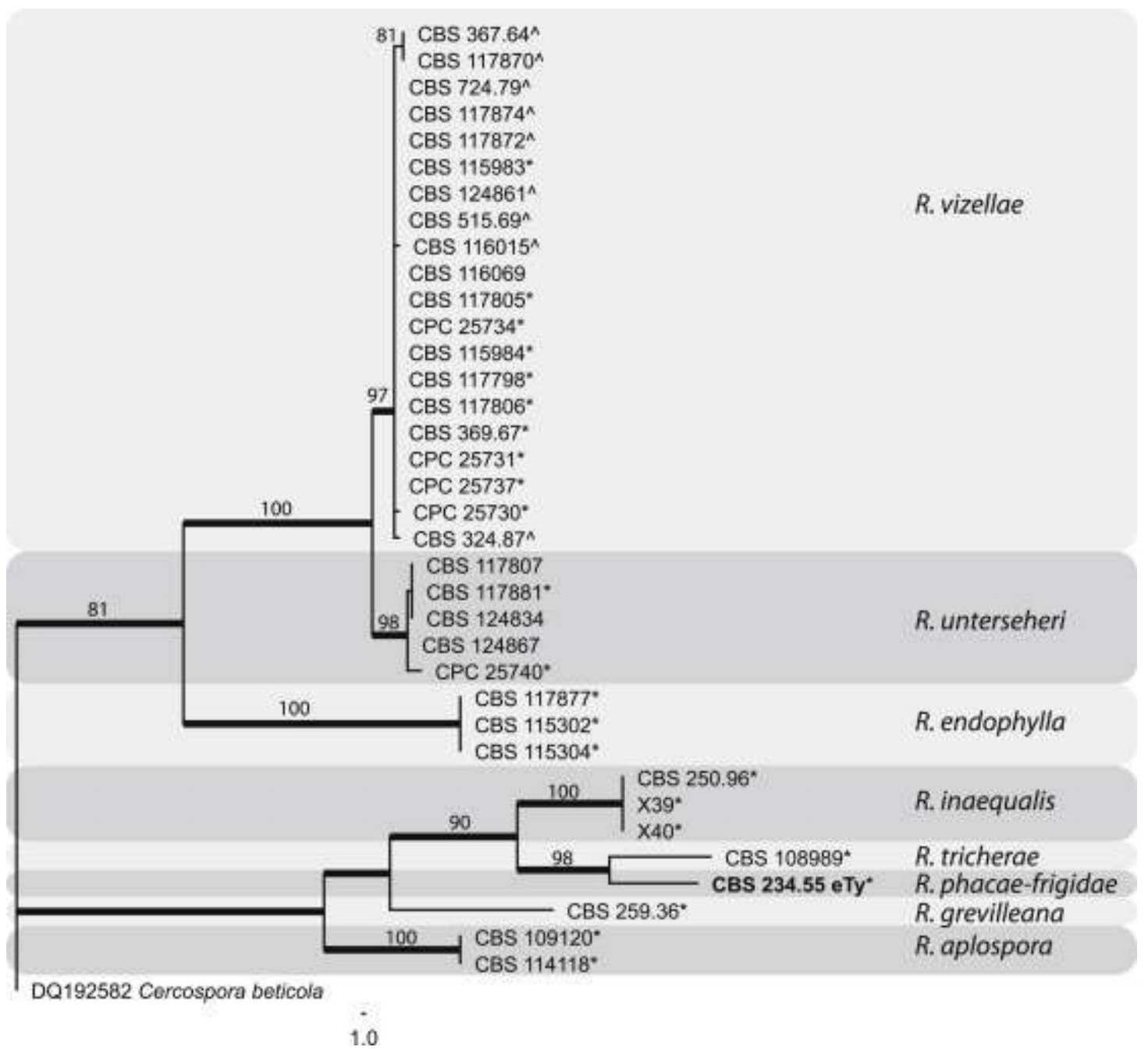

Fig 3. The first of nine equally most parsimonious trees obtained from the MAT1-2-1 sequence alignment. Bootstrap support values from 1000 replicates are shown at the nodes. The tree was rooted to Cercospora beticola (GenBank DQ192582). TL = 379 steps, $\mathrm{CI}=0.736, \mathrm{RI}=0.873, \mathrm{RC}=0.643, \mathrm{HI}=0.264$. Strains in bold and marked as 'eTy' are ex-types and those marked as 'eepTy' are ex-epitypes. The asterisk (*) represents sequences obtained with the primer combination MAT1-1-1 forward and MAT1-2-1 reverse (Table 2) and the caret $(\wedge)$ represents strains obtained with both the usual primer combination MAT1-2-1 forward and reverse and the unusual primer combination MAT1-1-1 forward and MAT1-2-1 reverse (Table 2). Strains without these symbols represent sequences obtained only with the regular primer combination MAT1-2-1 forward and reverse (Table 2).

\section{Taxonomy}

Ramularia endophylla Verkley \& U. Braun, Mycol. Res.108: 1276 (2004)

Synonyms: Sphaeria punctiformis Pers., Ann. Bot. (Usteri) 11: 26 (1794), non Ramularia punctiformis Sacc. (Saccardo, 1904).

Astoma punctiforme (Pers.) Gray, Nat. Arr. Brit. Pl. (London) 1: 524 (1821) 
Sphaerella punctiformis (Pers.) Rabenh., Klotzschii Herb. Viv. Mycol., ed. nov.: no. 264 (1856)

Mycosphaerella punctiformis (Pers.) Starbäck, Bih. Kongl. Svenska Vetensk.-Akad. Handl.15 (2): 9 (1889)

Diatrype punctiformis (Pers.) Zahlbr., Cat. Lich. Univers.7: 780 (1931)

For further synonyms, see Tomilin (1979) and Aptroot (2006).

Specimens examined. Belgium: Namur, on leaves of Quercus sp., 7 May 1997, A. Aptroot (CBS 942.97). d Netherlands: Utrecht, on dead leaves of Castanea sativa, 23 Feb. 1999, A. Aptroot (CBS 101680); on dead leaves of Quercus robur, Apr. 2003, G. Verkley (CBS H7949, epitype; ex-epitype culture CBS 113265); on living leaf of Quercus robur, G. Verkley (CBS 113868; CBS 113869; CBS 113870); on fallen leaf of Quercus robur, G. Verkley (CBS 113871); on living leaves of Quercus robur, Sep. 2008, G. Verkley (CBS 115299; CBS 115302); on living leaf of Quercus robur, May 2013 (CBS 115303; CBS 115304); on dead leaf of Quercus robur, Aug. 2002, (CBS 115310; CBS 115311); on Quercus robur, G. Verkley (CBS 117876); on Quercus robur, 18 Jun. 2009, G. Verkley (CBS 117877). d South Korea: unknown host, 1 Jan. 2004, H.D. Shin (CPC 11503).

Notes: The link between Ramularia endophylla (Verkley et al. 2004) and Mycosphaerella punctiformis ( Starbäck 1889), initially described as Sphaeria punctiformis ( Persoon 1794), was experimentally proven by Verkley et al. (2004) with morphological and phylogenetic data. Although the oldest epithet among these two names is 'punctiformis' ( Persoon 1794), the name Ramularia punctiformis Sacc. (Saccardo, 1904) is already in use. Several possible epithets can be found among the synonyms proposed by Tomilin (1979) and Aptroot (2006). However, these specimens are often in poor state, contain immature perithecia or represent species never collected or observed after their first description (Aptroot 2006). In addition, several type specimens of other Mycosphaerella species have been found to be indistinguishable from M. punctiformis ( Aptroot 2006) and the names represent valid epithets in case this material is recollected and prove to be the same species. With the objective to clarify and stabilize the taxonomy of this species, we propose that the epithet 'endophylla' is conserved since it represents an unequivocally proven link between sexual and asexual stage of this species, both biologically and phylogenetically.

Ramularia grevilleana (Oudem.) Jørst., Meld. Stat. Plantepatol. Inst.1: 17 (1945)

Basionym: Cylindrosporium grevilleanum Oudem., Arch. Néerl. Sci. Exact. Nat.8: 392 (1873), asexual morph [Cylindrosporium sp., in Tulasne \& Tulasne (1863: 288)].

Synonyms: Sphaeria fragariae Tul. \& C. Tul., Ann. Sci. Nat., Bot.5: 112 (1856), nom. illeg., non Schwein. 1832.

Stigmatea fragariae Tul. \& C. Tul., Select. Fung. Carpol.2: 288 (1863).

Ramularia fragariae Peck, Ann. Rep. N.Y. State Mus. Nat. Hist.32: 43 (1880).

Sphaerella fragariae (Tul. \& C. Tul.) Sacc., Syll. Fung.1: 505 (1882). 
Mycosphaerella fragariae (Tul. \& C. Tul.) Lindau, Nat. Pflanzenfam., Teil 1, 1(1): 424 (1897).

Ramularia punctiformis Sacc., Alaska Exp. Crypt.: 16 (1904).

For further synonyms based on asexual morphs, see Braun (1995: 248).

Specimens examined. Sweden: Uppland, Alsike, on Fragaria ananassa, 4 Oct. 1989, E. Gunnerbeck (CBS 114732 = UPSC 3244). d Netherlands: unknown district, host, collector and date (CBS 259.36; CBS 298.34). d New Zealand: Auckland, on Fragariaxananassa 'Tioga' (CBS 719.84).

Notes: This pathogen is known for causing leaf spot disease in strawberry, both cultivated and wild species, and has a worldwide distribution (Braun 1998). The link between Ramularia grevilleana ( Jørstad 1945) and Mycosphaerella fragariae ( Lindau 1897) was experimentally proven by Dudley (1889) who observed the ascospores germinating within the ascus inside the perithecium, developing into mycelium that grew out through the perithecium wall and ostiolum, and produced conidia. Since then, most authors have treated this link as reliable and both names have appeared together in several publications ( Maas, 1984, Crous et al., 2000, Braun and Pennycook, 2003 and Kirschner, 2009). Ramularia grevilleana ( Jørstad 1945) was initially described as Cylindrosporium grevilleanum by Oudemans (1873). The confused nomenclatural history of this asexual morph name, previously attributed to Tulasne \& Tulasne (1863), was discussed and clarified by Braun \& Pennycook (2003). Mycosphaerella fragariae ( Lindau 1897) was first described as Sphaeria fragariae ( Tulasne 1856), which is a nom. illeg. (homonym). Stigmatea fragariae Tul. \& Tul. ( Tulasne \& Tulasne 1863) is the first valid name for this species but a reallocation of this name to Ramularia is not possible because $R$. fragariae already exists. Cylindrosporium grevilleanum (Oudemans 1873) is the oldest available epithet among the synonyms and the basionym of the current name Ramularia grevilleana ( Jørstad 1945), which is the nomenclaturally correct denomination for this species.

Ramularia phacae-frigidae (E. Müll. \& Wehm.) Videira \& Crous, comb. nov.

MycoBank No.: MB812600

Basionym: Mycosphaerella phacae-frigidae E. Müll. \& Wehm., Sydowia8: 190 (1954).

Specimens examined. Switzerland: Corveglia, above St. Moritz, from Phaca frigida, 20 Jul. 1953, E. Müller (ex-type culture CBS 234.55).

Notes: When Mycoshaerella phacae-frigidae was originally described ( Müller \& Wehmeyer 1954), the ascospores were isolated, producing a Ramularia state that was not named at that time. Based on morphological and molecular evidence we propose a new combination for this name in Ramularia. Culture CBS 234.55 was deposited by E. Müller in the CBS culture collection in May 1955 and is from the same host, locality and date as the original material used for the description of $M$. phacae-frigidae, which indicates that it is an ex-type strain.

Ramularia unterseheri Videira \& Crous, sp. nov.

MycoBank No.: MB812599 

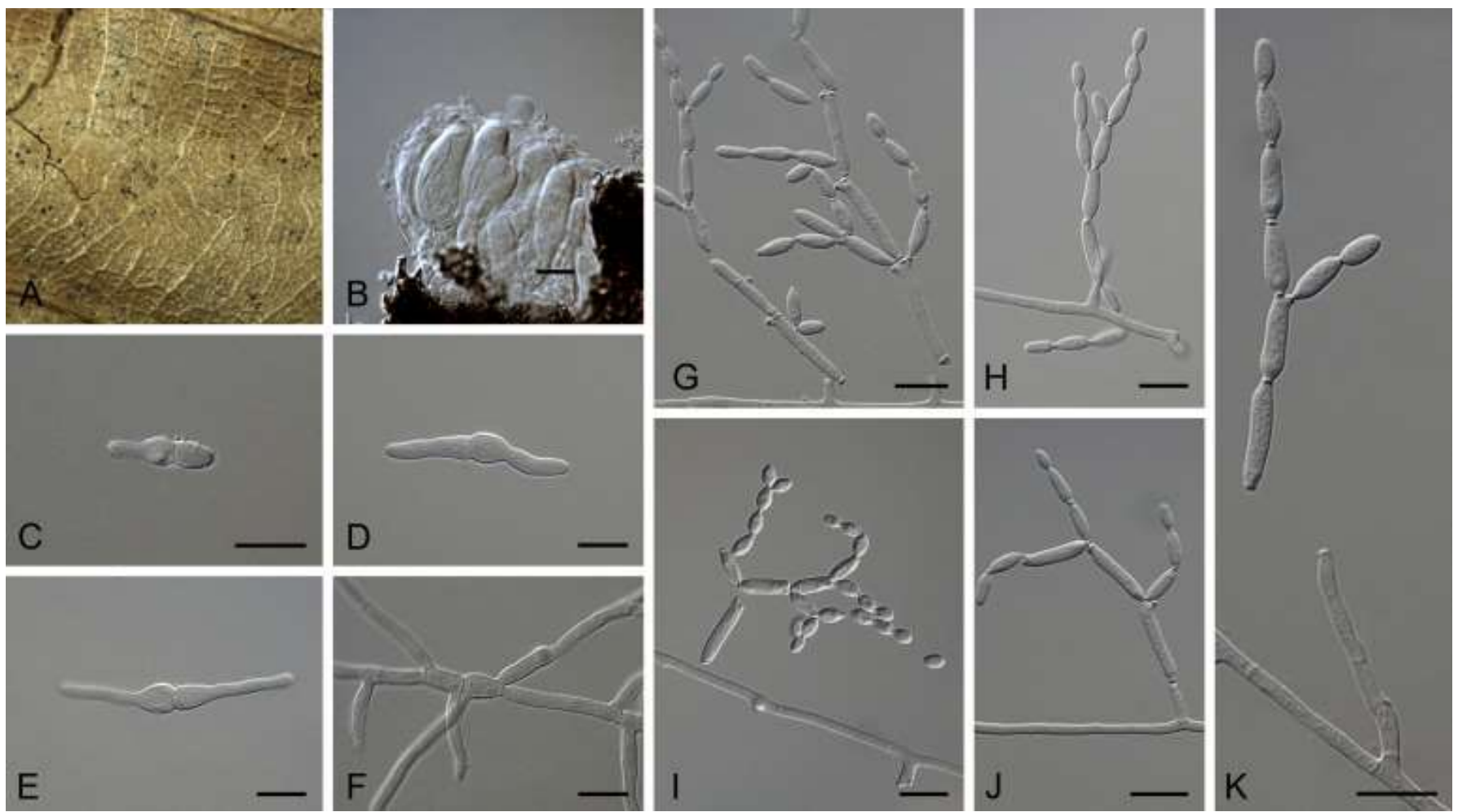

Fig 4. Ramularia unterseheri. (A). leaf of Fagus sylvatica (CPC 25740); (B). Broken ascoma bearing asci with ascospores (CPC 25740); (C-F). germinating ascospores (CPC 25740); (G-K). hypha, conidiophores and conidia (CBS 124884). - Scale bars $=10 \mu \mathrm{m}$.

Etymology. Named after Martin Unterseher, whose research focus on biodiversity and ecology of endophytic fungi, and the person who collected most of the strains of this species currently deposited at the CBS-KNAW collection.

Description: Mycelium consisting of septate, branched, smooth, hyaline hyphae, (1-)1.5$2 \mu \mathrm{m}$ diam. Conidiophores reduced to conidiogenous cells. Conidiogenous cells smooth, hyaline, arising from hyphae, terminal and lateral, $(5.5-) 11-14(-20) \times(1.5-) 2 \mu \mathrm{m}$,

sympodially proliferating with 1-3 apical loci, flattened or protuberant, cylindrical; scars thickened, darkened, refractive, 0.5-1 $\mu \mathrm{m}$ diam. Ramoconidia subcylindrical to oval or ovoid, 0-1-septate, hyaline, smooth, (8-)10-12(-18) $\times(1.5-) 2-2.5(-3) \mu \mathrm{m}$. Intercalary conidia hyaline, smooth, aseptate, oval to ovoid, $(6-) 8-9(-13) \times(2-) 2.5-3 \mu \mathrm{m}$, in branched chains of up to six conidia. Terminal conidia hyaline, smooth, aseptate, obovoid to oval (3.5-)5-6(7) $\times(1.5-) 2-2.5(-3) \mu \mathrm{m}$; hila thickened, darkened, refractive, $0.5-1 \mu \mathrm{m}$ diam.

Culture characteristics: On MEA surface raised, radially striated, with smooth mycelium, rosy vinaceus, with undulate margins and reverse cinnamon, reaching $10 \mathrm{~mm}$ after $2 \mathrm{wk}$ at $25^{\circ} \mathrm{C}$. On OA surface flat, smooth mycelium, with undulate edge, reaching $15 \mathrm{~mm}$ after $2 \mathrm{wk}$ at $25^{\circ} \mathrm{C}$. On PDA radially striated, smooth mycelium, rosy buff with undulate margins, reverse cinnamon, reaching $12 \mathrm{~mm}$ after $2 \mathrm{wk}$ at $25^{\circ} \mathrm{C}$.

Specimens examined. Germany: Mecklenburg-Vorpommern, Greifswald, Elisenhain, on leaf litter of Fagus sylvatica, 4 Jan. 2008, M. Unterseher (holotype CBS H-22285, ex-type culture CBS 124884), additional collections with same details (CBS 124844, 124846, 124852, CBS 124867); on living leaves from understorey of Fagus sylvatica, 8 Jan. 2008, M. Unterseher (CBS 124826, CBS 124827, CBS 124830, CBS 124831, CBS 124834, CBS 124836, CBS 124838); without locality, on seed of Fagus sylvatica, date unknown, U. Delfs-Siemer (CBS 
355.90); Hessen, Schlangenbad, on leaf of Alnus sp., 2012, W. Quaedvlieg (CPC 25739 = W6); Mecklenburg-Vorpommern, Bornhof, on Lupinus sp., U. Feiler 1993 (CBS 588.93); Bavaria, Munich, room inside a castle, May 2011, unknown collector (CBS 130721). Netherlands: Utrecht, Amelisweerd, on dead leaves of Fagus sylvatica, 25 Apr. 2005, G. Verkley (CBS 117801 = CPC 12091); Amersfoort, dead leaves of Fagus sylvatica, 25 Jul. 2005, G. Verkley (CBS 117807 = CPC 12095); Baarn, Baarnsche Bos, on Tilia sp., 26 Apr. 2004, G. Verkley (CBS 117880 = CPC 11209, CBS $117881=$ CPC 11211); Baarn, decaying leaves of Acer pseudoplatanus, 26 Apr. 2004, G. Verkley (CBS $117878=$ CPC 11206, CBS 117879 = CPC 11207); Rhijnauwen forest, decaying leaves of Fagus sylvatica, 17 May 2012, S.I.R. Videira $($ CPC $25740=$ X2).

Notes - Ramularia unterseheri is a plurivorous species that is often found in Fagus sylvatica leaves in Germany and the Netherlands. It differs from $R$. vizellae by shorter and narrower ramoconidia $[(8-)$ 10-12 (-18) $\times(1.5-) 2-2.5(-3) \mu \mathrm{m}$ versus $(8-) 10-12(-23) \times(2.5-) 3-$ $3.5(-5) \mu \mathrm{m}]$ and longer and narrower terminal conidia $[(3.5-) 5-6(-7) \times(1.5-) 2-2.5(-3)$ versus $4-5(-5.5) \times(2-) 3(-3.5) \mu \mathrm{m}]$. It has been previously isolated from dead overwintered leaves as well as from living leaves (Verkley et al. 2004). In this study, a mycosphaerellalike sexual morph was observed (Fig 4, a-f) in newly collected samples of overwintered leaves in the Netherlands, but the available material was too scarce to provide a description.

Ramularia vizellae Crous, Persoonia27: 37 (2011)

\section{MycoBank No.: MB560566}
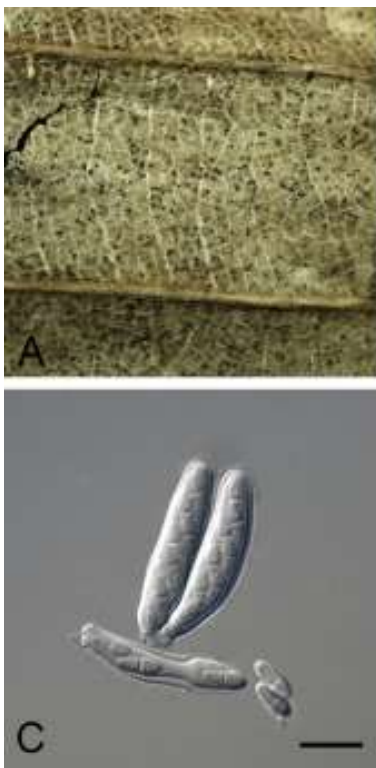
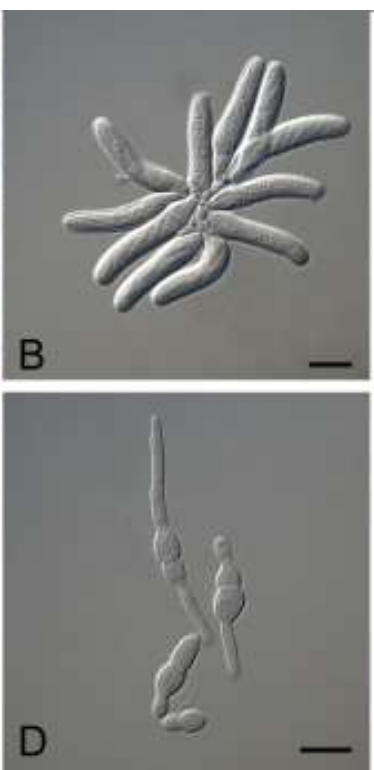
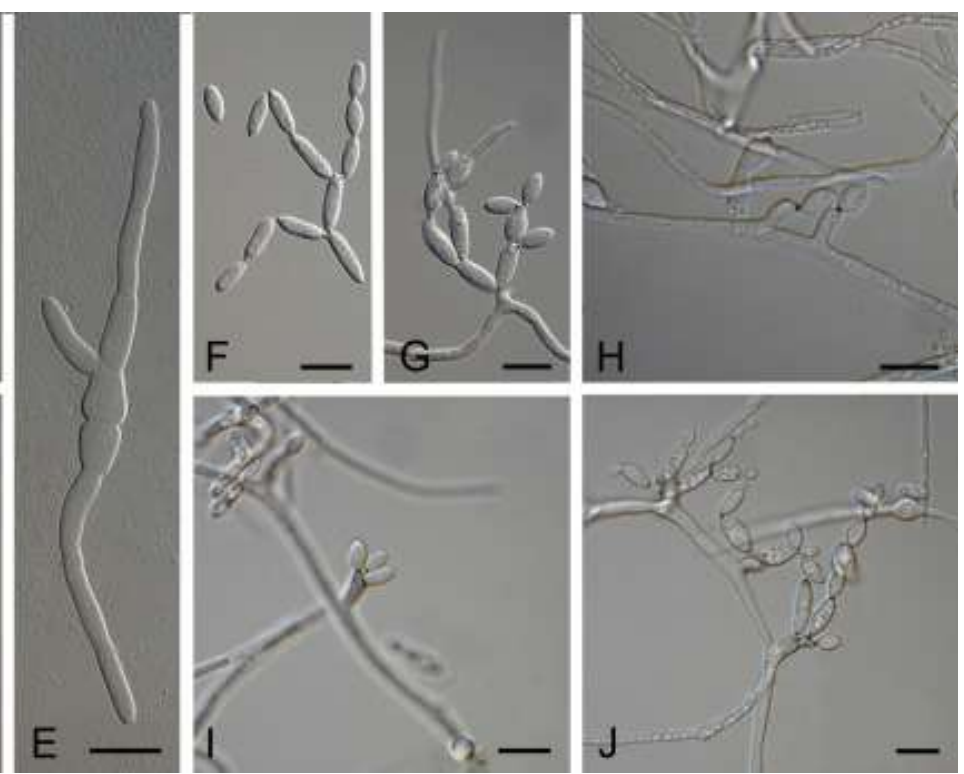

Fig 5. Ramularia vizellae. (A). leaf of Carpinus sp. (CPC 25730); (B), (C). Asci bearing ascospores (CPC 25730). (D, E). Germinating ascospores (CPC 25730); (F-J). hypha, conidiophores and conidia (F, G: CPC 25729; H: CBS 117871; I, J: CBS 117799). — Scale bars $=10 \mu \mathrm{m}$.

Specimens examined. France: on fruit of Malus sylvestris, C. Moreau (CBS 367.64) Austria: Graz, Innere Ragnitz, on Sambucus nigra, 12 Oct. 2012, C. Scheuer (CPC $25738=$ X31). d Germany: Mecklenburg-Vorpommern, Greifswald, Elisenhain, on leaf litter from Fagus sylvatica, 4 Jan. 2008, M. Unterseher (CBS 124861); Hessen, Schlangenbad, on leaf of unidentified plant, W. Quaedvlieg (CPC $25733=$ W7); Bavaria, München, on overwintering leaves of Tilia sp., Jul. 1979, A. John (CBS 724.79) d Netherlands: in leaf spot caused by 
Mycosphaerella sp. on Brassica sp. (CBS 324.87); Gelderland: Randwijk, on dead leaf litter of Malus sp. (CBS 115980); Randwijk, on dead leaf litter of Malus sp. (CBS 115981, CBS 115982, CBS 115983, CBS 115984, CBS 116015, CBS 116069). Utrecht: Amelisweerd, on dead leaves of Acer pseudoplatanus, 25 Apr. 2005, G. Verkley (CBS $117799=$ CPC 12089); on dead leaves of Carpinus betulus, 25 Apr. 2005, G. Verkley (CBS $117802=$ CPC 12092); Amersfoort, on dead leaves of Tilia sp., 25 Apr. 2005, G. Verkley (CBS 117806 = CPC 12096); Baarn, Park Kasteel Groeneveld, on decaying leaves of Quercus rubra, 26 Apr. 2004, G. Verkley (CBS 117870 = CPC 11193), on decaying leaves of Quercus rubra, G. Verkley (CBS 117871 = CPC 11194), on Amelanchier lamarckii, 26 Apr. 2004, G. Verkley (CBS $117872=$ CPC 11197, CBS $117873=$ CPC 11198); Lage Vuursche, on Aesculus hippocastanum, G. Verkley (CBS $117874=$ CPC 11200, CBS $117875=$ CPC 11201), on decaying leaves of Sorbus aucuparia, 26 Apr. 2004, G. Verkley (CBS $117882=$ CPC 11212, CBS 117883 = CPC 11213); garden, Eemnesserweg 90, on dead leaves of Acer pseudoplatanus, 7 May 1996, H.A. van der Aa (CBS 184.97, CBS 185.97), on Acer pseudoplatanus, 15 Oct. 1968, H.A. van der Aa (CBS 515.69); Baarn, ruderal terrain at Drakenburgerweg, on young leaves of Lotus uliginosus, 18 Jun. 1967, H.A. van der Aa (CBS 369.67); Utrecht Botanical Garden, on overwintered leaves of Corylus sp., 21 Apr. 2012, S.I.R. Videira (CPC 25728 = MP19), on overwintered leaves of Quercus sp., 21 Apr. 2012, S.I.R. Videira (CPC $25729=$ MP20), on overwintered leaves of Carpinus sp., 21 Apr. 2012, S.I.R. Videira (CPC $25730=$ MP21), on overwintered leaves of Quercus sp., 21 Apr. 2012, S.I.R. Videira (CPC $25731=$ MP23), on overwintered leaves of Fagus sp., 21 Apr. 2012, S.I.R. Videira (CPC 25732 = MP24); Utrecht Rhijnauwen park, on Aesculus hippocastanum, 25 Apr. 2005, G. Verkley (CBS 117805 = CPC 12094), on overwintered leaves of Fagus sp., 17 May 2012, S.I.R. Videira (CPC $25734=$ X1, CPC $25735=$ X3), on fruit scales of Carpinus betulus, 25 Apr 2005, G. Verkley (CBS $117798=$ CPC 12088), on overwintered leaves of Corylus sp., 17 May 2012, S.I.R. Videira (CPC $25736=$ X4), on overwintered leaves of Aesculus hipocastanum, 17 May 2012, S.I.R. Videira (CPC $25737=$ X5); Soesterberg 'De Stompert', on dead fallen leaves of Quercus robur, G. Verkley (CBS 113267). d South Africa: on leaves of Protea sp. in association with Vizella interupta, 2 May 2010, P.W. Crous (ex-type culture CBS 130601 = CPC 18283). d Switzerland: on Phaseolus sp. (CBS 428.74 = IHEM 3995). Ukraine: Seversky Donets river, NNP Svjatie Gory, on Acer campestre, 21 Jul. 2008, A. Akulov (CPC 15539, CPC 15541).

Notes: This species was recently described from leaves of Protea sp. from South Africa ( Crous et al. 2011) in association with lesions caused by Vizella interrupta in what was deemed as either a chance encounter, as sporulation was not observed in the leaf itself, or an indication that the species was a secondary invader of the diseased leaf tissue. Ramularia vizellae is now known from numerous hosts in many European countries ( Fig 1, Table 1) as well as in South Africa. A mycosphaerella-like sexual morph was observed in freshly collected samples in the Netherlands (Fig 5, a-e), but a description is not provided due to the scarcity of material examined.

\section{Discussion}

Based on the epitypification of Mycosphaerella punctiformis (now Ramularia endophylla) ( Verkley et al. 2004), and the molecular characterization of Ramularia pusilla (type species of Ramularia) by Kirschner (2009), the names Mycosphaerella and Ramularia are confirmed as congeneric. This means it is now possible to separate species closely allied to $R$. endophylla, such as $R$. nyssicola ( Minnis et al. 2011). Based on the multigene phylogeny generated in this study (Fig 1), the host range and distribution of $R$. endophylla has been narrowed, since 
most of the strains were isolated from Quercus leaves collected in the Netherlands, with the exception of one strain collected from Castanea sativa and another strain collected from Korea.

The heterogeneity observed in the ITS sequences in the past was further accentuated when protein coding genes were added to the analysis and both the Bayesian and parsimony analyses based on five genes in the present study split this species complex into three species: $R$. endophylla, Ramularia vizellae and the newly described species, Ramularia unterseheri. The identification of these closely related species based on morphology alone is difficult, and the ITS barcode alone is insufficient for species level identification. Based on the individual gene trees, each of the partial gene sequences of ACT, RPB2 and GAPDH are good phylogenetic markers to use in addition to the ITS barcode since they successfully separate the three species.

The new species described in this study, R. unterseheri ( Fig 4), is only known from the Netherlands and Germany, but with a rather broad host range, namely Acer (Sapindaceae), Alnus (Betulaceae), Fagus (Fagaceae) and Tilia (Malvaceae). The intraspecific variation observed in each clade ( Fig 1) is a result of the variation observed in the gene sequences among the strains. The internal structure of this variation was not consistent between different loci and cryptic speciation is unlikely to account for these genetic differences.

In this study, a mycosphaerella-like sexual morph was observed for both $R$. unterseheri ( Fig 4) and R. vizellae ( Fig 5) in overwintered leaves collected in the Netherlands. In addition, several of the strains of $R$. unterseheri were isolated from living material as endophytes in the previous work of Verkley et al. (2004). These observations indicate that these species most likely have a life cycle similar to that of $R$. endophylla but more work needs to be done in order to fully understand these fungal life-cycles. Even though the lifecycle of $R$. endophylla is well known ( Verkley et al. 2004), some questions still remain unanswered, e.g. the role played by the Asteromella spermatial state in the development of the species.

Sexual reproduction plays an important role in the dynamics and fitness of a species by introducing variability through genetic recombination and the mating type genes are essential for the sexual cycle to occur. The similarity of homologous mating-type genes is usually very low except for the high mobility group and the alpha domains (Turgeon 1998). These conserved domains were successfully used to clarify the phylogenetic relationships among closely related species (Du et al., 2005 and Paoletti et al., 2005) but were not effective in resolving the Cercospora apii complex (Groenewald et al. 2006). The MAT1-2-1 tree showed that $R$. vizellae, $R$. unterseheri and $R$. endophylla strains cluster in separate well supported clades and the same can be observed in the MAT1-1-1 tree for the strains of $R$. endophylla and $R$. vizellae. In this study, the mating-type loci were effective in the separation of this complex. The complete characterization of the mating-type genes in Ramularia species has not been performed before and the evidence indicates these species are heterothallic since the strains with a MAT1-1-1 sequence did not amplify the MAT1-2-1 locus and vice-versa. However, transitions between heterothallic (self-sterile) and homothallic (self-fertile) sexual cycles are common among fungi and which represents the ancestral state is unknown.

Experimentally proven links in literature between Ramularia and Mycosphaerella are limited ( Table 3). There are six cases where the authors reported they observed the complete life 
cycle of the fungus from ascospore to conidia. Experimentally confirmed links include $R$. endophylla/M. punctiformis (= R. endophylla) ( Verkley et al. 2004), Ramularia grevilleana/Mycosphaerella fragariae (= R. grevilleana) (Oudemans, 1873 and Braun and Pennycook, 2003), Ramularia variabilis/Mycosphaerella mariae (=R. variabilis) ( von Arx 1949), and Ramularia inaequalis/Mycosphaerella hieracii (= R. inaequalis) ( Klebahn 1918). In the case of Mycosphaerella nyssicola, no Ramularia morph has been observed, but based on molecular evidence the species belongs in Ramularia, and a new combination $(=R$. nyssicola) was made for this species ( Videira et al. 2015). When Mycosphaerella phacaefrigidae was described ( Müller \& Wehmeyer 1954), the ascospores that were isolated produced a Ramularia state in culture that was not named at the time, and hence a new combination is introduced for this name in Ramularia (= Ramularia phacae-frigidae).

Sivanesan (1984) reported the links Ramularia gossypi/M. areola, Ramularia nigromaculans/Mycosphaerella nigromaculans, and Ramularia urticae/Mycosphaerella superflua, among others. Ramularia gossypii has been reassigned to the genus Ramulariopsis ( Braun \& Pennycook 1993) and R. nigromaculans has been excluded from Ramularia based on its pigmented conidia ( Braun 1998). Ramularia urticae/M. superflua, and at least eight other links ( Table 3), have not been experimentally proven, and await further collections and study.

Other existing links have been considered doubtful since Aptroot (2006) examined the herbarium type specimens of some Mycosphaerella that he considered belonged to Davidiella ( Table 3). An interesting case is that of Mycosphaerella nawae, a pathogen causing circular leaf spot of persimmon that was originally reported from Japan (Ikata \& Hitomi 1929) but has now spread worldwide (Berbegal et al. 2013). In Korea, a ramularia-like morph was observed (Kwon \& Park 2004) but its importance during the infection processes was not established (Berbegal et al. 2013). Despite its importance as a plant pathogen, no cultures of this species are available in public culture collections. A recent study by Berbegal et al. (2013) generated two ITS sequences (GenBank GQ465767 \& GQ465768) of M. nawae that, when compared with other dothideomyceteous ITS sequences in NCBI's GenBank, places the species near or in Phaeophleospora within the Mycosphaerellaceae ( Quaedvlieg et al. 2014). This link is considered doubtful, awaiting further collections of fresh material.

In conclusion, we have shown that the $R$. endophylla species complex consists of three species, namely $R$. endophylla, $R$. vizellae, and a novel species described in this paper, $R$. unterseheri. We show that $R$. vizellae has a much wider host range and geographical distribution than originally assumed and observed its sexual stage. In spite of close to 1000 species names in Ramularia, and more than 10000 species that have been described in Mycosphaerella s. lat., the present study could only confirm six connections in Ramularia, and one new combination was proposed to accommodate $R$. phacae-frigidae. Additional collections of other names in Mycosphaerella may reveal more species that are true members of Ramularia, but presently the majority appears to belong to other genera ( Quaedvlieg et al. 2014). In much of the plant pathology literature the name Mycosphaerella has been applied in a broad morphological and non-phylogenetic sense. For these fungi, the term mycosphaerella-like sexual morph is more appropriate. In accordance with the newly revised ICN code, the generic name Ramularia has been protected over that of Mycosphaerella and will be applied to this genus in the future. 


\section{Acknowledgement}

This research was supported by the Dutch Ministry of Education, Culture and Science through an endowment of the FES programme 'Making the tree of life work'. We would like to thank Dr. Christian Scheuer from the Karl-Franzens-University for collecting the samples of Verbascum sp. from Austria.

\section{References}

Aptroot A, 2006. Mycosphaerella and Its Anamorphs: 2. conspectus of Mycosphaerella CBS Biodiversity series 5. Centraalbureau voor Schimmelcultures, Utrecht, The Netherlands.

Arx von JA, 1949. Beiträge zur Kenntnis der Gattung Mycosphaerella. Sydowia 3: 28-100.

Bakhshi M, Arzanlou M, Babai-Ahari A, Groenewald JZ, Crous PW. Multi-gene analysis of Pseudocercospora spp. from Iran. Phytotaxa 184: 245-264.

Batzer JC, Arias MMD, Harrington TC, Gleason ML, Groenewald JZ, Crous PW, 2008. Four species of Zygophiala (Schizothyriaceae, Capnodiales) are associated with the sooty blotch and flyspeck complex on apple. Mycologia 100: 246-258.

Bensch K, Braun U, Groenewald JZ, Crous PW, 2012. The genus Cladosporium. Studies in Mycology 72: 1-401.

Bensch K, Groenewald JZ, Dijksterhuis J, Starink-Willemse M, Andersen B, Summerell BA, Shin HD, Dugan FM, Schroers H-J, Braun U, Crous PW, 2010. Species and ecological diversity within the Cladosporium cladosporioides complex (Davidiellaceae, Capnodiales). Studies in Mycology 67: 1-94.

Berbee ML, Pirseyedi M, Hubbard S, 1999. Cochliobolus phylogenetics and the origin of known, highly virulent pathogens, inferred from ITS and glyceraldehyde-3-phosphate dehydrogenase gene sequences. Mycologia 91: 964-977.

Berbegal M, Mora-Sala B, García-Jímenez J, 2013. A nested-polymerase chain reaction protocol for the detection of Mycosphaerella nawae in persimmon. European Journal of Plant Pathology 137: 273-281.

Braun U, 1995. A monograph of Cercosporella, Ramularia and allied genera (phytopathogenic hyphomycetes), Vol. 1, IHW-Verlag, Eching, Munich, Germany.

Braun U, 1998. A monograph of Cercosporella, Ramularia and allied genera (phytopathogenic hyphomycetes), Vol. 2, IHW-Verlag, Eching, Munich, Germany.

Braun U, Pennycook SR, 2003. Nomenclature and typification of Ramularia grevilleana. Mycotaxon 88: 49-52.

Carbone I, Kohn LM, 1999. A method for designing primer sets for speciation studies in filamentous ascomycetes. Mycologia 91: 553-556.

Crous PW, 1998. Mycosphaerella spp. and their anamorphs associated with leaf spot diseases of Eucalyptus. Mycologia Memoir 21 1-170.

Crous PW, Aptroot A, Kang J-C, Braun U, Wingfield MJ, 2000. The genus Mycosphaerella and its anamorphs. Studies in Mycology 45: 107-121. 
Crous PW, Braun U, Groenewald JZ, 2007. Mycosphaerella is polyphyletic. Studies in Mycology 58: $1-32$.

Crous PW, Braun U, Hunter GC, Wingfield MJ, Verkley GJM, 2013. Phylogenetic lineages in Pseudocercospora. Studies in Mycology 75: 37-114.

Crous PW, Gams W, Stalpers JA, Robert V, Stegehuis G, 2004a. MycoBank: an online initiative to launch mycology into the 21st century. Studies in Mycology 50: 19-22.

Crous PW, Groenewald JZ, Risede J-M, Hywel-Jones NL, 2004b. Calonectria species and their Cylindrocladium anamorphs: species with sphaeropedunculate vesicles. Studies in Mycology 50: 415-429.

Crous PW, Schoch CL, Hyde KD, Wood AR, Gueidan C, de Hoog GS, Groenewald JZ, 2009b. Phylogenetic lineages in the Capnodiales. Studies in Mycology 64: 17-47.

Crous PW, Slippers B, Wingfield MJ, Rheeder J, Marasas WFO, Philips AJL, Alves A, Burgess T, Barber P, Groenewald JZ, 2006. Phylogenetic lineages in the Botryosphaeriaceae. Studies in Mycology 55: 235-253.

Crous PW, Summerell BA, Carnegie AJ, Wingfield MJ, Groenewald JZ, 2009c. Novel species of Mycosphaerellaceae and Teratosphaeriaceae. Persoonia 23: 119-146.

Crous PW, Summerell BA, Carnegie AJ, Wingfield MJ, Hunter GC, Burgess TI, Andjic V, Barber PA, Groenewald JZ, 2009a. Unravelling Mycosphaerella: do you believe in genera? Persoonia 23: 99-118.

Crous PW, Summerell BA, Swart L, Denman S, Taylor JE, Bezuidenhout CM, Palm ME, Marincowitz S, Groenewald JZ, 2011. Fungal pathogens of Proteaceae. Persoonia 27: 20-45.

Crous PW, Verkley GJM, Groenewald JZ, Samson RA, 2009d. Fungal Biodiversity, CBS Laboratory Manual Series 1, Centraalbureau voor Schimmelcultures. Utrecht, Netherlands.

Crous PW, Wingfield MJ, Park RF, 1991. Mycosphaerella nubilosa a synonym of M. molleriana. Mycological Research 95: 628-632.

Damm U, Cannon PF, Woudenberg JHC, Crous PW, 2012b. The Colletotrichum acutatum species complex. Studies in Mycology 73: 37-113.

Damm U, Cannon PF, Woudenberg JHC, Johnston PR, Weir BS, Tan YP, Shivas RG, Crous PW, 2012a. The Colletotrichum boninense species complex. Studies in Mycology 73: 1-36.

Du M, Schardl CL, Nuckles EM, Vaillancourt LJ, 2005. Using mating-type gene sequences for improved phylogenetic resolution of Collectotrichum species complexes. Mycologia 97: 641-658.

Dudley WR, 1889. The strawberry Leaf-Blight, Sphaerella fragariae (Tul.) Sacc. Cornell University. Agricultural Experiment Station. Bulletin 14: 171-184.

Dugan FM, Braun U, Groenewald JZ, Crous PW, 2008. Morphological plasticity in Cladosporium sphaerospermum. Persoonia 21: 9-16.

Eriksson, 1992. The Non-lichenized Pyrenomycetes of Sweden. SBT förlaget, Lund, Sweden. 
Glass NL, Donaldson G, 1995. Development of primer sets designed for use with PCR to amplify conserved genes from filamentous ascomycetes. Applied and Environmental Microbiology 61: 13231330 .

Groenewald JZ, Nakashima C, Nishikawa J, Shin H-D, Park J-H, Jama AN, Groenewald M, Braun U, Crous PW, 2013. Species concepts in Cercospora: spotting the weeds among the roses. Studies in Mycology 75: 115-170.

Groenewald M, Barnes I, Bradshaw RE, Brown AV, Dale A, Groenewald JZ, Lewis KJ, Wingfield BD, Wingfield MJ, Crous PW, 2007. Characterization and distribution of mating type genes in the dothistroma needle blight pathogens. Phytopathology 97: 825-834.

Groenewald M, Groenewald JZ, Harrington TC, Abeln ECA, Crous PW, 2006. Mating type gene analysis in apparently asexual Cercospora species is suggestive of cryptic sex. Fungal Genetics and Biology 43: 813-825.

Hawksworth DL, Crous PW, Redhead SA, Reynolds DR, Samson RA, Seifert KA, Taylor JW, Wingfield MJ, Abaci O, Aime C, Asan A, Bai FY, de Beer ZW, Begerow D, Berikten D, Boekhout T, Buchanan PK, Burgess T, Buzina W, Cai L, Cannon PF, Crane JL, Damm U, Daniel HM, van Diepeningen AD, Druzhinina I, Dyer PS, Eberhardt U, Fell JW, Frisvad JC, Geiser DM, Geml J, Glienke C, Gräfenhan T, Groenewald JZ, Groenewald M, de Gruyter J, Guého-Kellermann E, Guo LD, Hibbett DS, Hong SB, de Hoog GS, Houbraken J, Huhndorf SM, Hyde KD, Ismail A, Johnston PR, Kadaifciler DG, Kirk PM, K oljalg U, Kurtzman CP, Lagneau PE, Lévesque CA, Liu X, Lombard L, Meyer W, Miller A, Minter DW, Najafzadeh MJ, Norvell L, Ozerskaya SM, Ozic , R, Pennycook SR, Peterson SW, Pettersson OV, Quaedvlieg W, Robert VA, Ruibal C, Schnürer J, Schroers HJ, Shivas R, Slippers B, Spierenburg H, Takashima M, Taşkın E, Thines M, Thrane U, Uztan AH, van Raak M, Varga J, Vasco A, Verkley G, Videira SI, de Vries RP, Weir BS, Yilmaz N, Yurkov A, Zhang N, 2011. The Amsterdam declaration on fungal nomenclature. IMA Fungus 2: 105112.

Hillis DM, Bull JJ, 1993. An empirical test of bootstrapping as a method for assessing confidence in phylogenetic analysis. Systematic Biology 42: 182-192.

Hoog GS de, Gerrits van den Ende AHG, 1998. Molecular diagnostics of clinical strains of filamentous Basidiomycetes. Mycoses 41: 183-189.

Ikata S, Hitomi T, 1929. Studies on circular leaf spot of persimmon caused by Mycosphaerella nawae. Special Bulletin of the Okayama Prefecture Agricultural Experiment Station 33: 1-36 (in Japanese).

Jaap O, 1908. Drittes Verzeichnis zu meinem Exsiccatenwerk "Fungi selecti exsiccati”, Serien IX-XII (Nummern 201e300), nebst Beschreibungen neuer Arten und Bemerkungen. Verhandlungen des Botanischen Vereins der Provinz Brandenburg 50: 29-51.

Jaap O, 1910. Viertes Verzeichniss zu meinem Exsiccatenwerk "Fungi Selecti Exsiccati", Serien XIIIXVI (Nummern 301e400), nebst Beschreibungen neuer Arten und Bemerkungen. Verhandlungen des Botanischen Vereins der Provinz Brandenburg 52: 1-19.

Johanson CJ, 1884. Svampar frăn Island. Bestämda af C.J. Johanson. Öfversigt af Kongl. VetenskapsAkademiens Föhandlingar 41: 157-174.

Jørstad I, 1945. Parasittsoppene pă kultur- og nyttevekster I Norge I. Sekksporesopper Ascomycetes) og konidiesopper (Fungi imperfecti). Meld. Stat. Plantepatol. Inst 1: 1-142.

Katoh K, Standley DM, 2013. MAFFT Multiple Sequence Alignment Software Version 7: improvements in performance and usability. Molecular Biology Evolution 30: 772-780. 
Kawato M, Shinobu R, 1959. On Streptomyces herbaricolour, nov sp., supplement: a simple technique for the microscopic observation. Memoirs of the Osaka University of Liberal Arts and Education B. Natural Sciences 8: 114-119.

Kearse M, Moir R, Wilson A, Stones-Havas S, Cheung M, Sturrock S, Buxton S, Cooper A, Markowitz S, Duran C, Thierer T, Ashton B, Mentjies P, Drummond A, 2012. Geneious basic: an integrated and extendable desktop software platform for the organization and analysis of sequence data. Bioinformatics 28: 1647-1649.

Kirschner R, 2009. Cercosporella and Ramularia. Mycologia 101: 110-119.

Klebahn H, 1918. Haupt- und Nebenfruchtformen der Askomyzeten. Borntraeger, Leipzig.

Koike ST, Baameur A, Groenewald JZ, Crous PW, 2011. Cercosporoid leaf pathogens from whorled milkweed and spineless safflower in California. IMA Fungus 2: 7-12.

Kwon J-H, Park C-S, 2004. Ecology of disease outbreak of circular leaf spot of persimmom and inoculum dynamics of Mycosphaerella nawae. Research in Plant Disease 10 209-2016 (in Korean).

Laibach F, 1921. Untersuchungen über einige Ramularia- und Ovularia-Arten und ihre Beziehungen zur Ascomycetengattung Mycosphaerella II. Zentralblatt für Bakteriologie Abt. II 55: 284-293.

Li HY, Sun GY, Zhai XR, Batzer JC, Mayfield DA, Crous PW, Groenewald JZ, Gleason ML, 2012. Dissoconiaceae associated with sooty blotch and flyspeck on fruits in China and the United States. Persoonia 28: 113-125.

Lindau, 1897. In: Engler A, Prantl K (eds), Die Naturlichen Pflanzenfamilien, 1(1), p. 424.

Liu YJ, Whelen S, Hall BD, 1999. Phylogenetic relationships among ascomycetes: evidence from an RNA polymerase II subunit. Molecular Biology and Evolution 16: 1799-1808.

Maas JL, 1984. Compendium of Strawberry Diseases. American Phytopathological Society, St. Paul, MN 138.

Maddison WP, Maddison DR, 2011. Mesquite: a modular system for evolutionary analysis Version 2.75. http://mesquiteproject.org.

Minnis AM, Rossman AY, Olsen RT, 2011. Mycosphaerella nyssicola revisited: a species distinct from M. punctiformis. Mycotaxon 115: 311-322.

Müller EV, Wehmeyer LE, 1954. Ein neuer, alpiner Ascomycet: Mycosphaerella phacae-frigidae. Sydowia 8: 190-191.

Nugent LK, Sangvichen E, Sihanonth P, Ruchikachorn N, Whalley AJS, 2006. A revised method for the observation of conidiogenous structures in fungi. Mycologist 20: 111-114.

Nylander JAA, 2004. MrModeltest 2.0. Program Distributed by the Author. Uppsala University, Uppsala, Sweden.

O’Donnell K, Cigelnik E, 1997. Two divergent intragenomic rDNA ITS2 types within a monophyletic lineage of the fungus Fusarium are nonorthologous. Molecular Phylogenetics and Evolution 7: 103-116.

O’Donnell K, Kistler HC, Cigelnik E, Ploetz RC, 1998. Multiple evolutionary origins of the fungus causing Panama disease of banana: concordant evidence from nuclear and mitochondrial 
gene genealogies. Proceedings of the National Academy of Sciences (USA) 95: 2044-2049.

Oudemans CAJA, 1873. Aanwinsten voor de Flora Mycologica van Nederland II. Nederlandsch Kruidkundig Archief 1: 252-267.

Paoletti M, Buck KW, Brasier CM, 2005. Cloning and sequence analysis of the MAT-B (MAT-2) genes from the three Dutch elm disease pathogens, Ophiostoma ulmi, O. novo-ulmi, and O. himalulmi. Mycological Research 109: 983-991.

Phillips AJL, Alves A, Abdollahzadeh J, Slippers B,Wingfield MJ, Groenewald JZ, Crous PW, 2013. The Botryosphaeriaceae: genera and species known fromculture. Studies in Mycology 76: 51-167.

Persoon CH, 1794. Nähere Bestimmung und Beschreibungen einiger sich nahe verwandter Pflanzen. Annalen der Botanik (Usteri) 11: 1-32.

Petrak F, 1915. Beiträge zur Pilzflora von Mähren und Österr.- Schlesien. Annales Mycologici 13: 4451.

Petrak F, 1927. Mykologische Notizen IX. Annales Mycologici 25: 193-343.

Petrak F, 1940a. Beiträge zur Kenntnis der Pilzflora der Umgebung von Lunz am See und des Dürrensteins in Niederdonau. Annales Mycologici 38: 121-180.

Petrak F, 1940b. Mykologische Notizen XIII. Annales Mycologici 38: 181-267.

Plakidas AG, 1941. Purple leaf spot of strawberry. Phytopatholy 31: 225-240.

Potebnja AA, 1908. K istorii razvitija nekotoryh askomicetov. 1. Mycosphaerella, 2. Gnomonia, Glomerella I Pseudopeziza. Charkov.

Quaedvlieg W, Binder M, Groenewald JZ, Summerell BA, Carnegie AJ, Burgess TI, Crous PW, 2014. Introducing the consolidated species concept to resolve species in the Teratosphaeriaceae. Persoonia 33: 1-40.

Quaedvlieg W, Groenewald JZ, Yáňez-Morales M de J, Crous PW, 2012. DNA barcoding of Mycosphaerella species of quarantine importance to Europe. Persoonia 29: 101-115.

Rayner RW, 1970. A Mycological Colour Chart. CMI and British Mycological Society, Kew, Surrey, England.

Ronquist F, Teslenko M, van der Mark P, Ayres DL, Darling A, Höhna S, Larget B, Liu L, Suchard MA, Huelsenbeck JP, 2011. MrBayes 3.2: efficient Bayesian phylogenetic inference and model choice across a large model space. Systematic Biology 61: 539-542.

Savile DBO, 1962. Some fungal parasites of Onagraceae. Canadian Journal of Botany 40: 1385-1398.

Savile DBO, 1968. Some parasites of Scrophulariaceae. Canadian Journal of Botany 46: 461-471.

Schellenberger HC, 1917. Zur Kenntnis der Entwicklungsverhältnisse von Mycosphaerella fragariae (Tul.) Lindau. Vierteljahrsschrift der Naturforschenden Gesellschaft in Zürich 62: 383-392.

Schoch CL, Seifert KA, Huhndorf S, Robert V, Spouge JL, Levesque CA, Chen WFungal Barcoding Consortium, 2012. Nuclear ribosomal internal transcribed spacer (ITS) region as a universal DNA barcode marker for Fungi. Proceedings of the National Academy of Sciences (USA) 109: 6241-6246. 
Schubert K, Groenewald JZ, Braun U, Dijksterhuis J, Starink M, Hill CF, Zalar P, de Hoog GS, Crous PW, 2007. Biodiversity in the Cladosporium herbarum complex (Davidiellaceae, Capnodiales), with standardisation of methods for Cladosporium taxonomy and diagnostics. Studies in Mycology 58: $105-156$

Sivanesan A, 1984. The Bitunicate Ascomycetes and Their Anamorphs. Cramer Verlag, Vaduz.

Starbäck K, 1889. Ascomyceter frän Öland och Östergötland. Bihang till Kungliga svenska Vetenskaps-Akademiens Handlingar 15: 1-28.

Stukenbrock EH, Quaedvlieg W, Javan-Nikhah M, Zala M, Crous PW, McDonald BA, 2012. Zymoseptoria ardabiliae and Z. pseudotritici, two progenitor species of the septoria tritici leaf blotch fungus Z. tritici (synonym: Mycosphaerella graminicola). Mycologia 104: 1397-1407.

Švarcman SR, Vasjagina MP, Byzova ZM, Filimonova NM, 1973. Flora sporovykh rastenij Kazakhstana. Nesoversennye griby - Fungi imperfecti (Deuteromycetes). 1. Monilial'nye Moniliales. 8. Nauka, Alma Ata.

Swofford DL, 2003. PAUP*: phylogenetic analysis using parsimony (*and other methods), version 4. Sinauer Associates, Sunderland, Massachusetts.

Tamura K, Peterson D, Peterson N, Stecher G, Nei M, Kumar S, 2011. MEGA5: molecular evolutionary genetics analysis using maximum likelihood, evolutionary distance, and maximum parsimony methods. Molecular Biology and Evolution 28: 2731-2739.

Taylor JW, 2012. One Fungus = One Name: DNA and fungal nomenclature twenty years after PCR . IMA Fungus 2: 113-120.

Taylor JW, Jacobson DJ, Kroken S, Kasuga T, Geiser DM, Hibbett DS, Fisher MC, 2000. Phylogenetic species recognition and species concepts in Fungi. Fungal Genetics and Biology 31: 21-32.

Tomilin BA, 1979. Opredelitel' gribov roda Mycosphaerella Johans. Nauka, Leningrad, Leningradskoe otd-nie. (in Russian).

Tulasne LR, 1856. Note sur l'appareil reproducteur multiple des Hypoxylées (DC.) ou Pyrénomycètes (Fr.). Annales des Sciences Naturelles, Botanique, 4e Série 5: 107-118.

Tulasne LR, Tulasne C, 1863. Selecta fungorum carpologia. Tomus secundus. Xylariei - Valsei Sphaeriei, Paris.

Turgeon BG, 1998. Application of mating type technology to problems in fungal biology. Annual Review of Phytopathology 36: 115-137.

Unger F, 1833. Die Exantheme der Pflanzen und einige mit diesen verwandte Krankheiten der Gewächse. Gerold, Wien.

Vasil'evskij, Karakulin, 1937. Parazitnye Nesoveršennye Griby. Č. I. Gifomicety. Moskva, Leningrad, (in Russian).

Verkley GJM, Crous PW, Groenewald JZ, Braun U, Aptroot A, 2004. Mycosphaerella punctiformis revisited: morphology, phylogeny, and epitypification of the type species of the genus Mycosphaerella (Dothideales, Ascomycota). Mycological Research 108: 1271-1282. 
Videira SIR, Groenewald JZ, Kolecka A, van Haren L, Boekhout T, Crous PW, 2015. Elucidating the Ramularia eucalypti species complex. Persoonia 34: 50-64.

Vilgalys R, Hester M, 1990. Rapid genetic identification and mapping of enzymatically amplified ribosomal DNA from several Cryptococcus species. Journal of Bacteriology 172: 4238-4246.

White TJ, Bruns T, Taylor J, 1990. Amplification and direct sequencing of fungal ribosomal RNA genes for phylognetics. In: Innis MA, Gelfand DH, Sninsky JJ, White JW (eds), A Guide to Molecular Methods and Applications. Academic Press, New York, pp. 315-322.

Wijayawardene NN, Crous PW, Kirk PM, Hawksworth DL, Boonmee S, Braun U, Dai D-Q, D'souza MJ, Diederich P, Dissanayake A, Doilom M, Hongsanan S, Gareth Jones EB, Groenewald JZ, Jayawardena R, Lawrey JD, Liu J-K, Lücking R, Madrid H, Manamgoda DS, Muggia L, Nelsen MP, Phookamsak R, Suetrong S, Tanaka K, Thambugala KM, Wanasinghe DN, Wikee S, Zhang Y, Aptroot A, Ariyawansa HA, Bahkali AH, Bhat JD, Gueidan C, Chomnunti P, De Hoog GS, Knudsen K, Li W-J, McKenzie EHC, Miller AN, Mortimer PE, Phillips AJL, Piątek M, Raja HA, Shivas RS, Slippers B, Taylor JE, Wang Y, Woudenberg JHC, Cai L, Jaklitsch WM, Hyde KD, 2014. Naming and outline of Dothideomycetese-2014 including proposals for the protection or suppression of generic names. Fungal Diversity 69: 1-55.

Wikee S, Lombard L, Nakashima C, Motohashi K, Chukeatirote E, Cheewangkoon R, McKenzie EHC, Hyde KD, Crous PW, 2013. A phylogenetic re-evaluation of Phyllosticta (Botryosphaeriales). Studies in Mycology 76: 1-29.

Wingfield MJ, De Beer ZW, Slippers B, Wingfield BD, Groenewald JZ, Lombard L, Crous PW, 2012. One fungus, one name promotes progressive plant pathology. Molecular Plant Pathology 13: 604-613.

Wolf FA, 1912. The Brown Leaf Spot of Colt's foot, Tussilago farfara L. Annales Mycologici 10: 6567. 